\title{
Heterogeneity of Gain-Loss Attitudes and Expectations-Based Reference Points
}

\author{
Lorenz Goette* \\ University of Bonn \\ National University of Singapore
}

\author{
Thomas Graeber $^{\dagger}$
Harvard University \\ Thomas Graeber
Harvard University
}

Charles Sprenger $\S$

UC San Diego

\author{
Alexandre Kellogg $\ddagger$ \\ UC San Diego
}

This Version: May 20, 2020

\begin{abstract}
This project examines the role of heterogeneity in gain-loss attitudes for identifying models of expectations-based reference dependence (Köszegi and Rabin, 2006, 2007) (KR). Different gain-loss attitudes lead to different signs for KR comparative statics. Failure to account for the known heterogeneity in gain-loss attitudes is a central confounding factor challenging prior tests of the KR model conducted under the assumption of universal loss aversion. We document heterogeneous treatment effects over gain-loss types in both an initial experiment and an exact replication. Recognizing heterogeneity over types allows us to both recover the KR model's central predictions, and account for inconsistency across prior empirical tests.
\end{abstract}

JEL classification: D81, D84, D12, D03

Keywords: Reference-Dependent Preferences, Rational Expectations, Personal Equilibrium, Endowment Effect, Expectations-Based Reference Points

${ }^{*}$ University of Bonn, Institute for Applied Microeconomics, Adenauerallee 24 - 42, 53113 Bonn, Germany; lorenz.goette@uni-bonn.de. National University of Singapore, Department of Economics, 1 Arts Link, Singapore 117570.

${ }^{\dagger}$ Harvard University, Department of Economics, Littauer Center, 1805 Cambridge St, MA 02138; graeber@fas.harvard.edu

${ }^{\ddagger}$ Department of Economics, University of California, San Diego, 9500 Gilman Drive, La Jolla, CA 92093; alexkellogg@ucsd.edu

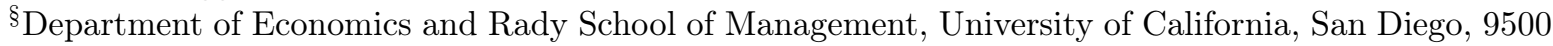
Gilman Drive, La Jolla, CA 92093; csprenger@ucsd.edu 


\section{Introduction}

Models of reference-dependent preferences are regarded as a major advance in behavioral economics, rationalizing a range of observations at odds with the canonical model of expected utility over final wealth (Kahneman et al., 1990; Camerer et al., 1997; Odean, 1998; Rabin, 2000). Critical to such applications is the formulation of the reference point around which gains and losses are encoded. A recent literature has examined characterizations of the reference point based on rational expectations of potential outcomes (Köszegi and Rabin, 2006, 2007) (henceforth KR). ${ }^{1}$ These expectations-based formulations have the promise to be readily and broadly applicable, closing the model with a foundation to which economic tools are already well adapted.

Despite the promise of the KR formulation of the reference point, tests of the theory have yielded mixed results (see, e.g., Smith, 2019; Ericson and Fuster, 2011; Heffetz and List, 2014; Cerulli-Harms et al., 2019; Abeler et al., 2011; Gneezy et al., 2017). While early experimental applications in exchange behavior and effort provision showed treatment effects in line with KR comparative statics, subsequent replications and extensions have shown more limited or contradictory effects. A plausible interpretation from this literature is that the KR model of expectations-based reference points lacks a strong empirical foundation. This manuscript begins by recognizing that these experimental tests of the KR model have actually been tests of a joint hypothesis. Explicitly, they are posed as tests of the hypothesis that reference points are derived from expectations. Implicitly, all prior empirical tests of the KR model have been conducted under a specific assumption for the model's key behavioral parameter of gain-loss attitudes: that individuals are universally loss-averse - weighting losses more than commensurately-sized gains. The conducted tests have thus investigated the joint hypothesis that reference points are based in expectations and that all subjects are loss-averse. The mixed empirical evidence noted above can be read

\footnotetext{
${ }^{1}$ Our analysis will focus on the formulations of KR. An earlier literature also provided formulations of reference dependence grounded in rational expectations, but without the equilibrium concepts we analyze (Bell, 1985; Loomes and Sugden, 1986).
} 
as rejecting expectations-based reference points, or as rejecting the notion that gain-loss attitudes are universal. We explore the latter interpretation and provide the first evidence of expectations-based reference dependence after splitting the joint hypothesis into its component parts.

There are two reasons why the "non-universal gain-loss attitudes" interpretation of the prior evidence is plausible. First, heterogeneity in gain-loss attitudes has a critical influence on what can be inferred from prior empirical tests of the $\mathrm{KR}$ model. $\mathrm{KR}$ comparative statics used as the basis of prior experiments change sign when individuals are gain-loving — weighting gains more than commensurately-sized losses — rather than loss-averse. If loss aversion is not a universal characteristic, prior empirical tests have unintentionally aggregated these different signed effects. Given the nature of this aggregation, which we discuss in detail in section 2.2, the average treatment effect will not coincide with the treatment effect of the average preference, and may be of opposite sign to that of the average preference. Even when the signs of the average treatment effect and that of the average preference coincide, powering a test for the average treatment effect is challenging. Our findings indicate that well-powered experiments for detecting average KR treatment effects require sample sizes around an order of magnitude larger than current practice.

Second, heterogeneity of gain-loss attitudes is a documented phenomenon, becoming more widely appreciated in recent years. Distributional assessments identify sizable minorities of gain-loving subjects (see, e.g. Burks et al., 2009; Sprenger, 2015; Erev et al., 2008; Harinck et al., 2007; Nicolau, 2012; Sokol-Hessner et al., 2009; Chapman et al., 2017, 2018). Reviewing eight previous experimental studies, Chapman et al. (2018) report a weighted average of 22 percent gain-loving subjects. ${ }^{2}$ A natural psychology for this documented gain-loving preference is that individuals enjoy potential gains enough to tolerate potential losses. When given an opportunity to exchange an endowed object or purchase a negative expected value gamble, such an individual may exhibit an 'anti-endowment effect' or risk tolerance, rather than the standard behavioral patterns.

\footnotetext{
${ }^{2}$ Seven of the eight papers noted elicit gain-loss attitudes through lottery choice. The exception is the prior version of this manuscript.
} 
One may be tempted to eschew the minority of gain-loving subjects as reflecting decision errors or natural variability of response. Such a view is challenged by prior work indicating that individual differences in measured gain-loss attitudes from lottery choices are predictive of anomalies in labor supply and exchange decisions (see, e.g., Fehr and Goette, 2007; Gachter et al., 2007; Dean and Ortoleva, 2015). ${ }^{3}$ Our project proceeds under an opposing view: that gain-loving behavior is indicative of true preferences, and represents a key dimension of heterogeneity in gain-loss attitudes heretofore ignored by tests of the KR model.

We implement an experimental study of exchange behavior in an initial sample of 607 subjects and a pre-registered replication sample with a further 417 subjects. ${ }^{4}$ Our experiment has two stages. In Stage 1, subjects are randomly endowed with one of two objects. Though no choices are made, subjects are asked to provide a series of preference statements for both objects given this endowment. Specifically, we ask subjects for their hypothetical choice between the two objects; how much they 'want' each object on a nine-point scale; and how much they 'like' each object on a nine-point scale.

The Stage 1 preference statements allow us to form a taxonomy of gain-loss types, constructed from a structural model of the preference statements for the endowed and alternative object. ${ }^{5}$ Our structural model fits a distribution of gain-loss attitudes to the

\footnotetext{
${ }^{3}$ Additionally, the view that gain-loving behavior is mere noise generates a null prediction for the central tests documented in this manuscript.

${ }^{4}$ In Appendix Section A we provide analysis laid out in our initial draft and pre-registered replication. This analysis differs from our current presentation of the results as we have adopted a mixed logit methodology for identifying gain-loss attitudes rather than our prior standard logit methods. Using these prior methods, the results from our initial study and replication are closely in line. Section 4.3.2 provides additional discussion and Table 6, which replicates the results using our current methodology, as well.

${ }^{5} \mathrm{An}$ alternative design would attempt to measure gain-loss attitudes either through small stakes risk aversion or some other choice. Such tests would face a number of challenges, requiring both additional assumptions (e.g., about the correlation between intrinsic utilities and gain-loss parameters across contexts) and additional experimental choices. Recognizing both the polluting potential of such choices and the challenge of modeling the full body of experimental behavior through the lens of the KR model (Sprenger, 2015), we believe there is substantial value in our method. In section 4.2, we show predictive power for our measure of gain-loss attitudes and exchange behavior in a standard exchange paradigm. Subjects we classify as loss-averse exhibit an endowment effect in their actual choices, and subjects we classify as gainloving exhibit an anti-endowment effect. Of course, failure to correctly categorize gain-loss types should lead to a lack of predictive validity in Stage 2 of the experiment, working against these and other identified results.
} 
distribution of choices using standard mixed logit methods, and yields an expected value of the key gain-loss parameter for every individual given their Stage 1 statements. We provide complementary, reduced-form evidence to ensure our findings are not driven by our structural assumptions. We also explore an alternate interpretation of Stage 1 behavior: that heterogeneity in intrinsic values rather than gain-loss attitudes drives choice. Both structural estimates yield point predictions for our critical Stage 2 tests of the KR model. In Stage 2, subjects are endowed with one of two objects, both completely different from those used in Stage 1, and are randomly assigned to one of two conditions. One group of subjects is assigned to Condition $\mathrm{B}$, a baseline endowment effect condition, where they decide whether they would like to exchange their object for the alternative. Another group of subjects is assigned to Condition F, where they decide whether to exchange their object under a probabilistic forced exchange mechanism akin to Cerulli-Harms et al. (2019). With probability 0.5 , regardless of their decision, exchange will be forced.

Under the KR model, loss-averse subjects should be more willing to exchange when probabilistically forced in Condition $\mathrm{F}$ than in Condition B. Intuitively, exchanging eliminates the potential loss associated with attempting to retain the endowed object in Condition $\mathrm{F}$ and being forced to exchange anyways. A loss-averse subject who is unwilling to exchange in Condition B may be willing to do so in Condition F. In contrast, gain-loving subjects should exhibit the opposite pattern, growing less willing to exchange in Condition F relative to Condition B. Intuitively, not exchanging in Condition F creates potential gains and losses associated with probabilistic forced exchange, and the latter outweighs the former. A gain-loving subject who is willing to exchange in Condition B may be unwilling to do so in Condition F. We examine heterogeneous treatment effects in Stage 2 over the gain-loss attitudes measured and estimated in Stage 1. Stage 2 behavior is also analyzed under the interpretation that Stage 1 preference statements are driven by heterogeneity in utility rather than gain-loss attitudes.

We document three key findings. First, on average subjects do appear to prefer their randomly endowed object in Stage 1, indicating an endowment effect in preference statements. 
Fifty-seven percent of subjects state they would choose their randomly endowed object, and two-thirds provide weakly higher wanting and liking ratings for their endowed object. These preference statements are highly correlated with each other: all pairwise correlations exceed 0.7. Despite the regularity of an endowment effect in preference statements, choices also exhibit marked heterogeneity. Roughly 25 percent of subjects' hypothetical choice, wanting rating, and liking rating all indicate an anti-endowment effect. Our primary structural model interprets the distribution of choices as driven by heterogeneous gain-loss attitudes. This model identifies a distribution of the gain-loss parameter, $\lambda$, with loss aversion, $\lambda>1$, on average but substantial heterogeneity. Indeed, the fitted distribution estimates 38 percent of individuals as gain-loving, $\lambda<1$. The alternative structural model, attributing the same distribution of behavior to heterogeneity in intrinsic utilities with homogeneous gain-loss attitudes, indicates universal loss aversion and substantial heterogeneity in intrinsic utilities. Interestingly, the model with heterogeneous gain-loss attitudes has superior penalized likelihood, indicating better in-sample fit.

Second, in Stage 2 a substantial endowment effect exists in Condition B. Thirty-eight percent of subjects choose to exchange their randomly endowed object, which deviates significantly from the neoclassical benchmark of 50 percent exchange. On average, probabilistic forced exchange has a null effect, reducing exchange by 0.4 percentage points in Condition F. The aggregate null effect in our sample of over 1000 observations contradicts the predictions of the KR model under the standard assumption of universal loss aversion. Third, Stage 2 behavior differs substantially by previously measured gain-loss attitudes. Loss-averse subjects are markedly less willing to exchange than gain-loving subjects in Condition B. This intuitive relationship between $\lambda$ and behavior in a standard exchange paradigm validates our methodology for identifying gain-loss attitudes. In Condition $\mathrm{F}$ the relationship between gain loss attitudes and exchange behavior reverses, leading to a heterogenous treatment effect over the previously measured types. Loss-averse subjects are more willing to exchange in Condition $\mathrm{F}$ relative to Condition B, while gain-loving subjects are less-so. The sign and magnitude of our heterogeneous treatment effects are 
closely in line with the predictions of the KR model. In contrast, interpreting Stage 1 behavior as driven by heterogeneous utilities rather than heterogeneous gain-loss attitudes delivers zero predictive power. ${ }^{6}$

The findings described above also hold for alternate methodologies for identifying gainloss attitudes. In particular, we provide a reduced-form exercise which infers gain-loss attitudes based upon residualized Stage 1 behavior. There again, individual differences in gain-loss attitudes closely relate to differences in Stage 2 treatment effects. Additionally, the findings provided for our joint data set replicate in both of our samples. Appendix A details exactly our pre-registered analysis, which featured centrally in prior drafts of this manuscript, and shows close correspondence in the heterogeneous treatment effects in our initial and replication studies. ${ }^{7}$ Table 6 in the main text also shows such reproducibility.

Our identified heterogeneity of gain-loss attitudes, respected in heterogeneous treatment effects over gain-loss types, carries important implications for interpreting the body of experimental evidence on expectation-based reference dependence. We show that even with over 1000 collective observations, we are dramatically underpowered to identify the theoretical average treatment effect in our experiment. The theoretical average treatment effect is around 5.9 percentage points, a value that we calculate would require a sample size of around 2250 observations to estimate with 80 percent power. Prior experimental tests focused on average treatment effects are likely to be similarly underpowered.

Our results add two key points to the discussion on the source of reference points and the nature of reference-dependent preferences. First, given inconsistent findings across prior studies, our null aggregate effect in a sample of over 1000 subjects, and our theoretical development, heterogeneity in gain-loss attitudes appears to be an issue of first order importance precluding strong inferences from prior work. Mixed evidence on the KR model is likely not driven by a failure of the expectations-based formulation of reference points,

\footnotetext{
${ }^{6}$ Such lack of predictive power is intuitive given that subjects are endowed with different objects in Stage 2 than in Stage 1 and there is random assignment to conditions.

${ }^{7}$ We are indebted to an anonymous referee for suggesting the current path of structural analysis. This analysis differs from our prior presentation of the results, as we have adopted a mixed logit methodology for identifying gain-loss attitudes rather than our prior standard logit methods.
} 
but rather by a failure of the second component of the joint hypothesis inherent to this prior work: that gain-loss attitudes are universal. We show, in a simple and reproducible way that the predictions of the expectations-based KR model are reliably recovered once heterogeneity in gain-loss attitudes is accounted for.

Second, we add a key observation on the heterogeneity of gain-loss attitudes to a growing literature on the topic. Chapman et al. (2018) indicate eight prior studies with a documented distribution of gain-loss attitudes, only one of which is measured outside of lottery choice: a prior version of this paper. Ours are the first findings to document the distribution of gain-loss attitudes in exchange settings and predictive validity of resulting individual measures. In our exchange setting, we document an average attitude of loss aversion, but a sizable proportion of the distribution, 38 percent, exhibits gain lovingness. This proportion of gain-loving subjects somewhat exceeds estimates from risk experiments

in the lab, but falls below the field estimates of Chapman et al. (2018). Future work providing further documentation and evaluation of the heterogeneity in gain-loss attitudes across domains is equipped with an initial observation from exchange behavior.

The paper proceeds as follows. In Section 2, we set the theoretical background and derive behavioral predictions. Section 3 and 4 present the experimental design and results, respectively. Section 5 concludes.

\section{Theoretical Considerations and Design Guidance}

We examine the predictions of the KR model in simple exchange settings with two objects, recognizing heterogeneity of gain-loss attitudes. The theoretical development hues closely to our experimental design, providing motivation for our analysis. We contrast two conditions: a standard exchange paradigm, termed Condition B, where subjects are endowed with an object and decide whether to exchange or not; and a probabilistic forced exchange paradigm, termed Condition F, identical to Condition B except with probability 0.5, regardless of choice, exchange will be forced. We show that loss-averse subjects should grow 
more willing to exchange in Condition F relative to Condition B. In contrast, gain-loving subjects should grow less willing to exchange in Condition F relative to Condition B.

There is a central intuition for the heterogeneous response to probabilistic forced exchange. When attempting not to exchange their endowment in Condition $\mathrm{F}$, an individual faces the potential of having this object taken from them and exchanged anyways. A loss-averse individual disproportionately dislikes the sensation of potential loss and so may choose to exchange to avoid the possible loss. In contrast, a gain-loving individual disproportionately likes the sensation of potential gain and so may choose not to exchange to maintain the possible gain.

Consider a two-dimensional utility function over two objects of interest, object $X$ and object $Y$. Let $\mathbf{c}=\left(m_{X}, m_{Y}\right)$ and $\mathbf{r}=\left(r_{X}, r_{Y}\right)$ represent vectors of intrinsic utility and reference utility, respectively. The KR model specifies a utility function with two components, intrinsic utility, $m(\mathbf{c}) \equiv m_{X}+m_{Y}$, and gain-loss utility, $n(\mathbf{c} \mid \mathbf{r}) \equiv n_{X}\left(m_{X} \mid r_{X}\right)+$ $n_{Y}\left(m_{Y} \mid r_{Y}\right) \equiv \mu\left(m_{X}-r_{X}\right)+\mu\left(m_{Y}-r_{Y}\right)$, with separability across consumption dimensions. Let $m_{X} \in\{0, X\}$ and $m_{Y} \in\{0, Y\}$ stand for both the outcome and the corresponding intrinsic utility of owning zero or one unit of object $\mathrm{X}$, and zero or one unit of object $\mathrm{Y}$, respectively. Overall utility is described by

$$
\begin{aligned}
u(\mathbf{c} \mid \mathbf{r})=u\left(m_{X}, m_{Y} \mid r_{X}, r_{Y}\right) & =m_{X}+n_{X}\left(m_{X} \mid r_{X}\right)+m_{Y}+n_{Y}\left(m_{Y} \mid r_{Y}\right) \\
& =m_{X}+\mu\left(m_{X}-r_{X}\right)+m_{Y}+\mu\left(m_{Y}-r_{Y}\right),
\end{aligned}
$$

where

$$
\mu(z)=\left\{\begin{array}{cl}
\eta z & \text { if } z \geq 0 \\
\eta \lambda z & \text { if } z<0
\end{array}\right.
$$

In this piece-wise linear gain-loss function, the parameter $\eta$ captures the magnitude of changes relative to the reference point, and $\lambda$ captures gain-loss attitudes. If $\lambda>1$, the individual is loss-averse, experiencing losses more than commensurately-sized gains. If 
$\lambda<1$, the individual is gain-loving, experiencing gains more than commensurately-sized losses.

\subsection{Determination of the Reference Point in Exchange Behavior}

In the KR model, unless exogenously determined, the vector $\mathbf{r}$ is established as part of a consistent forward-looking plan for behavior. The KR model posits a reference-dependent expected utility function $U(F \mid G)$, taking as input a distribution $F$ over consumption outcomes, c, which are valued relative to a distribution $G$ of reference points, $\mathbf{r}$. That is

$$
U(F \mid G)=\iint u(\mathbf{c} \mid \mathbf{r}) d F(\mathbf{c}) d G(\mathbf{r})
$$

A Personal Equilibrium is a situation where, given that the decision-maker expects as a referent some distribution $F$, they indeed prefer $F$ as a consumption distribution over all alternative consumption distributions, $F^{\prime}$. Ex-ante optimal behavior has to accord with expectations of that behavior. Formally, given a choice set, $\mathcal{D}$, of lotteries, $F$, over consumption outcomes c $=\left(m_{X}, m_{Y}\right)$, KR's Personal Equilibrium states the following:

Personal Equilibrium (PE): A choice $F \in \mathcal{D}$, is a personal equilibrium if

$$
U(F \mid F) \geq U\left(F^{\prime} \mid F\right) \forall F^{\prime} \in \mathcal{D} .
$$

Regardless of endowment, if object $\mathrm{X}$ is to be chosen in a PE, then $\mathbf{r}=(X, 0)$ and if object $\mathrm{Y}$ is to be chosen in a $\mathrm{PE}$ then $\mathbf{r}=(0, Y)$.

Given the potential for the multiplicity of PE selections, the KR model is constructed with a notion of equilibrium refinement, Preferred Personal Equilibrium (PPE), and an alternate non-PE criterion, Choice Acclimating Personal Equilibrium (CPE). In both of these constructs, ex-ante utility is used as a basis for selection and, hence, for making more narrow predictions. For ease of explication, we focus our analysis on the CPE criterion. In Appendix B we provide theoretical analyses under the PE and PPE approaches. Im- 
portantly, all three formulations share common comparative statics, and therefore make qualitatively similar predictions, for our KR test.

Given a choice set, $\mathcal{D}$, of lotteries, $F$, over consumption outcomes $\mathbf{c}=\left(m_{X}, m_{Y}\right)$, ChoiceAcclimating Personal Equilibrium states the following:

Choice Acclimating Personal Equilibrium (CPE): A choice $F \in \mathcal{D}$, is a choice-acclimating personal equilibrium if

$$
U(F \mid F) \geq U\left(F^{\prime} \mid F^{\prime}\right) \forall F^{\prime} \in \mathcal{D} \text {. }
$$

Under CPE, an individual selects between options like $[\mathbf{c}, \mathbf{r}]=[(X, 0),(X, 0)]$ and $[\mathbf{c}, \mathbf{r}]=$ $[(0, Y),(0, Y)] .^{8}$

\subsubsection{Manipulating r: Probabilistic Forced Exchange}

The CPE concept noted above requires consistency between the distributions of $\mathbf{c}$ and r. We consider a baseline simple exchange condition, Condition B, for an individual endowed with object $X$. We focus on the choice set consisting of pure strategy choices $\mathcal{D}=\{(X, 0),(0, Y)\}$, with the first element reflecting choosing not to exchange and the second choosing to exchange. ${ }^{9}$

In this setting, there are two potential CPE selections, $[\mathbf{c}, \mathbf{r}]=[(X, 0),(X, 0)]$ and $[\mathbf{c}, \mathbf{r}]=$ $[(0, Y),(0, Y)]$. The individual can support not exchanging, $[\mathbf{c}, \mathbf{r}]=[(X, 0),(X, 0)]$, in a CPE if

$$
U(X, 0 \mid X, 0) \geq U(0, Y \mid 0, Y)
$$

which, under our functional form assumptions, becomes

$$
X \geq Y
$$

\footnotetext{
${ }^{8}$ Note that a selection need not be PE in order to be CPE. The alternate concept, PPE requires $F$ and $F^{\prime}$ to be $\mathrm{PE}$, rather than simply elements of $\mathcal{D}$.

${ }^{9}$ In Appendix B, we conduct the analysis with $\mathcal{D}$ including all mixtures of exchanging and not exchanging and reach quite similar results.
} 
Figure 1, Panel A graphs the Condition B CPE cutoff, $\underline{X}_{B}=Y$, the smallest value of $X$ at which the individual can support not exchanging, which is constant for all values of the gain-loss parameter, $\lambda$.

The value $\underline{X}_{B}=Y$ implies that choice in Condition B is governed only by intrinsic utility. This represents the inability of KR-CPE to rationalize the standard endowment effect. This prediction is not shared by the PE formulation, wherein the value of gain-loss attitudes tunes the set of permissible PE choices and can lead to an endowment effect (see Appendix B). Nonetheless, the critical comparative static shared by both formulations is delivered by comparing exchange behavior in this baseline Condition $\mathrm{B}$ with probabilistic forced exchange.

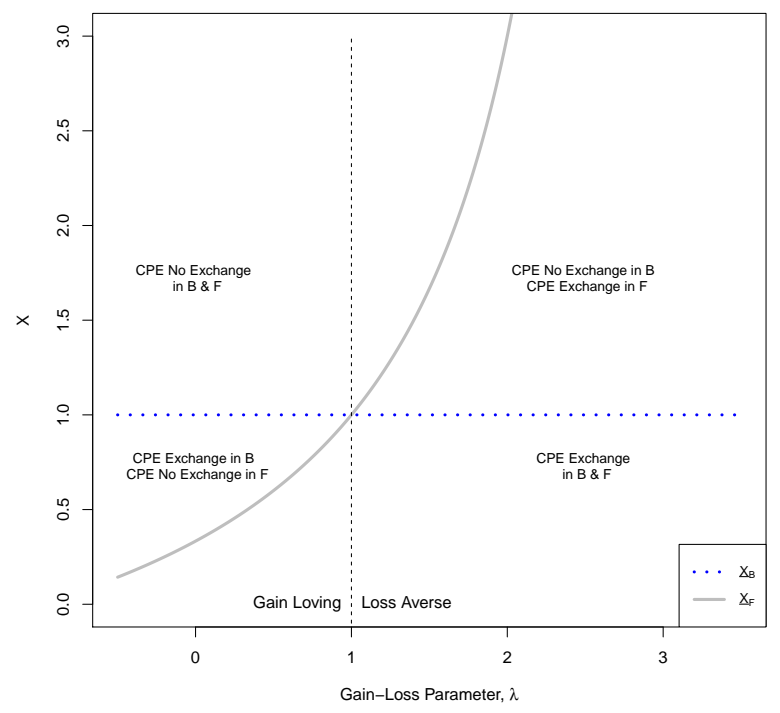

Panel A: Theoretical CPE Thresholds

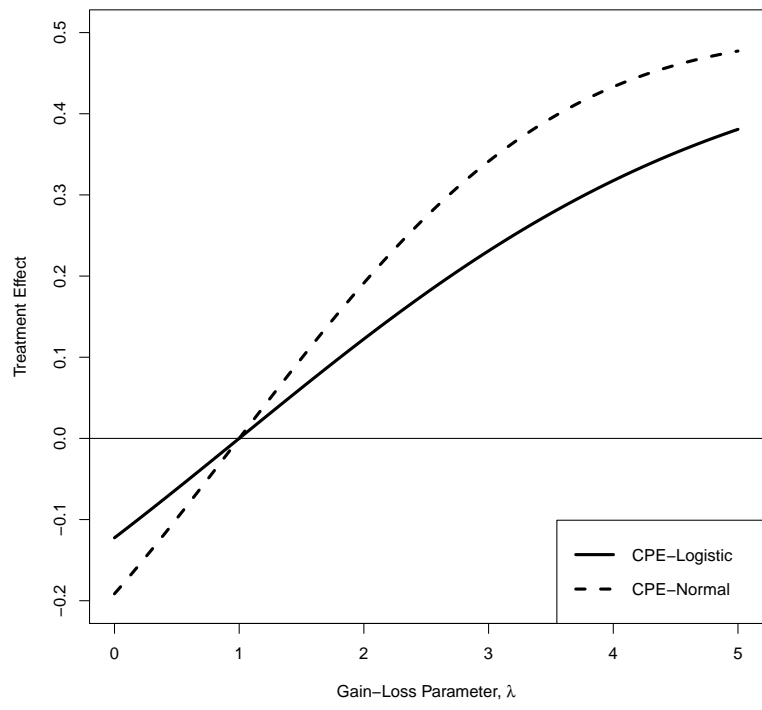

Panel B: Predicted Treatment Effects

Figure 1: Gain-Loss Attitudes, Theoretical Thresholds, and Treatment Effects Notes: Panel A: CPE cutoff values for agent endowed with $X, Y=1$ and $\eta=1$. For $X \geq \underline{X}_{B}=Y$, individuals can support not exchanging as a CPE in a baseline exchange environment (Condition B). For $X \geq \underline{X}_{F}=\frac{1+0.5 \eta(\lambda-1)}{1+0.5 \eta(1-\lambda)} Y$, individuals can support not exchanging as a CPE in a forced exchange environment (Condition F). Panel B: Simulated treatment effects for the probability of exchange plotted by $\lambda$ with $Y / X=1, \eta=1$ under logistic or normal probability distributions.

Now, consider an environment of probabilistic forced exchange, Condition F. With probability 0.5 , the agent, assumed endowed with $X$, will be forced to exchange $X$ for $Y$ regard- 
less of their choice. If the individual wishes to retain their object, they are subject to a stochastic reference point, as with probability 0.5 their object will be exchanged. Now, the potential selections for someone endowed with $X$ are $\mathcal{D}=\{0.5(X, 0)+0.5(0, Y),(0, Y)\}$, with the first element reflecting attempting not to exchange and the second reflecting exchange, as before. They can support attempting not to exchange as a CPE if

$$
U(0.5(X, 0)+0.5(0, Y) \mid 0.5(X, 0)+0.5(0, Y)) \geq U(0, Y \mid 0, Y)
$$

which, under our functional form assumptions, becomes

$$
\begin{array}{r}
0.5 X+0.5 Y+0.25 \eta(1-\lambda)(X+Y) \geq Y \\
X \geq \frac{1+0.5 \eta(\lambda-1)}{1+0.5 \eta(1-\lambda)} Y .
\end{array}
$$

The manipulation of probabilistic forced exchange changes the CPE threshold from $\underline{X}_{B}=$ $Y$ to $\underline{X}_{F}=\frac{1+0.5 \eta(\lambda-1)}{1+0.5 \eta(1-\lambda)} Y$. Figure 1, Panel A illustrates the changing CPE cutoff values associated with not exchanging. In Condition $\mathrm{F}$, the individual can support attempting to retain $X$ in $\mathrm{CPE}$ on the basis of both intrinsic utility and gain-loss attitudes.

The gain-loss parameter, $\lambda$, tunes precisely how behavior should change between Conditions $\mathrm{B}$ and F. Figure 1, Panel A is partitioned into four regions. Two critical regions of changing CPE choice are identified. For $X>Y$ and $\lambda>1$, it is CPE to not exchange in Condition B and CPE to exchange in Condition F. This region has been the basis of prior experimental tests under the assumption of universal loss aversion as such individuals become more willing to exchange when probabilistically forced. Ignored to date is the region where $X<Y$ and $\lambda<1$. In this region, it is CPE to exchange in Condition $\mathrm{B}$ and $\mathrm{CPE}$ to not exchange in Condition F. In contrast to the loss-averse prediction, such gain-loving individuals become less willing to exchange when probabilistically forced. 


\subsection{Heterogeneity in Gain-Loss Attitudes and Theoretical Treat- ment Effects}

Manipulating probabilistic forced-exchange carries clear value for testing the KR model. The altered thresholds for supporting exchange in CPE illustrated in Figure 1, Panel A form the basis of experimental tests. Importantly, to date, these tests have been conducted under the standard assumption of loss aversion, $\lambda>1$. Figure 1, Panel A makes clear that these thresholds are differentially altered for different values of $\lambda$. In this subsection, we evaluate theoretical treatment effects when $\lambda>1$ or $\lambda<1$. We demonstrate different signed treatment effects around the value of $\lambda=1$, and the corresponding challenge of aggregating treatment effects.

In order to make predictions on the behavioral response to probabilistic forced exchange, we map from the CPE thresholds to the probability of making a specific selection. We simulate behavior assuming that $X$ and $Y$ have equal intrinsic utility, $Y / X=1, \eta=1$, and the CPE utilities are followed probabilistically subject to a specific logit choice model. ${ }^{10}$ That is, an individual chooses to exchange in Condition B with probability

$$
\begin{aligned}
\operatorname{Prob}(\text { Exchange })_{B} & =\operatorname{Prob}(Y>X)=\operatorname{Prob}(Y / X-1>0) \\
& =\operatorname{logistic}(0)=0.5 .
\end{aligned}
$$

Similarly, the individual chooses to exchange in Condition $\mathrm{F}$ with probability

$$
\begin{aligned}
\operatorname{Prob}(\text { Exchange })_{F} & =\operatorname{Prob}(Y>0.5 X+0.5 Y+0.25 \eta(1-\lambda)(X+Y)) \\
& =\operatorname{Prob}(0.5(Y / X-1)+0.25 \eta(\lambda-1)(1+Y / X)>0) \\
& =\operatorname{logistic}(0.5(\lambda-1)) .
\end{aligned}
$$

\footnotetext{
${ }^{10}$ In our actual empirical results, we estimate the value of $Y / X$ rather than fix it by assumption. We maintain $\eta=1$ throughout.
} 
And the treatment effect is simulated as

$$
\begin{aligned}
T E & =\operatorname{Prob}(\text { Exchange })_{F}-\operatorname{Prob}(\text { Exchange })_{B} \\
& =\operatorname{logistic}(0.5(\lambda-1))-\operatorname{logistic}(0)
\end{aligned}
$$

Figure 1, Panel B graphs this treatment effect against the value of $\lambda$ under the assumptions $\eta=1$ and $X / Y=1 .{ }^{11}$ The theoretical simulated treatment effect is negative for $\lambda<1$, positive for $\lambda>1$, and is generally concave in $\lambda$. Figure 1, Panel B also provides a theoretical benchmark under a normal probability distribution rather than the logistic, highlighting the robustness of the non-linearity prediction.

The apparent concavity of simulated treatment effects in $\lambda$ implies a substantial challenge in the aggregation of treatment effects. Not only do treatment effects change sign at $\lambda=1$, but gain-loving subjects can have an outsized impact on identified average effects. Loss aversion on average therefore does not guarantee positive aggregate treatment effects in exchange experiments testing the KR model. Heterogeneity is a confound of first-order importance plaguing prior experiments in this vein. Any test of KR must account for heterogeneity in gain-loss attitudes to credibly test the underlying expectation-based reference-dependent mechanism. Motivated by this point, our study combines the experimental manipulation of probabilistic forced exchange with a prior measurement of gain-loss attitudes.

\section{Experimental Design and Procedures}

Our design is comprised of two stages. In Stage 1, a taxonomy of gain-loss types is created. In Stage 2, subjects are assigned to either a standard exchange study or one with probabilistic forced exchange. Stage 1 measures of gain-loss attitudes can then be connected to Stage 2 behavior. Figure 2 illustrates the experimental order of events.

\footnotetext{
${ }^{11}$ Appendix B provides the same analysis under PE and PPE.
} 


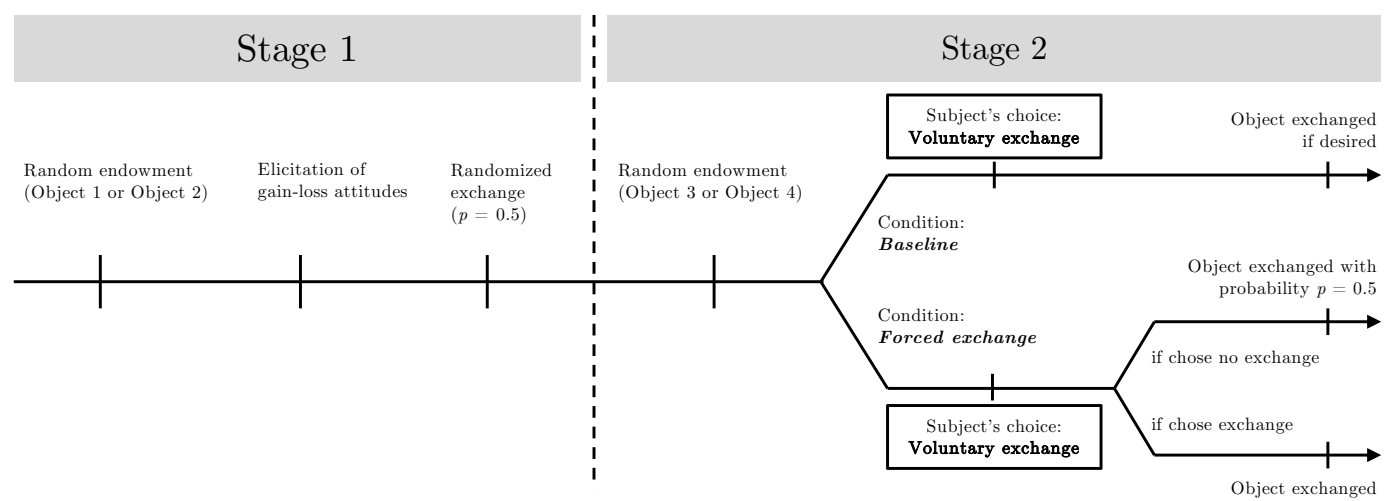

Figure 2: Timeline of Laboratory Experiment

Notes: The figure displays the course of events in both treatment conditions, Condition B(aseline) and Condition $\mathrm{F}$ (orced exchange).

\subsection{Stage 1: Measuring Gain-Loss Attitudes}

Procedures. The experimenter welcomed the participants in a small presentation room and informed them that the study would consist of two stages. At each seat was a card with a number (placed face down). Then, without further explanation, the experimenter projected on the wall two equally-sized pictures of the respective Stage 1 objects for that session, along with the description and two short bullet points on the characteristics of each product. The exact information presented to subjects is reproduced in Appendix E in German and translated to English.

After allowing sufficient time (three minutes) to study the projected information, the experimenter asked subjects to turn the card in front of them over and move to the cubicle with the corresponding number in the adjacent computer laboratory. In their private cubicle, which was separated and not visible from the outside, subjects would find one of the two presented objects. Computer instructions then informed the subject that they possess the object in front of them, and that they are free to inspect it more closely.

After three minutes allotted for inspection of the object, we asked subjects three questions. First, for each object subjects were asked "How much do you like this product?" with response scales ranging from $0=$ "Not at all" to $8=$ "Very much". Second, for each object 
they were asked "How much would you want to have this product?" on the same response scales. Third, they were asked "If you had to choose one of the objects, which one would you prefer to keep?", and were asked to provide a hypothetical choice between the two objects. These three preference statements are the raw data upon which our structural estimates of gain-loss attitudes are constructed. Given that subjects are endowed with one of the objects, our structural estimates of gain-loss attitudes assume this exogenous endowment is their reference point when providing these preference statements (see section 4.1.1 for further discussion).

This paper sidesteps several potential measurement issues within the KR model. First, our Stage 1 design exogenously endows subjects with objects and elicits preference statements under this fixed endowment without any discussion of actual exchange between the objects or future exchange opportunities. In the case of an exogenous endowment that cannot be expected to change, the KR model coincides exactly with the standard model of reference-dependent preferences with a fixed reference point. This allows us to elicit gain-loss attitudes under our exogenous endowment. See Kôszegi and Rabin (2006) for additional discussion of this point in the particular context of the endowment effect. Had we conducted an alternate design without such exogenous endowments or with salient discussion of exchange, the reference point would plausibly not be fixed, challenging our assumptions for measurement of gain-loss attitudes.

Second, there is a challenge associated with multiple choices and measurement within the KR model. In principle, all experimental choices should be considered part of a subject's strategy, with the suite of experimental choices forming a consistent plan of action (for related discussion, see Sprenger, 2015). Instead, we measure gain-loss attitudes in Stage 1 with non-choice response. Measuring gain-loss attitudes with choice would alter the analysis considerably, as the subject may be assumed to take any Stage 1 decision under a consistent forecast of their Stage 2 decision, and the choice set would consist of all potential two-period plans. Measurement of gain-loss parameters using choice responses would require attention to interactions across stages of the experiment and an accounting of 
subsequent behavior in generating a taxonomy of types. ${ }^{12}$ We assure that our non-choice taxonomy has close concurrence with actual choice by drawing links between estimated gain-loss attitudes in Stage 1 and subsequent choices made in Stage 2 for both conditions. We further ensure that the observed correlations are not driven by functional form assumptions by providing a companion reduced-form exercise.

Stage 1 of our experiment also featured one additional element of random variation: an experience with probabilistic exchange. After subjects provided their preference statements, the computer instructions announced that the experimenter would randomly draw a number between 1 and 20 using a rotating lottery drum placed on a table in the middle of the room. Half of the subjects were informed that the object in front of them would be replaced by the alternative object if a number between 1 and 10 was drawn. Instructions for the other half read that this replacement would only take place if a number between 11 and 20 was drawn. ${ }^{13}$ The experimenter drew the number in a way that both the lotto device containing the 20 balls and the drawn number was visible from every cubicle. Immediately following the draw, and without further comment, the experimenter replaced objects as dictated by the drawn number. As noted above, it is critical that introduction of random replacement procedure was done after all preference statements were elicited under the exogenously endowed object.

This random experience serves two purposes in our design. First, regardless of Stage 2 treatment assignment, individuals will have had some prior experience with probabilistic exchange (albeit without choice). Second, it removes a potential challenge to our interpretation associated with complementarities between objects across rounds. If there existed some un-modeled, unintentional complementarity between the objects endowed in Stage 1 and Stage 2, a subject might state a preference for or against both of their endowed objects in order to consume both endowed objects or both alternatives together. Random

\footnotetext{
${ }^{12}$ This not to say that such exercises could not valuably add to future work in this area.

${ }^{13}$ This loss condition was counterbalanced within each subsample endowed with the same object, such that irrespective of the draw, exchange would take place for exactly half of the subjects initially endowed with either object.
} 
replacement within Stage 1 breaks these potential complementarities as a driver of Stage 2 choice, and we can explore the relationship between Stage 1 experience and Stage 2 behavior. ${ }^{14}$ After completing Stage 1, the instructions asked subjects to return to the main lecture room for Stage 2.

\subsection{Stage 2: Probabilistic Forced Exchange, Heterogeneity, and Prior Experience}

Procedures. The basic procedures in Stage 2 were deliberately kept exactly identical to those in the Stage 1. Upon their return to the lecture room, the experimenter projected another page onto the wall, this time presenting the objects for Stage 2 of that session. In the meantime, a second experimenter allocated objects to the cubicles in the computer laboratory next door in a pre-specified order. Subjects were ushered back to their cubicle where they found their second endowed object and were allowed sufficient time for inspection. In Stage 2, subjects were randomized into one of two conditions: a baseline exchange condition, Condition B, and a treatment condition with probabilistic forced exchange, Condition F. The randomization was conducted at the session level. ${ }^{15}$ Across our two studies, 59 percent (603 of 1024 subjects) were randomly assigned to Condition F sessions. ${ }^{16}$

Condition B: Baseline Exchange. In Condition B, subjects had an opportunity to voluntarily exchange their endowed object for the alternative. Their decision was final -

\footnotetext{
${ }^{14}$ Immediately before and immediately after the random replacement was conducted, we elicited subjects' mood using standard psychological scales (Bradley and Lang, 1994). Subjects answered the question "Please answer the following questions about how you currently feel. Which expressions better apply to you at the moment?" by positioning a slider on an 11-point response scale. The lower end (0) was labeled using the words "Unhappy, Angry, Unsatisfied, Sad, Desperate" and the upper end (10) was labeled "Happy, Thrilled, Satisfied, Content, Hopeful'". The changes in these values were used as an initial validation of gain-loss types in prior versions of this manuscript. For space considerations we do not conduct this intermediate analysis here, but the results can be found in https://papers.ssrn.com/sol3/papers.cfm? abstractid=3170670 and https://papers.ssrn.com/sol3/papers. cfm?abstract_id=3589906.

${ }^{15}$ We present our analysis with robust standard errors in the main text and Appendix Tables A4 through A6 reproduce our results with standard errors clustered at the session level. Statistical significance is enhanced with clustering, and so we opt to provide the more conservative values in the main text.

${ }^{16}$ In our initial study 62 percent (374 of 607) were assigned to Condition F under an assignment probability of 60 percent, and in our replication study 55 percent (229 of 417) were assigned to Condition F under an assignment probability of 50 percent.
} 
whatever they chose they would receive. The baseline condition is a standard exchange setting common to endowment effect experiments.

Condition F: Probabilistic Forced Exchange. Condition F implemented an exchange study with probabilistic forced exchange. The instructions specified that regardless of their choice, exchange would take place with probability 0.5 based on a draw from the lotto drum, as in Stage 1. This means that for a subject who decided to exchange, the treatment had no effect. However, for a subject who attempted to keep their object, exchange would be forced probabilistically with a 50 percent chance.

Several noted issues with experimental investigations of market exchange motivated our purposefully simple design (Plott and Zeiler, 2005, 2007). First, subjects take a simple binary choice, alleviating potential concerns related to the use of 'multiple price lists' in exchange experiments. Specifically, we do not need to elicit a willingness to pay or willingness to accept in monetary terms, but simply ask whether the subject is willing to trade the endowed object for the alternative. As such, mistaken perceptions of market power do not play a role, nor do income effects. Second, unlike previous market exchange experiments, we create a private environment that limits confounds from social interaction. In particular, subjects make their decisions anonymously in a private cubicle; they find their endowment placed in front of them when entering the cubicle instead of receiving it personally through the hands of the experimenter, which has been criticized for triggering the misperception of the endowment as a gift (see, e.g., Plott and Zeiler, 2005, 2007); and subjects do not interact with other subjects at any stage during the experiment.

\subsection{Sample Details}

An initial sample of 607 students and a replication sample of a further 417 students from the University of Bonn participated in the experiment which was conducted using the software z-Tree (Fischbacher, 2007) in June and July 2015 and July 2018 at the BonnEconLab. ${ }^{17}$

\footnotetext{
17 Several minor differences between the original sessions and those in the replication deserve note. We opted to split the treatment assignments between Condition B and Condition F at 50 percent-50 percent
} 
We conducted 53 sessions with 16 to 20 participants each. Table 1 provides an overview of the subject pool by treatment conditions.

Table 1: Summary Statistics and Treatment Assignment

\begin{tabular}{|c|c|c|c|c|}
\hline \multicolumn{5}{|c|}{ Stage 1} \\
\hline & \multicolumn{2}{|c|}{ Pair 1} & \multicolumn{2}{|c|}{ Pair 2} \\
\hline & USB stick & Pen set & Picnic mat & Thermos \\
\hline A) Initial Endowment & 274 & 264 & 242 & 244 \\
\hline - in \% of subject pool & $26.76 \%$ & $25.78 \%$ & $23.63 \%$ & $23.83 \%$ \\
\hline \multicolumn{5}{|c|}{ Stage 2} \\
\hline & \multicolumn{2}{|c|}{ Pair 1} & \multicolumn{2}{|c|}{ Pair 2} \\
\hline & USB stick & Pen set & Picnic mat & Thermos \\
\hline B) Initial Endowment & 242 & 244 & 274 & 264 \\
\hline - in \% of subject pool & $23.63 \%$ & $23.83 \%$ & $26.76 \%$ & $25.78 \%$ \\
\hline C) Condition B & 113 & 117 & 97 & 94 \\
\hline$-i n \%$ of $B)$ & $46.70 \%$ & $47.95 \%$ & $35.40 \%$ & $35.60 \%$ \\
\hline D) Condition $F$ & 129 & 127 & 177 & 170 \\
\hline- in $\%$ of $B)$ & $53.30 \%$ & $52.05 \%$ & $64.60 \%$ & $64.40 \%$ \\
\hline
\end{tabular}

Total number of observations 1024

Notes: Stage 2 condition (Condition B or Condition F) is randomized within each session.

The use of each pair as the Stage 1 pair was counterbalanced at the session level.

The objects used for the exchange experiment included a USB stick, a set of three erasable pens, a picnic mat, and a thermos. ${ }^{18}$ We selected these four objects on the basis of a pre-experimental survey evaluation of 12 candidate objects. We put particular emphasis on ruling out complementarities between items across rounds. The former two (USB stick and pens) and the latter two objects (picnic mat and thermos) each constituted a pair.

rather than the original 40 percent-60 percent to maximize power. Since storage technology rapidly advanced, the $8 \mathrm{~GB}$ USB stick had to be replaced by a 16GB USB stick, as that was the new minimum. In addition, we were unable to repurchase the identical pattern for the picnic mat, so we opted for a visually similar one. Further, while only one experimenter ran the sessions for the original study, a total of 4 experimenters ran sessions during the course of the replication. In the Appendix, we repeat the analysis with experimenter fixed effects and find quantitatively similar results. Lastly, there was a small error in the implementation of sessions run by one specific experimenter who reversed the coded, randomly selected, endowments. Although this has no effect on the experiment, it did require us to recode the endowments for these sessions. The results excluding this experimenter's sessions also reproduce the findings here.

${ }^{18}$ Pictures and information presented to subjects are reproduced in Appendix E. 
Every subject faced exactly one stage with each pair of objects. The use of each pair as the Stage 1 pair was counterbalanced at the session level, with the respective other pair used in Stage 2. Within each session, the endowments of one of the two objects within the pair was counterbalanced in both stages. ${ }^{19}$

\section{Experimental results}

We present the results in three subsections. First, we examine the Stage 1 preference statements leading to our taxonomy of gain-loss attitudes. Second, we examine behavior in Stage 2, linking heterogeneity in gain-loss attitudes to the behavioral response to probabilistic forced exchange. Third, we provide robustness tests and separate analyses for our initial and replication studies.

\subsection{Stage 1: Identifying Gain-Loss Attitudes}

In Stage 1, we collect three critical preference statements for the endowed and alternative object. This is used to infer the gain-loss attitude for each individual. Figure 3 provides histograms for our three preference statements: hypothetical choice, and wanting and liking ratings for the two objects. We summarize the direction of preference in ratings statements using the ordinal information of rating the endowed object higher than the alternative, giving them equal rating, or rating the alternative higher. These values are aggregated across the four potential endowments of Stage 1. Given random assignment of endowed objects and the counterbalanced design, the distributions of preference statements should be identical between endowed and alternative objects. Instead, all three distributions show a clear preference for the subject's endowed object relative to the alternative. Fifty-seven percent of subjects state that they would choose their endowed object, 45 percent provide

\footnotetext{
${ }^{19}$ That is, if for a given session the USB stick and pens pair constituted the Stage 1 pair, the picnic mat and thermos pair would be the Stage 2 pair. Half of the subjects were initially endowed with the USB stick in Stage 1. Among this half of the session participants, again half would initially receive the picnic mat and the other half the thermos at the beginning of Stage 2.
} 
a higher liking rating for their endowed object compared to 33 percent for the alternative, and 45 percent provide a higher wanting rating for their endowed object compared to 32 percent for the alternative. For each measure we reject the null hypothesis that stated preferences are equal over the endowed and alternative objects. ${ }^{20}$

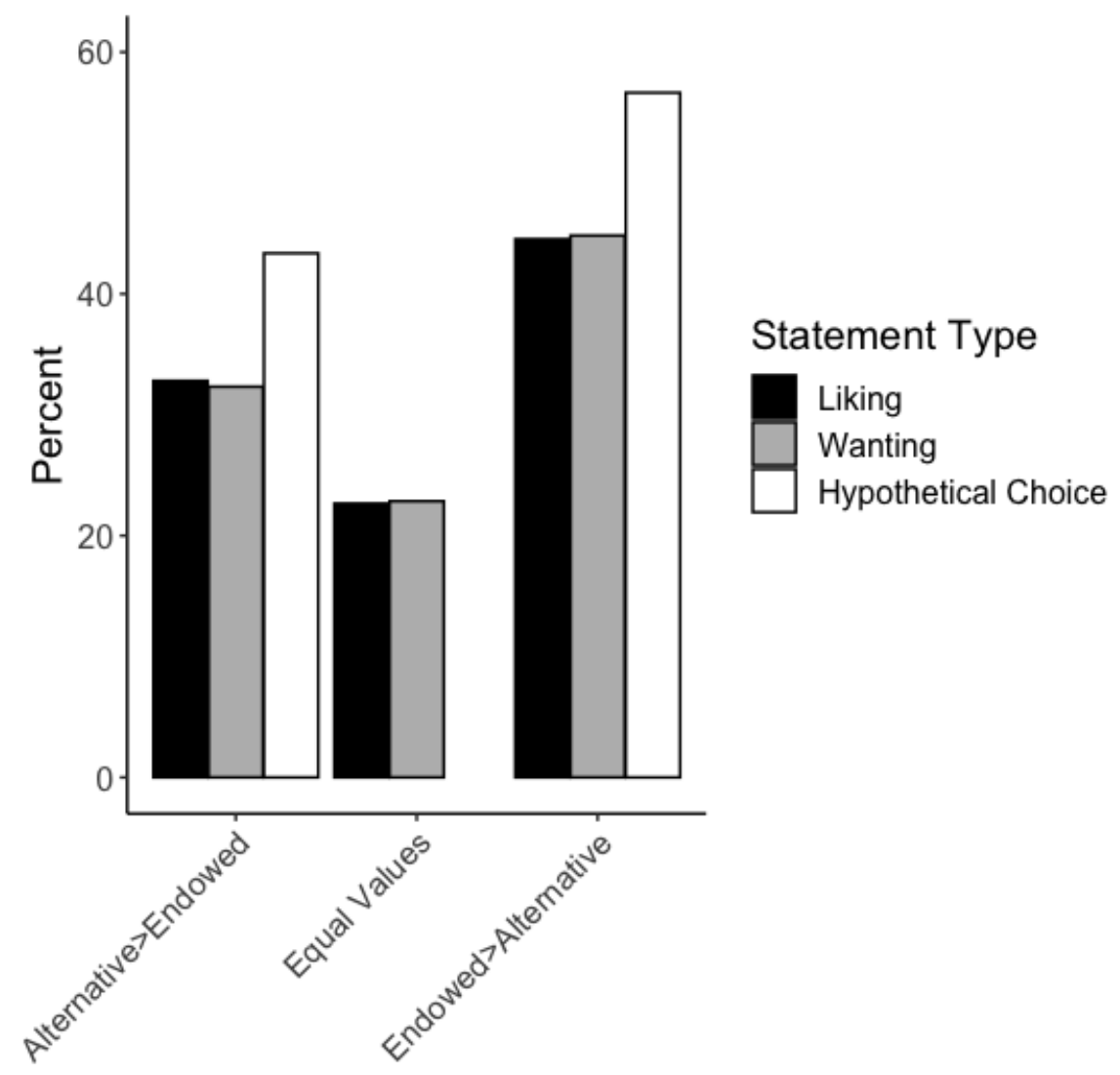

Figure 3: Stated Preferences and Endowments Notes: Relative preference statements for endowed and alternative objects. Wanting and liking ratings mapped from a nine-point scale onto a categorical variable representing whether the rating was higher for the endowed or alternative object, or equal for the two. Two sided t-tests comparing "Endowed $>$ Alternative" to "Alternative $>$ Endowed" are significant for all statements (Liking: $t=5.48$, Wanting: $t=5.86$, Hypothetical Choice: $t=6.06, p<0.01$ for all).

The collected preference statements show a clear endowment effect. Thirty-eight percent of subjects (385 of 1024) state that they would hypothetically choose, strictly like, and strictly want their endowed object. The different preference statements are remarkably correlated

\footnotetext{
${ }^{20}$ Two sided t-tests comparing "Endowed $>$ Alternative" to "Alternative $>$ Endowed" are significant for all statements (Liking: $t=5.48$, Wanting: $t=5.86$, Hypothetical Choice: $t=6.06,(p<0.01)$ for all).
} 
within individual. The pairwise correlations between hypothetical choice, relative liking, and relative wanting statements all exceed 0.7 . The phenomenon of an endowment effect in preference statements, however, is not universal in our sample. Twenty-six percent of subjects (262 of 1024) exhibit the opposite pattern of hypothetically choosing, strictly liking, and strictly wanting the alternative object. We interpret the heterogeneity in Stage 1 preferences as indicating heterogeneity in gain-loss attitudes. An alternative - though one that requires gain-loss considerations due to the average endowment effect - is that heterogeneity in behavior is driven by heterogeneity in the intrinsic utility of objects. We consider and compare both forms of heterogeneity.

\subsubsection{Estimating Gain-Loss Attitudes}

The preference statements summarized in Figure 3 provide a basis for estimating the distribution of gain-loss attitudes or utility values using standard mixed logit methods. Consider an individual endowed with object $X$ who is asked to provide preference statements between $X$ and $Y$. Under the $\mathrm{KR}$ model, the individual will state a preference in the form of a higher liking value for $X$, higher wanting value for $X$, or hypothetical choice of $X$ if

$$
u(X, 0 \mid X, 0)-u(0, Y \mid X, 0)>\delta
$$

where $\delta$ captures the possibility of equal rating levels (note $\delta=0$ for our hypothetical choice data as there was no possibility of stating indifference). Under our functional form assumptions for KR utility — piecewise linear gain-loss utility with $\eta=1$ - such a preference statement occurs with probability

$$
\operatorname{Prob}_{X \mid X}=\operatorname{Prob}\left((1+\lambda)-2 \frac{Y}{X}-\delta_{X}>0\right)
$$


where $\delta_{X} \equiv \frac{\delta}{X}$. Similarly, an individual endowed with $X$ would state a preference for $Y$ with probability

$$
\operatorname{Prob}_{Y \mid X}=\operatorname{Prob}\left(2 \frac{Y}{X}-(1+\lambda)-\delta_{X}>0\right)
$$

and, where appropriate, would provide equal ratings for the two objects with probability

$$
\operatorname{Prob}_{E \mid X}=1-\operatorname{Prob}_{X \mid X}-\operatorname{Prob}_{Y \mid X}
$$

Symmetric formulations exist for individuals endowed with object $Y{ }^{21}$ These probabilities summarize the connection between the relative preference statements illustrated in Figure 3 and our structural model of gain-loss attitudes in Stage 1.

We make five assumptions to estimate the distribution of gain-loss attitudes from Stage 1 preference statements. First, following the structure of our design, our exercise recognizes the exogenously endowed object, $X$, as the subject's reference point. This formulation of a fixed reference point is inherent to our design, which elicits preference statements for both objects under this fixed endowment (and prior to any discussion of replacement or future opportunities to exchange). ${ }^{22}$ Second, we assume that $\operatorname{Prob}(\cdot)$ is the logistic function leading to logit choice. Third, we assume that the value $\lambda$ is drawn from a $\log$-normal distribution with $\log (\lambda) \sim N\left(\mu_{\lambda}, \sigma_{\lambda}^{2}\right)$, leading to a mixed logit formulation. Fourth, we assume the relative utility value $\frac{Y}{X}$ is homogeneous in the population and a

${ }^{21}$ That is

$$
\begin{aligned}
& \operatorname{Prob}_{X \mid Y}=\operatorname{Prob}\left(2-(1+\lambda) \frac{Y}{X}-\delta_{X}>0\right) \\
& \operatorname{Prob}_{Y \mid Y}=\operatorname{Prob}\left((1+\lambda) \frac{Y}{X}-2-\delta_{X}>0\right) \\
& \operatorname{Prob}_{E \mid Y}=1-\operatorname{Prob}_{X \mid Y}-\operatorname{Prob}_{Y \mid Y} .
\end{aligned}
$$

\footnotetext{
${ }^{22}$ Though implausible under our design, potential alternatives to this formulation might be the CPE construction or to assume the subject considers retaining their endowed object, $X$, and gaining the alternative, $Y$, evaluating $U(X, Y \mid X, 0)=X+(1+\eta) Y$. Importantly, neither alternative would deliver any information on the key gain-loss parameter, $\lambda$, and so both would yield null predictions for heterogeneous treatment effects in Stage 2. As such, in addition to the structure of our design, the results we document further invalidate these formulations.
} 
parameter to be estimated. Fifth, we assume $\delta_{X}$ to be fixed at value 0.55 , a value that our prior research indicated to be appropriate in aggregate estimation. ${ }^{23}$ We make a similar set of assumptions to estimate the distribution of utility values, $\frac{Y}{X}$ : logit choice, homogeneous gain-loss attitudes, $\frac{Y}{X}$ drawn $\log$-normal with $\log \left(\frac{Y}{X}\right) \sim N\left(\mu_{\frac{Y}{X}}, \sigma_{\frac{Y}{X}}^{2}\right)$, and $\delta_{X}=0.55$. Appendix $\mathrm{C}$ provides the complete simulated likelihood formulation for both the estimation of heterogeneous gain-loss attitudes and heterogeneous utilities.

Table 2 provides estimates of these two models using the Method of Simulated Likelihood with 1000 Halton draws for each observation for relevant heterogeneous parameters. Each subject provides three observations to this estimation exercise: their hypothetical choice, their relative liking statement, and their relative ranking statement (assumed independent). We provide separate utility estimates for our initial and replication sample to account for the evolution of tastes over the three years between our studies.

In the first two columns of Table 2 we provide estimates and standard errors assuming heterogeneous gain-loss attitudes with homogeneous utility values. In both our initial and replication studies we find the pen set has relatively lower utility than the USB stick. The picnic mat and thermos carry more similar utility, with aggregate tastes evolving over the years of our study. For gain-loss utility we estimate the parameters of the lognormal distribution to be $\hat{\mu}_{\lambda}=0.17$ (s.e. $\left.=0.07\right)$. and $\hat{\sigma_{\lambda}^{2}}=0.29(0.21)$. This log-normal distribution has estimated mean equal to $\exp \left(\hat{\mu}_{\lambda}+1 / 2 \hat{\sigma}_{\lambda}^{2}\right)=1.37(0.08) .{ }^{24}$

Figure 4 provides the estimated distribution of gain-loss attitudes, $\log (\lambda) \sim N(0.17,0.29)$, as a dashed gray line. Under this distribution of gain-loss attitudes, there is a 38 percent chance of an individual being gain-loving, $\lambda<1$. The estimated distribution of gainloss attitudes provides the basis for our exercise examining heterogeneity in Stage 2. In

\footnotetext{
${ }^{23}$ See https://papers.ssrn.com/sol3/papers.cfm?abstractid=3170670 and Appendix A for these prior estimates. We found some substantial sensitivities of the value $\sigma_{\lambda}^{2}$ to attempting to estimate $\delta_{X}$ alongside the other parameters. The challenge is intuitive: a larger value of $\delta_{X}$ implies individuals should more frequently give the two objects equal ratings. All else equal, a higher variance of gain-loss attitudes is required to justify the relative infrequency of such observations. Appendix Table A3 provides sensitivity analysis setting $\delta_{X}$ at several different values and demonstrating corresponding sensitivity for the variance of gain-loss attitudes.

${ }^{24}$ Standard error calculated using the delta method.
} 
Table 2: Method of Simulated Likelihood Estimates

\begin{tabular}{|c|c|c|c|c|}
\hline & $(1)$ & $(2)$ & $(3)$ & $(4)$ \\
\hline & Estimate & (Std. Error) & Estimate & (Std. Error) \\
\hline & \multicolumn{2}{|c|}{ Heterogeneous $\lambda$} & \multicolumn{2}{|c|}{ Heterogeneous $\frac{Y}{X}$} \\
\hline \multicolumn{5}{|l|}{ Gain-Loss Attitudes: } \\
\hline$\hat{\lambda}$ & 1.37 & $(0.08)$ & 1.31 & $(0.05)$ \\
\hline$\hat{\mu_{\lambda}}$ & 0.17 & $(0.07)$ & - & - \\
\hline$\hat{\sigma_{\lambda}^{2}}$ & 0.29 & $(0.21)$ & - & - \\
\hline \multicolumn{5}{|c|}{ Pair 1 Utilities (USB Stick (X) - Pen Set $(\mathrm{Y})$ ) : } \\
\hline$\frac{\hat{Y}}{X}($ Initial $)$ & 0.62 & $(0.04)$ & 0.62 & $(0.03)$ \\
\hline$\frac{\hat{Y}}{X}($ Replication $)$ & 0.61 & $(0.04)$ & - & - \\
\hline$\hat{\mu_{Y}^{Y}}$ & - & - & -0.55 & $(0.09)$ \\
\hline$\hat{\sigma_{\frac{Y}{X}}^{2}}$ & - & - & 0.16 & $(0.13)$ \\
\hline \multicolumn{5}{|c|}{ Pair $\stackrel{X}{2}$ Utilities (Picnic Mat (X) - Thermos $(\mathrm{Y})$ ): } \\
\hline$\hat{Y} \frac{\hat{Y}}{X}($ Initial $)$ & 1.11 & $(0.03)$ & 1.03 & $(0.03)$ \\
\hline$\frac{\hat{Y}}{X}($ Replication $)$ & 0.88 & $(0.04)$ & - & - \\
\hline$\hat{\mu_{\hat{Y}}}$ & - & - & -0.03 & $(0.04)$ \\
\hline$\sigma_{\frac{Y}{X}}^{\widehat{X}^{X}}$ & - & - & 0.12 & $(0.08)$ \\
\hline \multicolumn{5}{|l|}{ Discernibility: } \\
\hline$\delta_{X}$ & 0.55 & - & 0.55 & - \\
\hline \# Observations & \multicolumn{2}{|c|}{3,072} & \multicolumn{2}{|c|}{3,072} \\
\hline Log-Likelihood & \multicolumn{2}{|c|}{-2743.13} & \multicolumn{2}{|c|}{-2751.72} \\
\hline Akaike's Information Criterion (AIC) & \multicolumn{2}{|c|}{5498.26} & \multicolumn{2}{|c|}{5513.44} \\
\hline
\end{tabular}

Notes: Maximum likelihood estimates. Standard errors in parentheses. 
subsection 4.1.2, we describe our methodology for identifying individual gain-loss attitudes. This methodology constructs an expected value of gain-loss attitudes, $E[\lambda]$, associated with subjects' preference statements given the estimated distribution. We then explore heterogeneous treatment effects over the value of $E[\lambda]$.

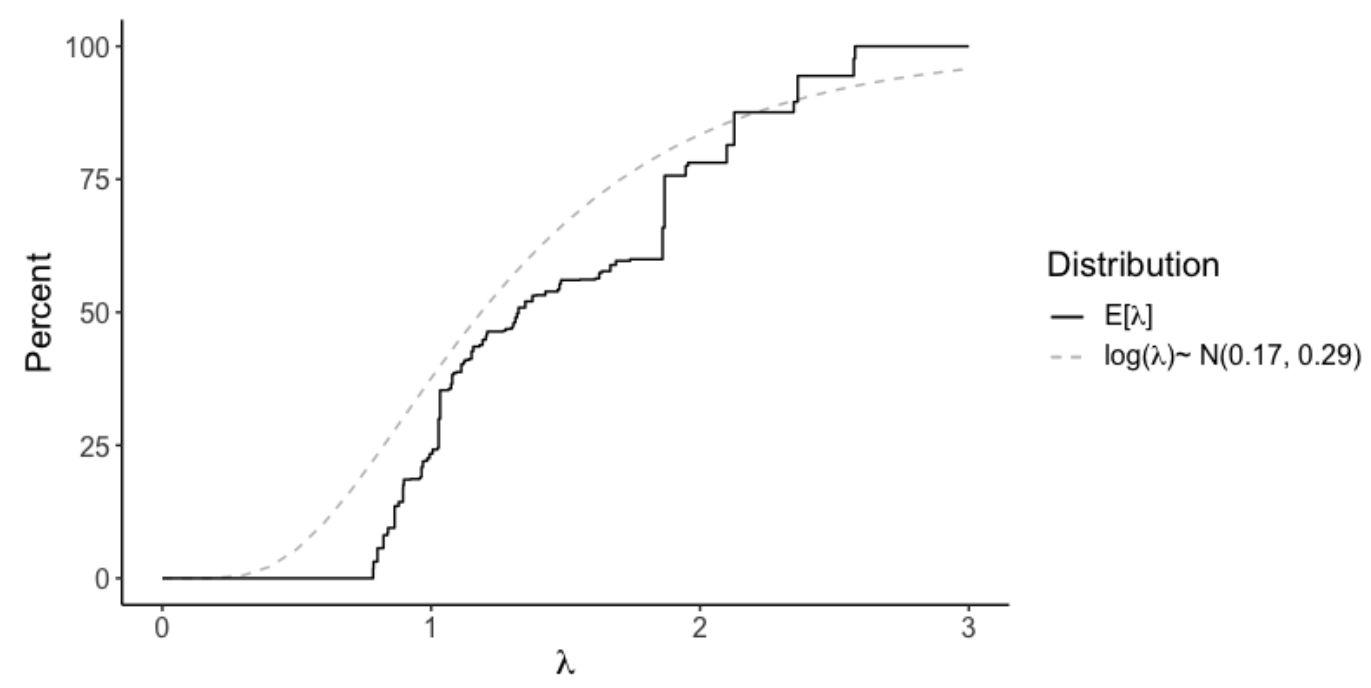

Figure 4: Estimated and Realized Distributions of Gain-Loss Attitudes

Notes: The dashed line represents estimated distribution $\log (\lambda) \sim N(0.17,0.29)$, resulting in a mean $\lambda=1.37$, a median $\lambda=1.18$, and $P(\lambda<1)=0.38$. Solid line represents the expected value of $\lambda$ conditional on the Stage 1 statements, $E[\lambda]$, as described in the main text.

In the second two columns of Table 2, we also provide estimates assuming homogeneous gain-loss attitudes and heterogeneous utility values. There, we find an aggregate $\hat{\lambda}=$ 1.31 (0.05), close to the previously reported mean value, and substantial variation in intrinsic utility values with estimated means also close to the previously reported values. The estimates of heterogeneous utilities provide an alternative interpretation for Stage 1 heterogeneity: that it is driven by heterogeneous values for the two objects and not gainloss attitudes. We present the results of this alternative by also examining heterogeneity in Stage 2 based upon these heterogeneous utility estimates in Stage $1 .^{25}$

\footnotetext{
${ }^{25}$ Note that, by construction, random assignment and the use of two new objects in Stage 2 would predict such an exercise to yield a constant treatment effect at the level of the aggregate $\lambda=1.31$. Nonetheless, we provide this exercise in section 4.2 .
} 
Table 2 provides the simulated likelihood and Akaike's Information Criterion (AIC) values for our two estimated models. Heterogeneous gain-loss attitudes has substantially better likelihood values, which, by the AIC, justify the additional degree of freedom it uses relative to the model with heterogeneous utilities (six versus five degrees of freedom). In-sample, our model of heterogeneous gain-loss attitudes has better fit in Stage 1. Of course, our project is not predicated on in-sample fit in Stage 1, but rather using Stage 1 measures out-of-sample to predict behavior in Stage 2.

\subsubsection{Individual Gain-Loss Attitudes}

Figure 4 provides the estimated distribution of gain-loss attitudes. Moving from this distribution to an expected value of $\lambda$ for each individual is a straightforward step. As proposed in Train (2009), we simulate the distribution of $\lambda$, and calculate the expected $\lambda$ for each possible Stage 1 statement profile. For example, under the estimated log-normal density, $g(\lambda)$, one simulates $\operatorname{Prob}_{X \mid X}(\lambda)$, and the expected value of $\lambda$ given a preference for $X$ when endowed with $X$ as

$$
E\left[\lambda_{X \mid X}\right]=\int \lambda \frac{\operatorname{Prob}_{X \mid X}(\lambda) g(\lambda)}{\int \operatorname{Prob}_{X \mid X}(\lambda) g(\lambda) d \lambda} d \lambda .
$$

For each endowment, subjects could provide one of two hypothetical choice statements, one of three relative liking statements, and one of three relative wanting statements, yielding 18 potential statement profiles. With four endowments, there are 72 potential profiles, each with an implication for the expected value of $\lambda .{ }^{26}$ We extend the above example to construct the probability of each such profile assuming independence between the simulated probabilities for hypothetical choice, liking, and wanting statements.

In Table 3, we provide the expected value of $\lambda$, averaged over the initial and replication study, for eight common statement profiles (accounting for 647 of 1024 (63.1 percent) of

\footnotetext{
${ }^{26}$ Note that because we allow for different utilities in our initial study and replication, there are 72 such values for each.
} 
observations). Consider an endowment of the USB stick: if a subject stated a preference for the USB stick in all three statements they would have $E[\lambda]=1.87$, while if they stated a preference for the pen set in all three they would have $E[\lambda]=0.78$. Providing the same profiles when endowed with the pen set leads to $E[\lambda]$ of 1.03 and 2.57 , respectively. The values exhibited in Table 3 are intuitive: stating a preference for one's endowed object indicates loss aversion, while stating a preference for the alternative indicates gain lovingness. The magnitudes of $E[\lambda]$ are tuned by the intrinsic values of the two objects reported in Table 2.

Table 3: Preference Statements and Individual Gain-Loss Classifications

\begin{tabular}{|c|c|c|c|}
\hline \multicolumn{4}{|c|}{ Endowed USB Stick } \\
\hline HC(USB Stick) > HC(Pen Set) & & $\mathrm{HC}($ USB Stick) $<\mathrm{HC}($ Pen Set) & \\
\hline L(USB Stick) $>$ L(Pen Set) & $E[\lambda]=1.87,(\mathrm{~N}=161)$ & L(USB Stick $)<\mathrm{L}($ Pen Set $)$ & $E[\lambda]=0.78,(\mathrm{~N}=32)$ \\
\hline $\mathrm{W}(\mathrm{USB}$ Stick $)>\mathrm{W}($ Pen Set $)$ & & W(USB Stick $)<W($ Pen Set $)$ & \\
\hline \multicolumn{4}{|c|}{ Endowed Pen Set } \\
\hline $\mathrm{HC}(\mathrm{USB}$ Stick $)>\mathrm{HC}($ Pen Set $)$ & & $\mathrm{HC}($ USB Stick) < HC(Pen Set) & \\
\hline L(USB Stick) $>$ L(Pen Set) & $E[\lambda]=1.03,(\mathrm{~N}=111)$ & $\mathrm{L}(\mathrm{USB}$ Stick $)<\mathrm{L}($ Pen Set $)$ & $E[\lambda]=2.57,(\mathrm{~N}=57)$ \\
\hline $\mathrm{W}($ USB Stick $)>\mathrm{W}($ Pen Set $)$ & & $\mathrm{W}(\mathrm{USB}$ Stick $)<\mathrm{W}$ (Pen Set) & \\
\hline \multicolumn{4}{|c|}{ Endowed Picnic Mat } \\
\hline HC(Mat) > HC(Thermos) & & $\mathrm{HC}($ Mat $)<\mathrm{HC}($ Thermos $)$ & \\
\hline $\mathrm{L}($ Mat $)>\mathrm{L}($ Thermos $)$ & $E[\lambda]=2.26,(\mathrm{~N}=84)$ & $\mathrm{L}($ Mat $)<\mathrm{L}($ Thermos $)$ & $E[\lambda]=0.85,(\mathrm{~N}=67)$ \\
\hline $\mathrm{W}$ (Mat) > W(Thermos) & & $\mathrm{W}$ (Mat) < W(Thermos) & \\
\hline \multicolumn{4}{|c|}{ Endowed Thermos } \\
\hline HC(Mat) > HC(Thermos) & & $\mathrm{HC}($ Mat $)<\mathrm{HC}($ Thermos $)$ & \\
\hline $\mathrm{L}($ Mat $)>\mathrm{L}($ Thermos $)$ & $E[\lambda]=0.85,(\mathrm{~N}=52)$ & $\mathrm{L}($ Mat $)<\mathrm{L}($ Thermos $)$ & $E[\lambda]=2.18,(\mathrm{~N}=83)$ \\
\hline $\mathrm{W}$ (Mat) > W(Thermos) & & $\mathrm{W}($ Mat $)<\mathrm{W}$ (Thermos) & \\
\hline
\end{tabular}

Though the 8 statement profiles provided in Table 3 account for over 60 percent of our observations, in total 54 (47) of 72 possible profiles are exhibited by subjects in our initial (replication) study. Figure 4 provides the distribution of $E[\lambda]$ conditional on the choices observed as the solid black line. This distribution has mean 1.49, median 1.32, with 23 percent of subjects exhibiting $E[\lambda]<1$. This distribution of $E[\lambda]$ is similar in shape and key statistics to the underlying distributional estimates from Figure 4. However, the distribution of $E[\lambda]$ does exhibit fewer extreme gain-loving and loss-averse observations than its underlying distribution. Individual heterogeneity in $E[\lambda]$ in hand, we are equipped to analyze heterogeneous treatment effects. 


\subsection{Stage 2: Probabilistic Forced Exchange and Heterogeneous Treatment Effects}

Table 4 presents results from Stage 2 of our study, with linear probability models for the indicator Exchange $(=1)$. Column (1) demonstrates the average treatment effect without accounting for heterogeneity in gain-loss attitudes. In Condition B, 38 percent of subjects choose to exchange. Comparing this value to the neoclassical benchmark of 50 percent indicates a significant endowment effect in Condition B, $F_{1,1022}=25.66,(p<0.01)$. The substantial endowment effect observed in the Condition B is unaffected by probabilistic forced exchange. In contrast to the prediction of the KR model with universal loss aversion (which would predict a positive treatment effect), we find that Condition F decreases the probability of exchange by -0.4 percentage points. We fail to reject that this treatment effect is zero, $F_{1,1022}=0.01,(p=0.91)$.

Figure 5 and Table 4, column (2) interact Stage 2 condition assignment with gain-loss attitudes measured in Stage 1. In Panel A of Figure 5, we plot binned values of $E[\lambda]$ from Stage 1 against the probability of exchange in Condition B of Stage $2 .{ }^{27}$ Our Stage 1 value of gain-loss attitudes closely correlates with prevalence of endowment effects in Stage 2. Subjects with low values of $E[\lambda]<1$ in Stage 1 exhibit an anti-endowment effect in Stage 2, exchanging with more than 50 percent probability. In contrast, subjects with $E[\lambda]>1$ exchange less than the neoclassical benchmark. Table 4, column (2) indicates a substantial correlation between $E[\lambda]$ and Condition B behavior, with a statistically significant slope coefficient of $-0.136,($ robust s.e. $=0.041), F_{1,1020}=11.23,(p<0.01)$.

The relationship between Stage 1 gain-loss attitudes and Stage 2 exchange behavior in Condition B is intuitive: loss aversion measured with one set of objects in Stage 1 is predictive of an endowment effect for a different set of objects in Stage 2. Note, however, that this intuitive connection is not strictly within the KR model's CPE predictions, which

\footnotetext{
${ }^{27}$ The size of each plotted point corresponds to the number of subjects with $E[\lambda]$ in a bin of size 0.2 around the reported value.
} 
Table 4: Exchange Behavior and Probabilistic Forced Exchange

\begin{tabular}{|c|c|c|c|}
\hline & \multicolumn{3}{|c|}{ Dependent Variable: Exchange $(=1)$} \\
\hline Condition $\mathrm{F}$ & $\begin{array}{l}-0.004 \\
(0.031)\end{array}$ & $\begin{array}{l}-0.340 \\
(0.087)\end{array}$ & $\begin{array}{l}-0.004 \\
(0.031)\end{array}$ \\
\hline$E[\lambda]$ & & $\begin{array}{l}-0.136 \\
(0.041)\end{array}$ & \\
\hline Condition $\mathrm{F}^{*} E[\lambda]$ & & $\begin{array}{c}0.225 \\
(0.054)\end{array}$ & \\
\hline Reduced Form Measure & & & $\begin{array}{l}-0.050 \\
(0.015)\end{array}$ \\
\hline Condition $\mathrm{F}^{*}$ Reduced Form & & & $\begin{array}{c}0.077 \\
(0.020)\end{array}$ \\
\hline Constant (Condition B) & $\begin{array}{c}0.380 \\
(0.024)\end{array}$ & $\begin{array}{c}0.584 \\
(0.067)\end{array}$ & $\begin{array}{c}0.380 \\
(0.023)\end{array}$ \\
\hline R-Squared & 0.000 & 0.017 & 0.014 \\
\hline \# Observations & 1024 & 1024 & 1024 \\
\hline$H_{0}:$ Zero Endowment Effect in B & $\begin{array}{c}F_{1,1022}=25.66 \\
(p<0.01)\end{array}$ & $\begin{array}{c}F_{1,1020}=1.57 \\
(p=0.21)\end{array}$ & $\begin{array}{c}F_{1,1020}=26.07 \\
(p<0.01)\end{array}$ \\
\hline$H_{0}:$ Zero Treatment Effect $(\mathrm{F}-\mathrm{B})$ & $\begin{array}{l}F_{1,1022}=0.01 \\
\quad(p=0.91)\end{array}$ & $\begin{array}{c}F_{1,1020}=15.12 \\
(p<0.01)\end{array}$ & $\begin{array}{c}F_{1,1020}=0.02 \\
\quad(p=0.90)\end{array}$ \\
\hline$H_{0}$ : Gain-Loss Attitudes $\perp$ Exchange in B & & $\begin{array}{c}F_{1,1020}=11.23 \\
(p<0.01)\end{array}$ & $\begin{array}{l}F_{1,1020}=10.69 \\
\quad(p<0.01)\end{array}$ \\
\hline$H_{0}:$ Gain-Loss Attitudes $\perp$ Treatment Effect & & $\begin{array}{c}F_{1,1020}=17.25 \\
(p<0.01)\end{array}$ & $\begin{array}{l}F_{1,1020}=14.65 \\
\quad(p<0.01)\end{array}$ \\
\hline
\end{tabular}

Notes: Ordinary least square regression. Robust standard errors in parentheses. Null hypotheses tested for 1) zero baseline endowment effect regression (Constant coefficient $=0.5$ ); 2) zero treatment effect (Condition $\mathrm{F}$ coefficient= $0)$; 3) no relationship between gain-loss attitudes and behavior in Condition B behavior $(E[\lambda]$ or Reduced Form Measure coefficient $=0$ ); 4 ) constant treatment effect over gain-loss attitudes (Condition $\mathrm{F} * E[\lambda]$ or Condition $\mathrm{F}$ $*$ Reduced Form coefficient $=0)$. $F$-statistics and two-sided $p$-values reported. 
predicts no $\mathrm{CPE}$ endowment effect in a standard exchange paradigm. ${ }^{28}$ In Appendix B we provide theoretical developments for $\mathrm{PE}$, which do permit endowment effects in standard paradigms such as our Condition B. Critically, though CPE and PE (as well as the PPE refinement) differ in their predictions for the level of exchange in Condition B, they all make qualitatively similar predictions for heterogeneous treatment effects over gain-loss types. That is, all three formulations predict that loss-averse subjects should grow more willing to exchange in Condition F relative to Condition B, while gain-loving subjects should grow less-so. See Appendix B for detail. We now turn to evaluating this robust prediction of the KR model.

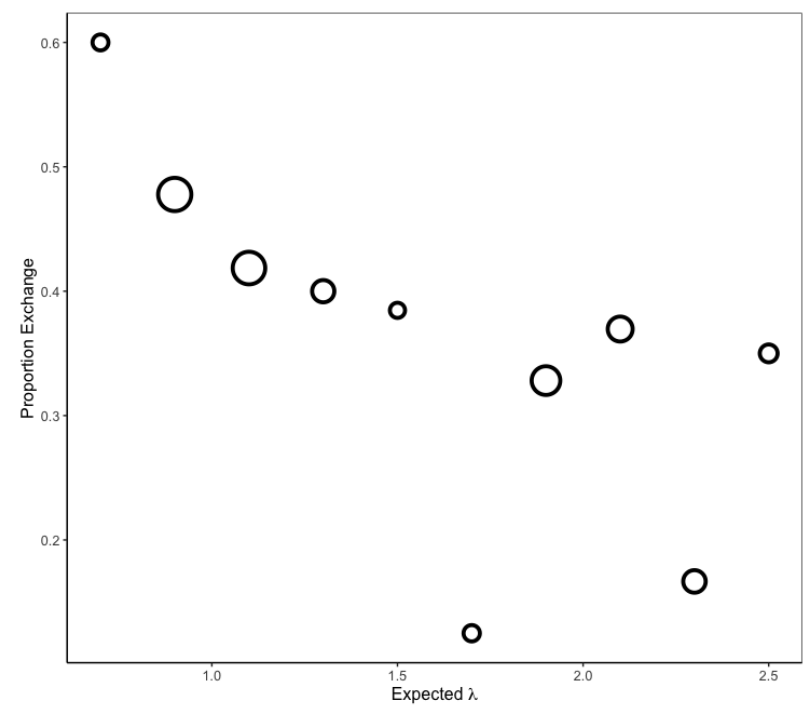

Panel A: Condition B Behavior

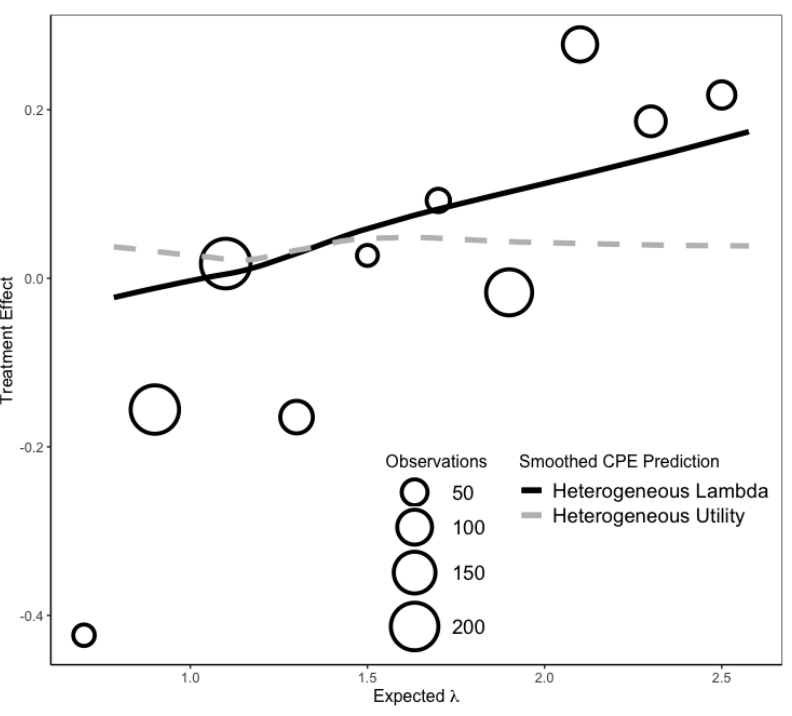

Panel B: Heterogeneous Treatment Effect

Figure 5: Stage 1 Gain-Loss Attitudes and Stage 2 Behavior

Notes: Panel A presents the observed proportion of exchange in Condition B by the expected value of $\lambda$, binned from 0.6 to 2.8 in increments of 0.2 and assigned the midpoint of the relevant interval. Panel B presents the observed treatment effect (exchange in Condition F- Condition B), as well as two smoothed KR predictions when we attribute heterogeneity to either gain-loss attitudes or utility values.

\footnotetext{
${ }^{28}$ Note that our Stage 1 design exogenously endows subjects with objects and elicits preference statements prior to any discussion of potential replacement. In this case the KR model coincides exactly with the standard model of reference-dependent preferences with a fixed reference point, which allows us to elicit gain-loss attitudes in Stage 1. See Köszegi and Rabin (2006) for additional discussion of this point in the particular context of the endowment effect.
} 
Figure 5, Panel B plots $E[\lambda]$ from Stage 1 against the treatment effect in Stage 2, Condition F-Condition B. Table 4, column (2) provides corresponding regression statistics. For subjects with low values of $E[\lambda]<1$, probabilistic forced exchange decreases exchange, while for those with values $E[\lambda]>1$, Condition $\mathrm{F}$ generally increases trading probabilities. The interaction effect between $E[\lambda]$ in Stage 1 and the Stage 2 treatment effect reported is 0.225 (0.054), and statistically significant at all conventional levels, $F_{1,1020}=17.25,(p<0.01)$. Appendix Table A4 provides the same analysis with standard errors clustered at the session level and reaches the same statistical conclusions.

Also graphed in Figure 5, Panel B are two smoothed predictions for theoretical treatment effects. The solid black line corresponds to the KR-CPE prediction under heterogeneous gain-loss attitudes. To construct this prediction, we use the values of $E[\lambda]$ obtained in our sample combined with the object assignments in Stage 2, and calculate the probability of exchange in CPE under logit choice. Under our estimated mixed logit model of heterogeneous gain-loss attitudes in Table 2, columns (1) and (2), this is the predicted relationship between $E[\lambda]$ and the treatment effect. The observed heterogeneous treatment effects are in line with the sign and magnitudes predicted by the KR model.

The theoretically predicted and observed heterogeneity in treatment effects provide an alternative interpretation to the null aggregate result presented in Table 4, column (1). Rather than indicating a failure of the KR model, it indicates a failure to account for the model's heterogeneous predictions. Indeed, the predicted average treatment effect under our mixed logit model is quite close to the zero average treatment effect observed in column (1). Even with a minority of gain-loving subjects, the average treatment effect is predicted to be only 5.9 percentage points under KR-CPE. ${ }^{29}$ In our concluding discussion, we reflect on this relatively low average prediction for conducting appropriately powered aggregate experiments on the KR model.

\footnotetext{
${ }^{29}$ This can be ascertained visually in Figure 5 as the weighted average value of the black KR-CPE prediction over the values of $E[\lambda]$.
} 
The dashed gray line in Figure 5, Panel B corresponds to the predictions from our alternative model of Stage 1 behavior: that differences in preference statements are driven by heterogeneous utilities rather than heterogeneous gain-loss attitudes. Under the model estimated in Table 2, columns (3) and (4), we construct KR-CPE predictions analogous to those for heterogeneous gain-loss attitudes. Under these predictions, $E[\lambda]$ is simply a misspecified object, which should be orthogonal to treatment effects given random assignment in Stage 2. The calculations yield exactly this prediction, indicating a positive treatment effect of around 0.033 - consistent with the homogeneous $\lambda=1.31$ - and no relation to the "misspecified" value of $E[\lambda] \cdot{ }^{30}$ Stated differently, had we misattributed Stage 1 behavior to gain-loss attitudes rather than the "true" model of heterogeneous utility, Stage 2 treatment effects should have corresponded to the dashed gray line. The data resoundingly reject this interpretation: we reject the null hypothesis of a constant treatment effect of $0.033, F_{2,1020}=9.20,(p<0.01)$.

\subsubsection{Reduced Form Exercise}

To here, we have interpreted Stage 1 behavior through the lens of a structural model estimating the heterogeneity of gain-loss attitudes. In the final column of Table 4 , we provide one additional analysis to ensure our results are not a spurious product of our structural assumptions. Our structural model attributes heterogeneity in preference statements to heterogeneity in gain-loss attitudes after accounting for utility values. In Table 4, column (3), we provide a reduced-form analog for gain-loss attitudes. Specifically, we first conduct principal components analysis on our three Stage 1 preference statements and reduce the data to the first principal component. This first component captures around 70 percent of the variation in the three preference statements. We regress this component on Stage 1 object assignment interacted with replication and use the residuals as our reduced form measure. These residuals capture the variation in preference statements across subjects

\footnotetext{
${ }^{30}$ The slight variation in the dashed gray line prediction in Figure 5 is due to the assigned objects in Stage 1 and Stage 2 and their heterogeneous valuations.
} 
taking into account their assigned object. Column (3) shows a close correspondence in our structural and reduced form results. A significant interaction effect of 0.077 (0.020) is observed between Condition F and the reduced form measure, echoing our structural results on heterogeneous treatment effects over gain-loss attitudes, $F_{1,1020}=14.65,(p<0.01)$.

\subsection{Robustness Tests}

\subsubsection{Complementarities Between Stages}

Our results indicate that gain-loss attitudes measured with one pair of objects in Stage 1 are predictive of exchange behavior in Stage 2. Though we attempted to choose Stage 1 and Stage 2 objects that would have no plausible complementarities, if some un-modeled, unintentional complementarity did exist it might spuriously appear as predictive power across stages. For example, a subject might state a preference for or against both of their endowed objects in order to consume both endowed objects or both alternatives together. Note that this mechanism cannot explain the Stage 2 treatment effect, but could perhaps provide a rationale for the correlations documented between Stage 1 gain-loss attitudes and exchange in Stage 2, Condition B.

Importantly, our Stage 1 design was constructed with one piece of random variation that serves to break complementarities between objects across stages. After providing their preference statements half of subjects have their endowed object replaced with the alternative. If our results are reproduced both for subjects who have their endowed object replaced and those who do not, then explanations based upon accidental complementarities cannot be relevant for our results. To explore this possibility, Table 5 reproduces the structural results of Table 4 separately by individuals who do and do not have their Stage 1 endowed object replaced. For both groups, our results are maintained. Appendix Table A5 provides the same analysis with standard errors clustered at the session level and reaches the same statistical conclusions. 
Table 5: Stage 2 Behavior and Stage 1 Experience

\begin{tabular}{|c|c|c|c|c|}
\hline & $\begin{array}{l}D \\
\text { Stage } 1 \text { Object } \\
(1)\end{array}$ & $\begin{array}{l}\text { pendent Variab } \\
\text { Not Replaced } \\
\text { (2) }\end{array}$ & $\begin{array}{l}\text { Exchange } \\
\text { Stage } 1 \text { Obj } \\
(3)\end{array}$ & $\begin{array}{l}\text { 1) } \\
\text { ct Replaced } \\
\text { (4) }\end{array}$ \\
\hline Condition F & $\begin{array}{c}0.013 \\
(0.044)\end{array}$ & $\begin{array}{l}-0.255 \\
(0.126)\end{array}$ & $\begin{array}{l}-0.019 \\
(0.043)\end{array}$ & $\begin{array}{l}-0.418 \\
(0.122)\end{array}$ \\
\hline$E[\lambda]$ & & $\begin{array}{l}-0.121 \\
(0.057)\end{array}$ & & $\begin{array}{l}-0.153 \\
(0.058)\end{array}$ \\
\hline Condition $\mathrm{F}^{*} E[\lambda]$ & & $\begin{array}{c}0.176 \\
(0.077)\end{array}$ & & $\begin{array}{c}0.272 \\
(0.077)\end{array}$ \\
\hline Constant (Condition B) & $\begin{array}{c}0.386 \\
(0.033)\end{array}$ & $\begin{array}{c}0.569 \\
(0.094)\end{array}$ & $\begin{array}{c}0.374 \\
(0.034)\end{array}$ & $\begin{array}{c}0.600 \\
(0.095)\end{array}$ \\
\hline $\begin{array}{l}\text { R-Squared } \\
\text { \# Observations }\end{array}$ & $\begin{array}{c}0.000 \\
511\end{array}$ & $\begin{array}{c}0.011 \\
511\end{array}$ & $\begin{array}{c}0.000 \\
513\end{array}$ & $\begin{array}{c}0.024 \\
513\end{array}$ \\
\hline$H_{0}:$ Zero Endowment Effect in B & $\begin{array}{l}F_{1,509}=11.73 \\
\quad(p<0.01)\end{array}$ & $\begin{array}{l}F_{1,507}=0.54 \\
(p=0.46)\end{array}$ & $\begin{array}{l}F_{1,511}=13.96 \\
\quad(p<0.01)\end{array}$ & $\begin{array}{c}F_{1,509}=1.11 \\
(p=0.29)\end{array}$ \\
\hline$H_{0}:$ Zero Treatment Effect (F-B) & $\begin{array}{l}F_{1,509}=.08 \\
(p=0.77)\end{array}$ & $\begin{array}{l}F_{1,507}=4.08 \\
(p=0.04)\end{array}$ & $\begin{array}{l}F_{1,511}=0.19 \\
\quad(p=.67)\end{array}$ & $\begin{array}{l}F_{1,509}=11.76 \\
\quad(p<0.01)\end{array}$ \\
\hline$H_{0}:$ Gain-Loss Attitudes $\perp$ Exchange in B & & $\begin{array}{l}F_{1,507}=4.52 \\
(p=0.03)\end{array}$ & & $\begin{array}{l}F_{1,509}=6.96 \\
(p<0.01)\end{array}$ \\
\hline$H_{0}$ : Gain-Loss Attitudes $\perp$ Treatment Effect & & $\begin{array}{c}F_{1,507}=5.25 \\
(p=0.02)\end{array}$ & & $\begin{array}{l}F_{1,509}=12.53 \\
(p<0.01)\end{array}$ \\
\hline
\end{tabular}

\subsubsection{Replication Consistency and Additional Controls}

Our results to here have combined the data from our initial and replication studies. Table 6 reproduces the structural results of Table 4 separately for the two samples. The null aggregate treatment effect and heterogeneous treatment effects over gain-loss attitudes are produced in both our initial and replication studies. Quantitatively the observed relationships between gain-loss attitudes and exchange behavior are broadly consistent, though the replication has less precise estimates due to the smaller sample size.

Our replication study was conducted to assure confidence in our previously obtained heterogeneous treatment effects. The registration of our pre-analysis plan, including power calculations, can be found at https://www.socialscienceregistry.org/trials/3124. The analysis proposed there carries one important difference to that conducted here: our proposed methodology for identifying gain-loss attitudes was based on standard logit, rather than mixed logit, methods. This was the methodology used in our initial draft posted 
Table 6: Replication Consistency and Additional Controls

\begin{tabular}{|c|c|c|c|c|c|}
\hline & \multicolumn{5}{|c|}{ Dependent Variable: Exchange $(=1)$} \\
\hline & \multicolumn{2}{|c|}{ Initial Study } & \multicolumn{3}{|c|}{ Replication Study } \\
\hline & (1) & $(2)$ & (3) & $(4)$ & (5) \\
\hline Condition F & 0.004 & -0.409 & -0.010 & -0.239 & -0.805 \\
\hline & $(0.040)$ & (0.117) & $(0.048)$ & (0.137) & $(0.415)$ \\
\hline$E[\lambda]$ & & -0.159 & & -0.103 & -0.116 \\
\hline & & $(0.054)$ & & $(0.065)$ & $(0.066)$ \\
\hline Condition $\mathrm{F}^{*} E[\lambda]$ & & 0.266 & & 0.161 & 0.174 \\
\hline & & $(0.070)$ & & $(0.089)$ & $(0.091)$ \\
\hline Constant (Condition B) & 0.365 & 0.616 & 0.399 & 0.542 & 0.917 \\
\hline & $(0.032)$ & $(0.093)$ & $(0.036)$ & $(0.099)$ & $(0.321)$ \\
\hline Additional Controls & No & No & No & No & Yes \\
\hline Additional Interactions & No & No & No & No & Yes \\
\hline R-Squared & 0.000 & 0.023 & 0.000 & 0.008 & 0.060 \\
\hline \# Observations & 607 & 607 & 417 & 417 & 417 \\
\hline$H_{0}:$ Zero Endowment Effect in B & $\begin{array}{c}F_{1,605}=18.32 \\
\quad(p<0.01)\end{array}$ & $\begin{array}{c}F_{1,603}=1.55 \\
(p=0.21)\end{array}$ & $\begin{array}{c}F_{1,415}=7.97 \\
(p<0.01)\end{array}$ & $\begin{array}{c}F_{1,413}=0.18 \\
(p=0.67)\end{array}$ & $\begin{array}{c}F_{1,393}=1.70 \\
(p=0.19)\end{array}$ \\
\hline$H_{0}:$ Zero Treatment Effect (F-B) & $\begin{array}{c}F_{1,605}=0.01 \\
(p=0.91)\end{array}$ & $\begin{array}{c}F_{1,603}=12.29 \\
(p<0.01)\end{array}$ & $\begin{array}{c}F_{1,415}=0.05 \\
(p=0.83)\end{array}$ & $\begin{array}{c}F_{1,413}=3.06 \\
(p=0.08)\end{array}$ & $\begin{array}{c}F_{1,393}=3.76 \\
(p=0.05)\end{array}$ \\
\hline$H_{0}$ : Gain-Loss Attitudes $\perp$ Exchange in B & & $\begin{array}{c}F_{1,603}=8.84 \\
(p<0.01)\end{array}$ & & $\begin{array}{c}F_{1,413}=2.50 \\
(p=0.12)\end{array}$ & $\begin{array}{c}F_{1,393}=3.08 \\
(p=0.08)\end{array}$ \\
\hline$H_{0}:$ Gain-Loss Attitudes $\perp$ Treatment Effect & & $\begin{array}{c}F_{1,603}=14.66 \\
(p<0.01)\end{array}$ & & $\begin{array}{c}F_{1,413}=3.28 \\
(p=0.07)\end{array}$ & $\begin{array}{c}F_{1,393}=3.69 \\
(p=0.06)\end{array}$ \\
\hline$H_{0}:$ Add'l Controls \& Interactions $\perp$ Exchange & & & & & $\begin{array}{c}F_{20,393}=1.21 \\
(p=0.24)\end{array}$ \\
\hline
\end{tabular}

Notes: Ordinary least square regression. Robust standard errors in parentheses. Null hypotheses tested for 1) zero baseline endowment effect regression (Constant coefficient $=0.5$ ); 2) zero treatment effect (Condition $\mathrm{F}$ coefficient $=0$ ); 3 ) no relationship between gain-loss attitudes and behavior in Condition B behavior $(E[\lambda]=0)$; 4) constant treatment effect over gain-loss attitudes (Condition $\left.\mathrm{F}^{*} E[\lambda]=0\right)$; 5$)$ no effect of additional controls or interactions (all coefficients $=0$ ). Additional controls include: gender, age, educational status, monthly income bracket, knowledge of economics, composite Raven matrices score, composite CRT score, and fixed effects for experimental assistant. Interactions include all controls interacted with Condition F. $F$-statistics and two-sided $p$-values reported. 
at https://papers.ssrn.com/sol3/papers.cfm?abstractid=3170670. Advice from an anonymous referee highlighted the value of the mixed logit methods that we currently conduct. For completeness, in Appendix A we provide the pre-registered replication analysis. There, as well, we find a striking consistency between the results obtained in our initial and replication samples.

Our results demonstrate clearly heterogeneous treatment effects over measured gain-loss attitudes. Stage 1 gain-loss attitudes represent the sole dimension of individual differences in this exercise and are closely predictive of Stage 2 behavior. A plausible critique of this approach is that it may be subject to omitted variable bias, with the documented correlations driven by other dimensions of heterogeneity. Importantly, in our replication data we have access to a rich set of covariates, and can control for age, gender, household income (in one of seven brackets), educational status, knowledge of economics, a composite score on the Cognitive Reflection Test (Frederick, 2005), and a composite score on a series of Raven matrices. Additionally, in our replication data, four different experimental assistants conducted the sessions providing another potential dimension of heterogeneity. In Table 6, column (5) we also interact each of these covariates with Condition F and include the main and interacted effects in regressions for our replication sample. The coefficients of interest for gain-loss attitudes and heterogeneous treatment effects are quite similar with and without these additional controls. If anything the results grow stronger when controlling for the rich set of control variables between columns (4) and (5). Importantly, we identify no other dimension of heterogeneity as being important for explaining Stage 2 behavior and fail to reject the null hypothesis that all other main effects and interactions are zero. Appendix Table A6 provides the same analysis with standard errors clustered at the session level and reaches even stronger statistical conclusions. 


\section{Discussion and Conclusion}

Expectations-based reference-dependent preferences (Köszegi and Rabin, 2006, 2007) (KR) represent a key advance in behavioral economics, but a host of conflicting evidence for the theory exists. In this paper we aimed to reconcile this conflicting evidence by explicitly recognizing and evaluating heterogeneity in gain-loss attitudes. Heterogeneity is critical both because the model's comparative statics change sign depending on the level of gainloss attitudes, and because prior work has noted that loss aversion is, by no means, a universal characteristic.

We measure gain-loss attitudes by evaluating preference statements for a first pair of objects, and then place subjects in an exchange environment where they make choices over a second, different pair of objects. We show that explicitly accounting for the heterogeneity in gain-loss attitudes restores behavior in line with $\mathrm{KR}$ predictions. Individual gain-loss attitudes are predictive of exchange behavior in a standard exchange environment: lossaverse subjects exhibit a standard endowment effect, while gain-loving subjects exhibit the opposite pattern. Using a mechanism of probabilistic forced exchange, we then show that individuals who are measured to be loss-averse grow more willing to exchange when probabilistically forced to do so; and individuals who are measured to be gain-loving grow less willing to exchange. These findings, and the magnitudes of the observed treatment effects, are closely in line with the predictions of the KR model.

Our results may help to reconcile conflicting results in the empirical study of the KR model (Ericson and Fuster, 2011; Heffetz and List, 2014; Cerulli-Harms et al., 2019) and follow naturally from the broad recognition of heterogeneity in gain-loss attitudes (Sprenger, 2015; Erev et al., 2008; Harinck et al., 2007; Nicolau, 2012; Sokol-Hessner et al., 2009; Knetsch and Wong, 2009; Chapman et al., 2017). If we are to recognize that loss aversion is not a universal trait, we must also recognize it as a confound of first-order importance for empirical tests of expectations-based reference dependence. 
Two factors are central to the confounding effects of heterogeneity for aggregate studies of KR preferences. First, we show that treatment effects that have been used to test the KR model change sign at $\lambda=1$ and do not aggregate linearly over gain-loss attitudes. Even with loss aversion on average, gain-loving individuals can have a substantial effect on the aggregate treatment effect. Under our estimates for gain-loss attitudes (with mean $E[\lambda]=1.49)$, the average treatment effect in our sample should be approximately 5.9 percentage points under logit choice. Second, if aggregation over gain-loss types reduces predicted treatment effects, it will also induce larger required sample sizes for reliably powered studies. To identify a 5.9 percentage point treatment effect with 80 percent power, a sample of 2250 is required. This value is more than twice as large as the sample size of Cerulli-Harms et al. (2019), and ten times as large as the sample sizes of Heffetz and List (2014) and Ericson and Fuster (2011). A reasonable conclusion would be that no prior aggregate test of the KR model is appropriately powered.

Though we provide replication of our results for exchange behavior, future work should examine other domains of application and other methodologies for identifying gain-loss attitudes. Relevant steps include examination of reference-dependent labor supply, lottery choice, and financial behavior. 


\section{References}

Abeler, Johannes, Armin Falk, Lorenz Goette, and David Huffman, "Reference points and effort provision," The American Economic Review, 2011, pp. 470-492.

Bell, David E., "Disappointment in Decision Making under Uncertainty," Operations Research, 1985, $33(1), 1-27$.

Bradley, Margaret and Peter Lang, "Measuring emotion: the self-assessment manikin and the semantic differential," Journal of behavior therapy and experimental psychiatry, 1994, 25 (1), 49-59.

Burks, Stephan, Jeffrey Carpenter, Lorenz Goette, and Aldo Rustichini, "Cognitive skills affect economic preferences, strategic behavior, and job attachment," Proceedings of the National Academy of Science, 2009, 106 (19), 7745-7750.

Camerer, Colin, Linda Babcock, George Loewenstein, and Richard Thaler, "Labor supply of New York City cabdrivers: One day at a time," The Quarterly Journal of Economics, 1997, pp. 407-441.

Cantillo, Víctor, Johanna Amaya, and Juan de Dios Ortúzar, "Thresholds and Indifference in Stated Choice Surveys," Transportation Research Part B, 2010, 44, 753-763.

Cerulli-Harms, Annette, Lorenz Goette, and Charles Sprenger, "Randomizing Endowments: An Experimental Study of Rational Expectations and Reference-Dependent Preferences," American Economic Journal - Microeconomics, 2019, 11 (1), 185-207. IZA Discussion Paper.

Chapman, Jonathan, Erik Snowberg, Stephanie Wang, and Colin Camerer, "Loss Attitudes in the US Population: Evidence from Dynamically Optimized Sequential Experimentation (DOSE)," Technical Report, National Bureau of Economic Research 2018.

_, Mark Dean, Pietro Ortoleva, Erik Snowberg, and Colin Camerer, "Willingness to Pay and Willingness to Accept are Probably Less Correlated Than You Think," Technical Report, National Bureau of Economic Research 2017. 
Dean, Mark and Pietro Ortoleva, "Is It All Connected," Working Paper, 2015.

Erev, Ido, Eyal Ert, and Eldad Yechiam, "Loss aversion, diminishing sensitivity, and the effect of experience on repeated decisions," Journal of Behavioral Decision Making, 2008, 21 (5), 575-597.

Ericson, Keith M. Marzilli and Andreas Fuster, "Expectations as Endowments: Evidence on Reference-Dependent Preferences from Exchange and Valuation Experiments," The Quarterly Journal of Economics, 2011, 126 (4), 1879-1907.

Fehr, Ernst and Lorenz Goette, "Do workers work more if wages are high? Evidence from a randomized field experiment," American Economic Review, 2007, 97 (1), 298-317.

Fischbacher, Urs, "z-Tree: Zurich toolbox for ready-made economic experiments," Experimental economics, 2007, 10 (2), 171-178.

Frederick, Shane, "Cognitive Reflection and Decision Making," Journal of Economic Perspectives, 2005, 19 (4), 25-42.

Gachter, Simon, Eric J. Johnson, and Andreas Herrmann, "Individual-Level Loss Aversion in Riskless and Risky Choices," Working Paper, 2007.

Gneezy, Uri, Lorenz Goette, Charles Sprenger, and Florian Zimmermann, "The Limits of Expectations-Based Reference Dependence," Journal of the European Economic Association, $2017,15(4), 861-876$.

Harinck, Fieke, Eric Van Dijk, Ilja Van Beest, and Paul Mersmann, "When gains loom larger than losses reversed loss aversion for small amounts of money," Psychological Science, 2007, 18 (12), 1099-1105.

Heffetz, Ori and John A. List, "Is the Endowment Effect an Expectations Effect?," Journal of the European Economic Association, 2014, 12 (5), 1396-1422.

Kahneman, Daniel, Jack L. Knetsch, and Richard H. Thaler, "Experimental Tests of the Endowment Effect and the Coase Theorem," Journal of Political Economy, 1990, 98 (6), $1325-1348$. 
Köszegi, Botond and Matthew Rabin, "A Model of Reference-Dependent Preferences," The Quarterly Journal of Economics, 2006, 121 (4), 1133-1165.

_ and _, "Reference-Dependent Risk Attitudes," The American Economic Review, 2007, 97 (4), 1047-1073.

Knetsch, Jack and Wei-Kang Wong, "The endowment effect and the reference state: Evidence and manipulations," Journal of Economic Behavior 63 Organization, 2009, 71 (2), 407-413.

Loomes, Graham and Robert Sugden, "Disappointment and Dynamic Consistency in Choice under Uncertainty," Review of Economic Studies, 1986, 53 (2), 271-82.

McFadden, Daniel, "Conditional Logit Analysis of Qualitative Choice Behavior," in Paul Zarembka, ed., Frontiers in Econometrics, New York: Academic Press, 1974, chapter 4.

Nicolau, Juan L, "Asymmetric tourist response to price: loss aversion segmentation," Journal of Travel Research, 2012, 51 (5), 568-676.

Odean, Terrance, "Are Investors Reluctant to Realize Their Losses?," The Journal of Finance, 1998, 53 (5), 177-1798.

Plott, Charles R. and Kathryn Zeiler, "The Willingness to Pay-Willingness to Accept Gap, the "Endowment Effect," Subject Misconceptions and Experimental Procedures for Eliciting Valuations," The American Economic Review, 2005, 95 (3), 530-545.

_ and _, "Exchange Asymmetries Incorrectly Interpreted as Evidence of Endowment Effect Theory and Prospect Theory?," The American Economic Review, 2007, 97 (4).

Rabin, Matthew, "Risk Aversion and Expected Utility Theory: A Calibration Theorem," Econometrica, 2000, 68 (5), 1281-1292.

Smith, Alex, "Lagged Beliefs and Reference-Dependent Utility," Journal of Economic Behavior E Organization, 2019, 167, 331-340.

Sokol-Hessner, Peter, Ming Hsu, Nina G Curley, Mauricio R Delgado, Colin F Camerer, and Elizabeth A Phelps, "Thinking like a trader selectively reduces individuals' loss aversion," Proceedings of the National Academy of Sciences, 2009, 106 (13), 5035-5040. 
Sprenger, Charles, "An endowment effect for risk: Experimental tests of stochastic reference points," Journal of Political Economy, 2015, 123 (6), 1456-1499.

Train, Kenneth E., Discrete Choice Methods with Simulation, Cambridge University Press, 2009. 


\section{Appendix: Not for Publication}

\section{A Replication and Reconciliation with Pre-Analysis Plan}

In this section we report the methodology and corresponding analyses from earlier versions of this paper (https://papers.ssrn.com/sol3/papers.cfm?abstractid=3170670 and https://papers.ssrn.com/sol3/papers.cfm?abstract_id=3589906) as specified in the pre-registration plan of our replication study (https://www.socialscienceregistry. org/trials/3124). The key difference is that while our approach in the present version of the paper relies on a mixed-logit methodology following a suggestion of an anonymous referee, our previous approach employed standard logit methods. All our previous results are closely in line with those obtained using the new methodology. Here we provide a summary of the central exercises conducted in prior versions of the manuscript. For the complete analysis please see https://papers.ssrn.com/sol3/papers.cfm?abstractid=3170670 and https://papers.ssrn.com/sol3/papers.cfm?abstract_id=3589906.

\section{A.1 Stage 1: Identifying Gain-Loss Attitudes}

Our previous methodology relied on the same preference statements that we introduced in Section 4.1, but focused only on the liking preference statements. As noted in the main text, the liking data indicate both a substantial endowment effect and potential differences in utility across objects. We construct a simple structural model of the liking preference statement based upon standard random utility methods (McFadden, 1974) with the objective of capturing the source of both of these features: gain-loss attitudes and differences in intrinsic utility for the two objects.

Consider an individual endowed with $X$ that is asked to provide ratings statements for both $X$ and $Y$. Under the KR model, an individual evaluates their endowment, $X$, based upon $U(X, 0 \mid X, 0)$. Given that the agent is endowed with $X$ and is uninformed of the 
possibility of confiscation at the time of the ratings, they plausibly evaluate $Y$ based upon $U(0, Y \mid X, 0)$. With standard logit shocks, $\epsilon_{X}$ and $\epsilon_{Y}$, the parameters associated with these KR utilities are easily estimated. We assume subjects will provide a higher rating for their endowed object, $X$, if

$$
U(X, 0 \mid X, 0)+\epsilon_{X}>U(0, Y \mid X, 0)+\epsilon_{Y}+\delta,
$$

where $\delta$ is a discernibility parameter which accounts for the fact that the goods may be given identical ratings (for use of such methods, see, e.g., Cantillo et al., 2010). Similarly, subjects provide a higher rating for the alternative object, $Y$, if

$$
U(0, Y \mid X, 0)+\epsilon_{Y}>U(X, 0 \mid X, 0)+\epsilon_{X}+\delta,
$$

and provide the same rating if the difference in utilities falls within the range of discernibility,

$$
\left|U(X, 0 \mid X, 0)+\epsilon_{X}-\left(U(0, Y \mid X, 0)+\epsilon_{Y}\right)\right| \leq \delta .
$$

Under the functional form assumptions of section 2 with $\eta=1$, for someone endowed with object $X$, we obtain familiar logit probabilities for the ranking of ratings $R(X)$ and $R(Y)$,

$$
\begin{aligned}
& P(R(X)>R(Y))=\frac{\exp (U(X, 0 \mid X, 0))}{\exp (U(X, 0 \mid X, 0))+\exp (U(0, Y \mid X, 0)+\delta)}=\frac{\exp (X)}{\exp (X)+\exp (2 Y-\lambda X+\delta)} \\
& P(R(Y)>R(X))=\frac{\exp (U(0, Y \mid X, 0))}{\exp (U(0, Y \mid X, 0))+\exp (U(X, 0 \mid X, 0)+\delta)}=\frac{\exp (2 Y-\lambda X)}{\exp (X+\delta)+\exp (2 Y-\lambda X)} \\
& P(R(X)=R(Y))=1-P(R(X)>R(Y))-P(R(Y)>R(X)),
\end{aligned}
$$


where the intrinsic utility values, $X$ and $Y$, the discernibility parameter $\delta$, and the gainloss parameter, $\lambda$, are the desired estimands. ${ }^{31}$ We normalize one of the good's values to be $Y=1$, and estimate the remaining parameters via maximum likelihood.

Table A1 provides aggregate estimates of intrinsic utilities, $\lambda$ and $\delta$, separately for each pair of goods in both the initial study and our replication. In each case we find aggregate support for loss aversion, $\lambda>1$, though less pronounced in our replication study.

Table A1: Prior Analysis: Aggregate Parameter Estimates

\begin{tabular}{|c|c|c|c|c|c|c|c|c|}
\hline & \multicolumn{4}{|c|}{ Initial Study } & $(5)$ & $\begin{array}{l}(6) \\
\text { Replicati }\end{array}$ & $\begin{array}{c}(7) \\
\text { on Stu }\end{array}$ & $(8)$ \\
\hline & Est. & (Std. Err.) & Est. & (Std. Err.) & Est. & (Std. Err.) & Est. & (Std. Err.) \\
\hline & & Pair 1 & & Pair 2 & & Pair 1 & & Pair 2 \\
\hline $\begin{array}{l}\text { Gain-Loss Attitudes: } \\
\quad \hat{\lambda}\end{array}$ & 1.56 & $(0.14)$ & 1.29 & $(0.12)$ & 1.18 & $(0.15)$ & 1.12 & $(0.13)$ \\
\hline $\begin{array}{l}\text { Utility Values: } \\
\qquad \hat{X}_{1} \text { (Pen Set) } \\
\hat{Y}_{1} \text { (USB Stick) } \\
\hat{X}_{2} \text { (Picnic Mat) } \\
\hat{Y}_{2} \text { (Thermos) }\end{array}$ & $\begin{array}{c}0.63 \\
1\end{array}$ & $\begin{array}{c}(0.05) \\
-\end{array}$ & $\begin{array}{c}0.84 \\
1\end{array}$ & $\begin{array}{c}(0.05) \\
-\end{array}$ & $\begin{array}{c}0.66 \\
1\end{array}$ & $\begin{array}{c}(0.06) \\
-\end{array}$ & $\begin{array}{c}1.05 \\
1\end{array}$ & $\begin{array}{c}(0.07) \\
-\end{array}$ \\
\hline $\begin{array}{l}\text { Discernibility: } \\
\quad \hat{\delta}\end{array}$ & 0.55 & $(0.06)$ & 0.45 & $(0.05)$ & 0.45 & $(0.06)$ & 0.62 & $(0.07)$ \\
\hline
\end{tabular}

Notes: Maximum likelihood estimates. Robust standard errors in parentheses.

\footnotetext{
${ }^{31}$ For someone endowed with the alternative object, $Y$, these same probabilities are $P(R(X)>R(Y))=\frac{\exp (U(X, 0 \mid 0, Y))}{\exp (U(X, 0 \mid 0, Y))+\exp (U(0, Y \mid 0, Y)+\delta)}=\frac{\exp (2 X-\lambda Y)}{\exp (Y+\delta)+\exp (2 X-\lambda Y)}$ $P(R(Y)>R(X))=\frac{\exp (u(0, Y \mid 0, Y))}{\exp (U(0, Y \mid 0, Y))+\exp (U(X, 0 \mid 0, Y)+\delta)}=\frac{\exp (Y)}{\exp (Y)+\exp (2 X-\lambda Y+\delta)}$ $P(R(X)=R(Y))=1-P(R(X)>R(Y))-P(R(Y)>R(X))$.
} 


\section{A.1.1 Individual Gain-Loss Attitudes}

The aggregate estimates show evidence of loss aversion. To construct bounds for estimates of individual gain-loss attitudes, we evaluate individual choices assuming average utility and discernibility values. For example, consider an individual endowed with the pen set in Pair 1 in the initial study. At the aggregate estimates of $\delta$ and $X$ for Pair 1, if this individual were to state a higher rating for the pen set than for the USB stick, it would imply $0.632>2-\hat{\lambda} * 0.632+0.549$ or $\hat{\lambda}>3.03$. Similarly, stating a higher rating for the USB stick would imply $\hat{\lambda}<1.30,{ }^{32}$ and stating the same rating implies $\hat{\lambda} \in[1.30,3.03]$. Of these three possible cases, two demonstrate evidence of loss aversion $\hat{\lambda}>1$, while the other case is plausibly loss neutral as $\hat{\lambda}=1$ can rationalize the ratings. ${ }^{33}$ In total, there exist twelve cases of endowments and relative liking statements.

Overall, in our initial study 217 subjects (35.7 percent) are categorized as loss-averse, 240 (39.5 percent) are categorized as potentially loss-neutral, and 150 (24.7 percent) are categorized as gain-loving. In our replication study, 124 subjects (29.7 percent) are categorized as loss-averse, 185 (44.4 percent) are categorized as potentially loss-neutral, and 108 (25.9 percent) are categorized as gain-loving. These are the taxonomies of individual gain-loss types used in our analysis.

\section{A.2 Stage 2: Heterogeneous Treatment Effects}

Table A2, presents linear probability models for Stage 2 behavior with dependent variable Exchange (=1). Panels A and B provide separate results for our initial and replication studies. Beginning with the initial study, we find a null average treatment effect in Column (1). In Condition B, 36.5 percent of subjects choose to exchange, demonstrating a significant endowment effect relative to the null hypothesis of 50 percent exchange,

\footnotetext{
${ }^{32}$ To state a higher rating for the USB implies $2-\hat{\lambda} * 0.632>0.632+0.549$ or $\hat{\lambda}<1.30$.

${ }^{33}$ It may seem prima-facie surprising that providing the same rating in this case is consistent with loss aversion. The logic is simple: given that the pen set has substantially lower intrinsic utility than the USB stick, one must be loss-averse to rate them equally.
} 
$F_{1,605}=18.32,(p<0.01)$. Probabilistic forced exchange has a null average treatment effect, increasing trading probabilities by only 0.4 percentage points on aggregate. Columns (2) through (4) conduct the same regressions separately for subjects categorized as lossaverse, loss-neutral, and gain-loving, based on their Stage 1 liking statements. Panel A of Table A2 shows a dramatic heterogeneous treatment effect. Loss-averse subjects exhibit a statistically significant endowment effect in Condition B, and grow more approximately 16 percentage points more willing to exchange in Condition F. Gain-loving subjects exhibit no endowment effect in Condition B, and grow approximately 25 percentage points less willing to exchange in Condition F. The heterogeneous treatment effect over gain-loving and loss-averse subjects of roughly 40 percentage points closely follows our theoretical development on the sign of comparative statics, and is significant at all conventional levels, $F_{1,363}=15.76,(p<0.01)$.

As detailed in the main text, we registered and conducted an exact replication in the summer of 2018 with 417 subjects, again at the University of Bonn. The registration of our pre analysis plan, including power calculations, can be found at https://www. socialscienceregistry.org/trials/3124. The number of subjects for the replication was guided by a requirement of 80 percent power for the 40 percentage point difference in treatment effect between gain-loving and loss-averse subjects noted above. Ex-post our initial study was slightly over-powered and the replication was thus conducted with around 400 subjects. Panel B of Table A2 provides the replication analysis analogous to that presented in Panel B. The null average treatment effect, positive treatment effect for lossaverse subjects, and negative treatment effect for gain-loving subjects are all reproduced with accuracy. Indeed, the 40 percentage point heterogeneous treatment effect in our initial study is echoed in a 37 percentage point difference between gain-loving and loss-averse subjects in our replication study.

Our replication study reproduces with precision the heterogeneous treatment effect over gain-loss types obtained in our initial study under our prior methods. Subjects classified 
Table A2: Prior Analysis: Exchange Behavior and Probabilistic Forced Exchange

\begin{tabular}{|c|c|c|c|c|}
\hline & (1) & $(2)$ & $(3)$ & $(4)$ \\
\hline & \multicolumn{4}{|c|}{ Dependent Variable: Exchange $(=1)$} \\
\hline & Full Sample & Loss Averse & Loss Neutral & Gain Loving \\
\hline \multicolumn{5}{|c|}{ Panel A: Initial Study } \\
\hline Condition $\mathrm{F}$ & $\begin{array}{c}0.004 \\
(0.034)\end{array}$ & $\begin{array}{c}0.158 \\
(0.067)\end{array}$ & $\begin{array}{c}0.027 \\
(0.066)\end{array}$ & $\begin{array}{l}-0.248 \\
(0.078)\end{array}$ \\
\hline Constant (Condition B) & $\begin{array}{c}0.365 \\
(0.028)\end{array}$ & $\begin{array}{c}0.330 \\
(0.049)\end{array}$ & $\begin{array}{c}0.361 \\
(0.053)\end{array}$ & $\begin{array}{c}0.429 \\
(0.067)\end{array}$ \\
\hline R-Squared & 0.000 & 0.025 & 0.001 & 0.072 \\
\hline \# Observations & 607 & 217 & 240 & 150 \\
\hline$H_{0}$ : Zero Endowment Effect in B & $\begin{array}{l}F_{1,605}=18.32 \\
\quad(p<0.01)\end{array}$ & $\begin{array}{l}F_{1,215}=12.21 \\
(p<0.01)\end{array}$ & $\begin{array}{c}F_{1,238}=6.85 \\
(p<0.01)\end{array}$ & $\begin{array}{c}F_{1,148}=1.15 \\
(p=0.29)\end{array}$ \\
\hline$H_{0}:$ Zero Treatment Effect (F-B) & $\begin{array}{l}F_{1,605}=0.01 \\
(p=0.90)\end{array}$ & $\begin{array}{l}F_{1,215}=5.64 \\
(p=0.02)\end{array}$ & $\begin{array}{l}F_{1,238}=0.17 \\
(p=0.68)\end{array}$ & $\begin{array}{l}F_{1,148}=10.18 \\
\quad(p<0.01)\end{array}$ \\
\hline \multicolumn{4}{|c|}{$H_{0}:$ Constant $($ col. 2) $=$ Constant $($ col. 4) } & $\begin{array}{l}F_{1,363}=1.44 \\
\quad(p=0.23)\end{array}$ \\
\hline \multicolumn{4}{|c|}{$H_{0}$ : Condition F (col. 2) =Condition F (col. 4) } & $\begin{array}{l}F_{1,363}=15.76 \\
\quad(p<0.01)\end{array}$ \\
\hline \multicolumn{5}{|c|}{ Panel B: Replication Study } \\
\hline Condition F & $\begin{array}{l}-0.010 \\
(0.044)\end{array}$ & $\begin{array}{c}0.206 \\
(0.085)\end{array}$ & $\begin{array}{l}-0.073 \\
(0.075)\end{array}$ & $\begin{array}{l}-0.160 \\
(0.094)\end{array}$ \\
\hline Constant (Condition B) & $\begin{array}{c}0.399 \\
(0.030)\end{array}$ & $\begin{array}{c}0.271 \\
(0.058)\end{array}$ & $\begin{array}{c}0.444 \\
(0.059)\end{array}$ & $\begin{array}{c}0.474 \\
(0.067)\end{array}$ \\
\hline R-Squared & 0.000 & 0.045 & 0.005 & 0.027 \\
\hline \# Observations & 417 & 124 & 185 & 108 \\
\hline$H_{0}$ : Zero Endowment Effect in B & $\begin{array}{c}F_{1,415}=7.97 \\
(p<0.01)\end{array}$ & $\begin{array}{l}F_{1,122}=15.40 \\
(p<0.01)\end{array}$ & $\begin{array}{l}F_{1,183}=0.89 \\
(p=0.35)\end{array}$ & $\begin{array}{l}F_{1,106}=0.16 \\
(p=0.69)\end{array}$ \\
\hline$H_{0}:$ Zero Treatment Effect $(\mathrm{F}-\mathrm{B})$ & $\begin{array}{l}F_{1,415}=0.05 \\
\quad(p=0.83)\end{array}$ & $\begin{array}{l}F_{1,122}=5.79 \\
\quad(p=0.02)\end{array}$ & $\begin{array}{c}F_{1,183}=0.95 \\
(p=0.33)\end{array}$ & $\begin{array}{c}F_{1,106}=2.92 \\
\quad(p=0.09)\end{array}$ \\
\hline \multicolumn{4}{|c|}{$H_{0}:$ Constant $($ col. 2$)=$ Constant $($ col. 4$)$} & $\begin{array}{c}F_{1,228}=5.22 \\
\quad(p=0.02)\end{array}$ \\
\hline \multicolumn{4}{|c|}{$H_{0}$ : Condition F (col. 2) =Condition F (col. 4) } & $\begin{array}{c}F_{1,228}=8.33 \\
\quad(p<0.01)\end{array}$ \\
\hline
\end{tabular}

Notes: Ordinary least square regression. Robust standard errors in parentheses. Significance levels: ${ }^{*} p<0.1$, ${ }^{* *} p<0.05,{ }^{* * *} p<0.01$. Null hypotheses tested for 1 ) zero baseline endowment effect, regression (Constant $=$ $0.5) ; 2)$ zero treatment effect (F-B); 3) Identical Condition B behavior across loss-averse and gain-loving subjects (Constant (col. 2) = Constant (col. 4)); 4) Identical treatment effects of forced exchange across loss-averse and gain-loving subjects (Forced Exchange (col. 2) = Forced Exchange (col. 4)). Hypotheses 3 and 4 tested via interacted regression with observations from columns (2) and (4). 
as loss-averse respond to Condition $\mathrm{F}$ by increasing their willingness to exchange; subjects classified as gain-loving respond by decreasing their willingness to exchange.

\section{B Additional Theoretical Analysis: PE and PPE}

This appendix provides additional theoretical development for heterogeneity in response to probabilistic forced exchange under Personal Equilibrium (PE) and the PE refinement, Preferred Personal Equilibrium, PPE. Throughout, our maintained assumptions will be $X, Y, \lambda, \eta>0$. We begin with the restrictions on behavior implied by PE. To begin, we focus on Condition B and a choice set consisting of pure strategy choices $\mathcal{D}=\{(X, 0),(0, Y)\}$. In this setting, there are two potential PE selections, $[\mathbf{c}, \mathbf{r}]=[(X, 0),(X, 0)]$ and $[\mathbf{c}, \mathbf{r}]=$ $[(0, Y),(0, Y)]$. The individual can support not exchanging, $[\mathbf{c}, \mathbf{r}]=[(X, 0),(X, 0)]$, in a $\mathrm{PE}$ if

$$
U(X, 0 \mid X, 0) \geq U(0, Y \mid X, 0)
$$

or

$$
X \geq \frac{1+\eta}{1+\eta \lambda} Y .
$$

Note that the smallest value of $X$ at which the individual can support not exchanging, $\underline{X}_{B, P E}=\frac{1+\eta}{1+\eta \lambda} Y$, is inferior to $Y$ if $\lambda>1$. As such, loss-averse individuals with $\lambda>1$ may be able support not exchanging $X$ for $Y$ even if $Y$ would be preferred on the basis of intrinsic utility alone. This describes the mechanism by which the KR model generates an endowment effect in PE. Similarly, the individual can support exchanging, $[\mathbf{c}, \mathbf{r}]=$ $[(0, Y),(0, Y)]$, if

$$
U(0, Y \mid 0, Y) \geq U(X, 0 \mid 0, Y)
$$

or

$$
X \leq \frac{1+\eta \lambda}{1+\eta} Y .
$$


The highest value of $X$ at which the agent can support exchanging, $\bar{X}_{B, P E}=\frac{1+\eta \lambda}{1+\eta} Y$, increases linearly with $\lambda$. For $\underline{X}_{B, P E} \leq X \leq \bar{X}_{B, P E}$, there will be multiple equilibria, with the agent able to support both exchanging and not exchanging as a PE.

Note that for gain-loving individuals with $\lambda<1$ it is also possible for $\bar{X}_{B, P E}<X<\underline{X}_{B, P E}$, such that no pure strategy PE selection from the assumed $\mathcal{D}$ exists. In this region, if $\mathcal{D}$ were to include all mixtures of exchanging and not exchanging, there would be a mixed strategy $\mathrm{PE}$ of not exchanging with a given probability, $p$. Below, we provide this analysis. Figure A1 provides the pure strategy PE cutoffs associated with exchanging not exchanging in Condition B.
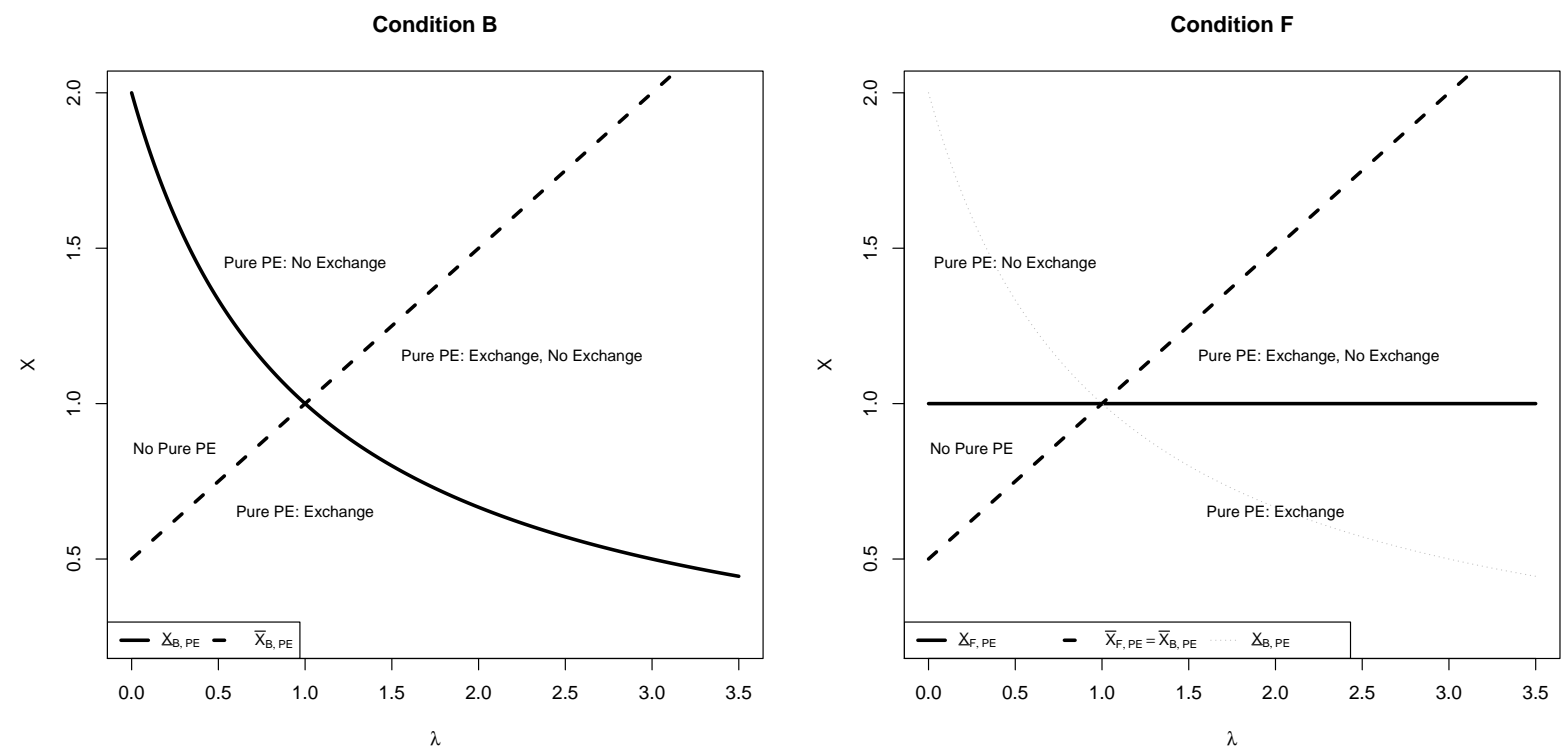

Figure A1: Gain-Loss Attitudes and Theoretical Pure PE Strategy Thresholds Notes: Threshold values for pure strategy PE for agent endowed with $X$, assuming $Y=1$ and $\eta=1$.

Now, consider Condition $\mathrm{F}$. The potential selections for someone endowed with $X$ are $\mathcal{D}=$ $\{0.5(X, 0)+0.5(0, Y),(0, Y)\}$, with the first element reflecting attempting not to exchange and the second reflecting exchange, as before. The individual can support attempting not to exchange in a $\mathrm{PE}$ if

$$
U(0.5(X, 0)+0.5(0, Y) \mid 0.5(X, 0)+0.5(0, Y)) \geq U(0, Y \mid 0.5(X, 0)+0.5(0, Y))
$$


or

$$
X \geq Y
$$

Under forced exchange, the individual can support attempting to retain $X$ in $\mathrm{PE}$ only on the basis of intrinsic utility values, regardless of the level of $\lambda$.

Though probabilistic forced exchange alters the PE considerations associated with not exchanging, it leaves unchanged the PE considerations associated with exchanging. The individual can support exchanging in PE if

$$
U(0, Y \mid 0, Y) \geq U(0.5(X, 0)+0.5(0, Y) \mid 0, Y)
$$

which as before is

$$
X \leq \frac{1+\eta \lambda}{1+\eta} Y
$$

Hence, $\bar{X}_{F, P E}=\bar{X}_{B, P E}$.

The manipulation of probabilistic forced exchange changes the PE cutoff for not exchanging from $\underline{X}_{B, P E}=\frac{1+\eta}{1+\eta \lambda} Y$ to $\underline{X}_{F, P E}=Y$. There is no longer any possibility in PE for a lossaverse individual to support keeping their object if $Y>X$. A loss-averse individual with $\lambda>1$ and valuation $\underline{X}_{B, P E}<X<\underline{X}_{F, P E}$ moves from a position of multiple PE in Condition B, to having a unique PE to exchange in Condition F. Such an individual plausibly grows more willing to exchange when moving from Condition B to Condition F. Similarly, a gain-loving individual with $\lambda<1$ and valuation $\underline{X}_{F, P E}<X<\underline{X}_{B, P E}$ moves from a position of no pure strategy PE in Condition B to having a unique PE of exchange in Condition F. Such an individual plausibly grows less willing to exchange when moving from Condition B to Condition F. Figure A1, illustrates these changing pure strategy PE considerations from Condition $\mathrm{F}$ to Condition B. The direction of these comparative statics is identical to that of our CPE analysis in the main text. 


\section{B.1 PE Mixed Strategy Analysis}

To provide more complete analysis, particularly when there is no pure strategy $\mathrm{PE}$, we now elaborate PE and PPE formulations when the choice set $\mathcal{D}$ includes all available mixtures of exchanging and not exchanging. For Condition $\mathrm{B}$, we assume $\mathcal{D}_{B}=\{p \in[0,1]: p(X, 0)+$ $(1-p)(0, Y)\}$, allowing all mixtures of exchange and no exchange to be chosen. A given mixture, $p$, will be PE if

$$
\begin{array}{r}
U(p(X, 0)+(1-p)(0, Y) \mid p(X, 0)+(1-p)(0, Y)) \geq \\
U(q(X, 0)+(1-q)(0, Y) \mid p(X, 0)+(1-p)(0, Y)) \forall q \in[0,1],
\end{array}
$$

or

$$
\begin{array}{r}
p X+(1-p) Y+p(1-p) \eta(1-\lambda)(X+Y) \geq \\
q X+(1-q) Y+(1-q) p \eta(Y-\lambda X)+q(1-p) \eta(X-\lambda Y) \forall q \in[0,1] .
\end{array}
$$

For a given $p$, let $\mathbf{q}^{*}(p) \equiv\left\{\operatorname{argmax}_{q} U(q, p)\right\} \equiv\left\{\operatorname{argmax}_{q} U(q(X, 0)+(1-q)(0, Y) \mid p(X, 0)+\right.$ $(1-p)(0, Y))\}$. The brackets indicate that $\mathbf{q}^{*}(p)$ may be a set. A mixture, $p \in[0,1]$, is PE if $p \in \mathbf{q}^{*}(p)$.

Note that

$$
\begin{aligned}
\frac{\partial U(q, p)}{\partial q} & =X-Y-p \eta(Y-\lambda X)+(1-p) \eta(X-\lambda Y) \\
& =(1+\eta) X-(1+\eta \lambda) Y-p \eta(1-\lambda)(Y+X)
\end{aligned}
$$

is constant for a given $p$, as $U(q, p)$ is linear in $q$. If $\frac{\partial U(q, p)}{\partial q}>(<) 0$, then it will attain a unique maximum $\mathbf{q}^{*}(p)=\{1\}(\{0\})$. As such, any strict mixtures, $p \in(0,1)$, for which $\frac{\partial U(q, p)}{\partial q} \neq 0$ cannot be PE. Note that this development implies that not exchanging with 
certainty, $p=1$, will be $\mathrm{PE}$ if $\frac{\partial U(q, 1)}{\partial q} \geq 0$, or

$$
\begin{array}{r}
(1+\eta) X-(1+\eta \lambda) Y-\eta(1-\lambda)(Y+X) \geq 0, \\
X \geq \frac{(1+\eta)}{(1+\eta \lambda)} Y,
\end{array}
$$

which corresponds to the pure strategy threshold noted above, $\underline{X}_{B, P E}$. Similarly, exchanging with certainty, $p=0$, will be PE if $\frac{\partial U(q, 0)}{\partial q} \leq 0$, or

$$
\begin{array}{r}
(1+\eta) X-(1+\eta \lambda) Y \leq 0 \\
X \leq \frac{(1+\eta \lambda)}{(1+\eta)} Y
\end{array}
$$

which corresponds to the pure strategy threshold, $\bar{X}_{B, P E}$. For values of $X$ such that

$$
\frac{(1+\eta)}{(1+\eta \lambda)} Y \leq X \leq \frac{(1+\eta \lambda)}{(1+\eta)} Y
$$

$p=1$ and $p=0$ will be PE.

Strict mixtures, $p \in(0,1)$, for which $\frac{\partial U(q, p)}{\partial q}=0, p \in \mathbf{q}^{*}(p)$, as all values of $q$, including $q=p$, attain the maximum. For each parameter constellation, $X, Y, \eta, \lambda$, if there exists a candidate mixture

$$
p \in(0,1) \text { s.t } p=\frac{(1+\eta) X-(1+\eta \lambda) Y}{\eta(1-\lambda)(Y+X)}
$$

such a $p$ is PE. Note that there will be at most one strict mixture PE. This strict mixture will be a proper probability provided $\frac{(1+\eta) X-(1+\eta \lambda) Y}{\eta(1-\lambda)(Y+X)} \in(0,1)$. For such a proper mixture probability to exist for $\lambda>1$, it must be that

$$
\frac{(1+\eta)}{(1+\eta \lambda)} Y<X<\frac{(1+\eta \lambda)}{(1+\eta)} Y
$$

That is, if $\lambda>1$, both pure strategies, $p=0$ and $p=1$, are $\mathrm{PE}$, and the required preferences are strict, there will also be a strict mixture PE. In contrast, for such a proper 
probability mixture to exist for $\lambda<1$, it must be that

$$
\frac{(1+\eta \lambda)}{(1+\eta)} Y<X<\frac{(1+\eta)}{(1+\eta \lambda)} Y
$$

That is, if $\lambda<1$, and neither pure strategy, $p=0$ or $p=1$, are PE, there will be a strict mixture PE.

Figure A2 summarizes the PE considerations in Condition B recognizing the possibility of mixed strategy equilibria with the corresponding value of the mixture probability noted. In contrast to the pure strategy analysis of Figure A1, for $\lambda<1$ within the bounds
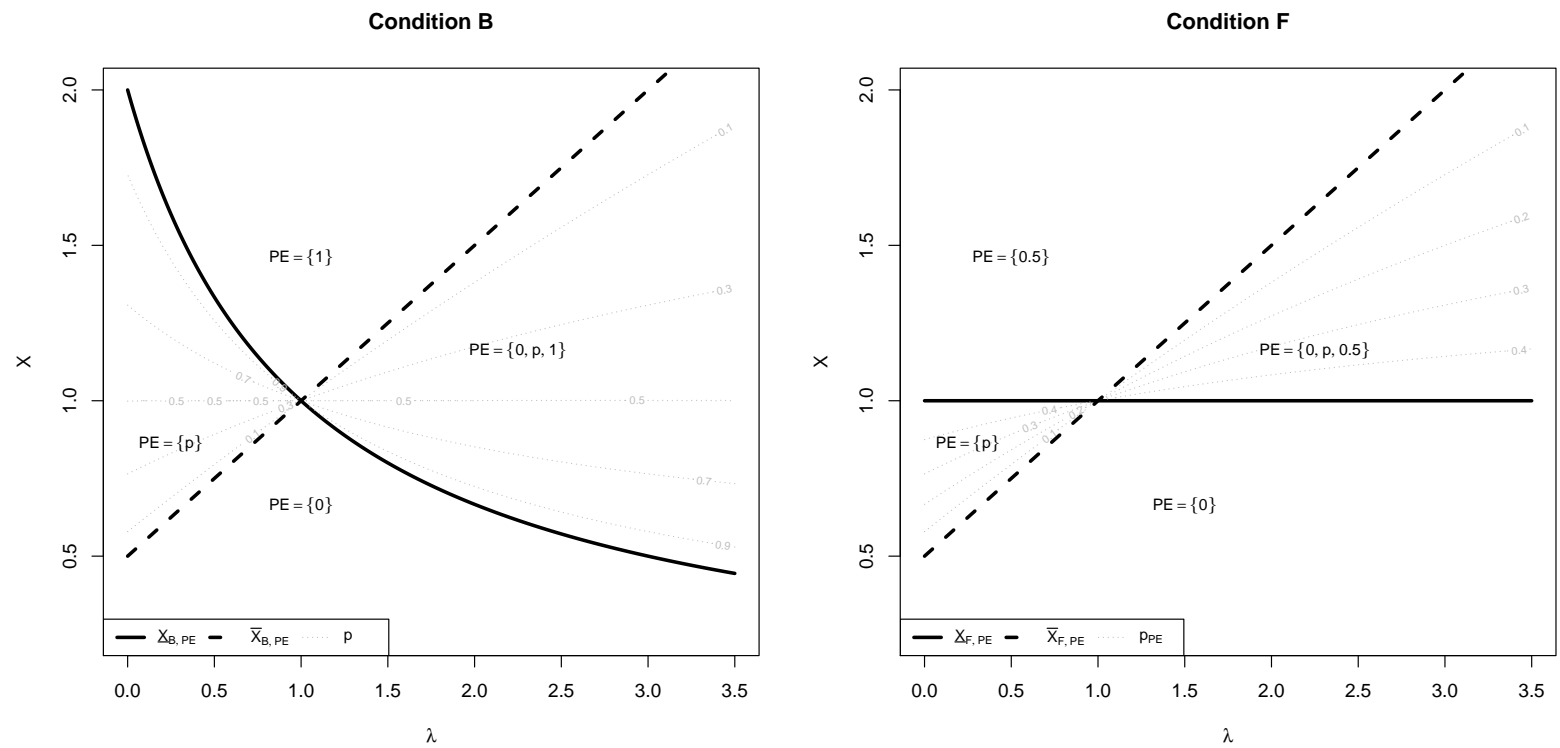

Figure A2: Gain-Loss Attitudes and Theoretical PE Strategy Thresholds

Notes: Threshold values for mixed strategy PE for agent endowed with $X$, assuming $Y=1$ and $\eta=1$.

$\frac{(1+\eta \lambda)}{(1+\eta)} Y<X<\frac{(1+\eta)}{(1+\eta \lambda)} Y$, there is now a mixed strategy PE. Further, for $\lambda>1$ and $\frac{(1+\eta)}{(1+\eta \lambda)} Y<X<\frac{(1+\eta \lambda)}{(1+\eta)} Y$ there are three equilibria when accounting for potential mixtures. Having elaborated the PE restrictions for Condition B, we proceed to Condition F. Condition $\mathrm{F}$ alters the choice set from $\mathcal{D}_{B}=\{p \in[0,1]: p(X, 0)+(1-p)(0, Y)\}$ to $\mathcal{D}_{F}=\{p \in[0,0.5]: p(X, 0)+(1-p)(0, Y)\}$. This alteration induces two potential changes to the PE calculus. First, potential PE choices from Condition B may not be 
available in Condition F. Second, lotteries, $q$, that prevent a specific $p$ from being PE may potentially be eliminated.

In Condition $\mathrm{F}$, a given mixture $p \in[0,0.5]$ will be $\mathrm{PE}$ if

$$
\begin{array}{r}
U(p(X, 0)+(1-p)(0, Y) \mid p(X, 0)+(1-p)(0, Y)) \geq \\
U(q(X, 0)+(1-q)(0, Y) \mid p(X, 0)+(1-p)(0, Y)) \forall q \in[0,0.5] .
\end{array}
$$

As before $U(q, p)$ is linear in $q$, and so a boundary strategy of attempting to keep one's object, $(p=0.5)$ will be PE if

$$
\begin{array}{r}
\frac{\partial U(q, 0.5)}{\partial q}=(1+\eta) X-(1+\eta \lambda) Y-0.5 \eta(1-\lambda)(Y+X) \geq 0 \\
(1+0.5 \eta(1+\lambda)) X \geq(1+0.5 \eta(1+\lambda)) Y \\
X \geq Y,
\end{array}
$$

which corresponds to the pure strategy threshold, $\underline{X}_{F, P E}$. Similarly, exchanging with certainty, $p=0$, will be be PE if

$$
\begin{array}{r}
\frac{\partial U(q, 0)}{\partial q}=(1+\eta) X-(1+\eta \lambda) Y \leq 0 \\
X \leq \frac{(1+\eta \lambda)}{(1+\eta)} Y,
\end{array}
$$

which corresponds to the pure strategy threshold, $\bar{X}_{F, P E}=\bar{X}_{B, P E}$.

Again strict mixtures, $p \in(0,0.5)$, for which $\frac{\partial U(q, p)}{\partial q}=0, p \in \mathbf{q}^{*}(p)$, as all values of $q$, including $q=p$, attain the maximum. For each parameter constellation, $X, Y, \eta, \lambda$, if there exists a candidate mixture

$$
p \in(0,0.5) \text { s.t } p=\frac{(1+\eta) X-(1+\eta \lambda) Y}{\eta(1-\lambda)(Y+X)}
$$


such a $p$ is PE. Note that there will be at most one strict mixture PE. This strict mixture will be a proper probability and within the choice set provided $\frac{(1+\eta) X-(1+\eta \lambda) Y}{\eta(1-\lambda)(Y+X)} \in(0,0.5)$. For such a proper mixture probability to exist for $\lambda>1$, it must be that

$$
Y<X<\frac{(1+\eta \lambda)}{(1+\eta)} Y
$$

That is, if $\lambda>1$, both pure strategies, $p=0$ and $p=0.5$, are $\mathrm{PE}$, and the required preferences are strict, there will also be a strict mixture PE. In contrast, for such a proper probability mixture to exist for $\lambda<1$, it must be that

$$
\frac{(1+\eta \lambda)}{(1+\eta)} Y<X<Y
$$

That is, if $\lambda<1$, and neither pure strategy, $p=0$ or $p=0.5$, are PE, there will be a strict mixture PE.

Figure A2 summarizes the PE considerations in Condition F recognizing the possibility of mixed strategy equilibria with the corresponding value of the mixture probability noted. Moving from Condition $\mathrm{B}$ to Condition $\mathrm{F}$ all mixed strategy $\mathrm{PE}$ with $p \in(0.5,1)$ are eliminated from the choice set. Individuals with $\lambda>1$ and multiple equilibria, $P E=$ $\{0, p>0.5,1\}$ in Condition B have a unique $P E=\{p=0\}$ in Condition F. Such individuals may exchange less than 100 percent of the time in Condition B and do so 100 percent of the time in Condition F, growing more willing to exchange. In contrast, individuals with $\lambda<1$ and a unique $P E=\{p>0.5\}$ in Condition $\mathrm{B}$, have a unique $P E=\{p=0.5\}$ in Condition F. Such individuals would attempt to retain their object less than 100 percent of the time in Condition B and would do so 100 percent of the time in Condition F, growing less willing to exchange. This analysis highlights exactly the intuition laid out with our prior pure strategy analysis and that for the CPE concept. We next turn to PPE analysis to select among multiple PE selections. 


\section{B.1.1 Preferred Personal Equilibrium Analysis}

Where there exist multiple PE selections, the KR model is equipped with an equilibrium selection mechanism, Preferred Personal Equilibrium (PPE). PPE selects among PE values on the basis of ex-ante utility. Having elaborated the PE values in the Figure A2, it is straightforward to identify the selection, $p$, with the highest value of $U(p(X, 0)+(1-$ $p)(0, Y) \mid p(X, 0)+(1-p)(0, Y))=p X+(1-p) Y+p(1-p) \eta(1-\lambda)(X+Y)$. In the case of Condition B, there is a region of multiplicity for $\lambda>1$ where the set of $P E=\{0, p \in$ $(0,1), 1)\}$. In this region it is clear that not exchanging, $p=1$, will yield higher ex-ante utility than exchanging,$p=0$, if

$$
X>Y \text {. }
$$

If $X>Y, p=1$ will also yield higher ex-ante utility than any PE mixture $p \in(0,1)$ as all mixtures will both lower intrinsic utility (as $X>Y \rightarrow X>p X+(1-p) Y \forall p \in(0,1)$ ) and expose the individual to the overall negative sensations of gain loss embodied in the term $p(1-p) \eta(1-\lambda)(X+Y)<0$ for $\lambda>1$. Following this logic, in Condition B, multiplicity is resolved via PPE by selecting either $p=1$ if $X>Y$ or $p=0$ if $X<Y$.
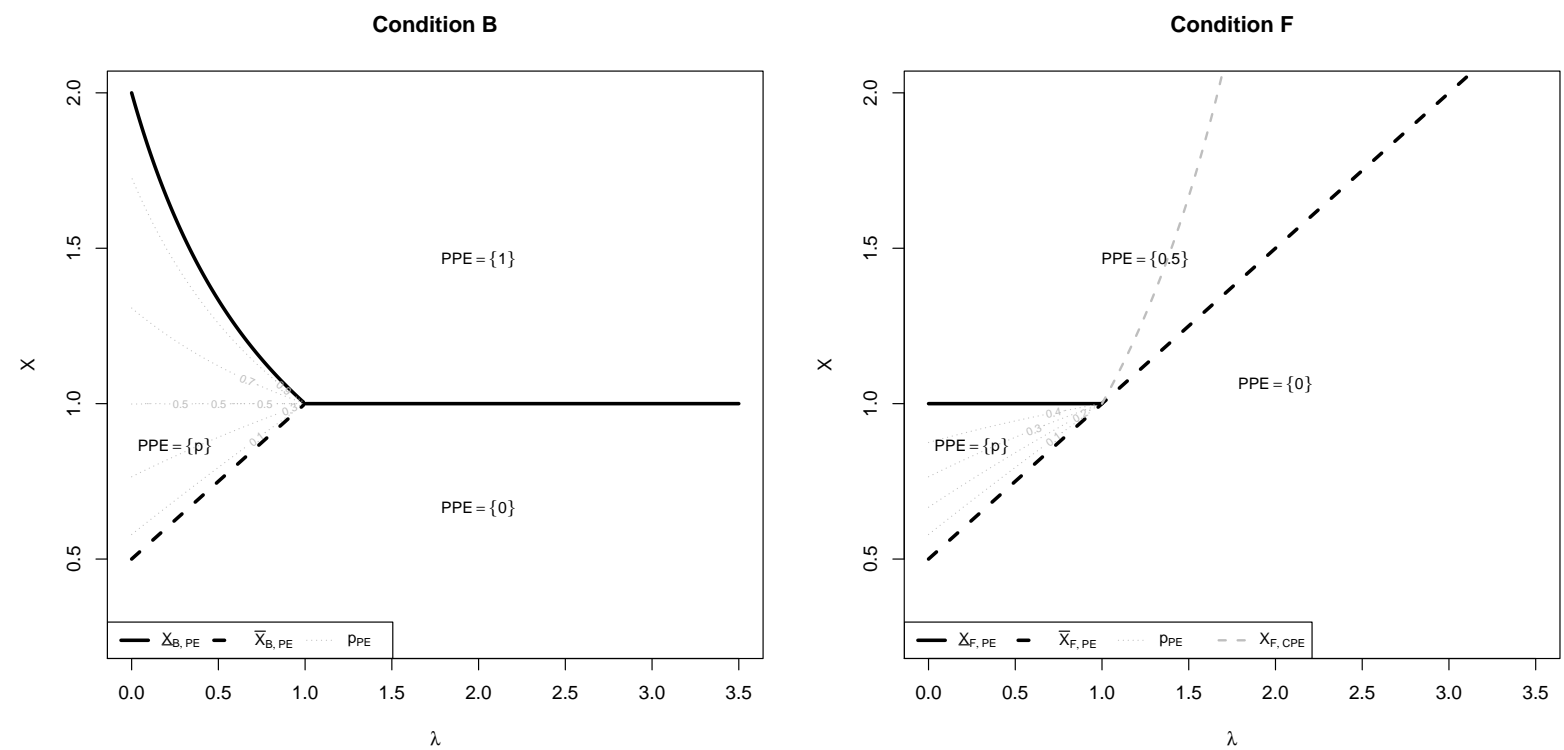

Figure A3: Gain-Loss Attitudes and Theoretical PPE Strategy Thresholds Notes: Threshold values for PPE for agent endowed with $X$, assuming $Y=1$ and $\eta=1$. 
Similarly, in Condition $\mathrm{F}$, there is a region of multiplicity for $\lambda>1, Y<X<\frac{(1+\eta \lambda)}{(1+\eta)} Y$ where the set of $P E=\{0, p \in(0,0.5), 0.5\}$. Note that for $\lambda>1$, if $X<\frac{(1+\eta \lambda)}{(1+\eta)} Y$, then $X<\frac{(1+0.5 \eta(\lambda-1))}{(1+0.5 \eta(1-\lambda))} Y=\frac{(1+\eta \lambda-0.5 \eta(\lambda+1)}{(1+\eta-0.5 \eta(\lambda+1))}$. That is, in this region of multiplicity, $X$ is below the $X_{F, C P E}$ cutoff noted in the main text. Hence, we know that exchanging, $p=0$, yields higher ex-ante utility than attempting not to exchange, $p=0.5$, in this region. It suffices to check which of the remaining PE selections $\left\{0, p=\frac{(1+\eta) X-(1+\eta \lambda) Y}{\eta(1-\lambda)(Y+X)} \in(0,0.5)\right\}$ provide higher utility. For this key mixture,

$$
\begin{array}{r}
p=\frac{(1+\eta) X-(1+\eta \lambda) Y}{\eta(1-\lambda)(Y+X)} \\
(1-p)=\frac{\eta(1-\lambda)(Y+X)}{\eta(1-\lambda)(Y+X)}-\frac{(1+\eta) X-(1+\eta \lambda) Y}{\eta(1-\lambda)(Y+X)}
\end{array}
$$

The PPE selection will be $p=0$ provided

$$
\begin{array}{r}
Y>p X+(1-p) Y+p(1-p) \eta(1-\lambda)(X+Y) \\
Y>X+(1-p) \eta(1-\lambda)(X+Y) \\
Y>X+\left[\frac{\eta(1-\lambda)(Y+X)}{\eta(1-\lambda)(Y+X)}-\frac{(1+\eta) X-(1+\eta \lambda) Y}{\eta(1-\lambda)(Y+X)}\right] \eta(1-\lambda)(X+Y) \\
Y>X+[\eta(1-\lambda)(Y+X)-(1+\eta) X+(1+\eta \lambda) Y] \\
Y-(1+\eta \lambda) Y-\eta(1-\lambda) Y>X+\eta(1-\lambda)(X)-(1+\eta) X \\
-\eta Y>-\eta \lambda X \\
X>\frac{1}{\lambda} Y,
\end{array}
$$

Which is satisfied as $X>Y$ and $\lambda>1$ in this region.

Figure A3 summarizes the PPE considerations in Conditions B and F recognizing the possibility of a mixed strategy PPE with the corresponding value of the mixture probability noted. Also graphed in Figure A3 is the relevant CPE cutoff for $\lambda>1$ in Condition F to reinforce both that in the region of multiplicity exchanging, $p=0$, yields higher ex-ante utility than attempting not to exchange, $p=0.5$, and that the restrictions on behavior differ meaningfully between CPE and PPE. Nonetheless, both solution concepts share the 
same directional comparative statics that individuals with $\lambda>1$ should grow more willing to exchange moving from Condition $\mathrm{B}$ to Condition $\mathrm{F}$, while individuals with $\lambda<1$ should grow less-so.

\section{Estimation Strategy}

In this appendix, we provide the likelihood formulation for our mixed-logit methodology to estimate heterogeneity in gain-loss attitudes and utilities. There are three relative preference statements that subjects provide in Stage 1: relative wanting statements, relative liking statements, and hypothetical choice. Let $i=1, \ldots, N$ represent the index for subjects, and let $\{w, l, h\}$ represent the index of the three preference statements, referring to (w)anting, (l)iking, and (h)ypothetical choice, respectively. Let $w, l \in\{-1,0,1\}$ correspond to providing a higher rating for the alternative object, providing equal ratings for both objects, and providing a higher rating for the endowed object, respectively. Let $h \in\{-1,1\}$ correspond to hypothetically choosing the alternative object or the endowed object, respectively.

We begin by presenting a standard logit formulation and then extend to the mixed logit case. Let $G(\cdot)$ represent the CDF of the logistic distribution. For each individual there are three potential probabilities associated with the three potential wanting ratings for those endowed with $X, \operatorname{Prob}_{w_{i}, X}$,

$$
\begin{array}{lll}
\operatorname{Prob}_{w_{i}, X}= & G\left((1+\lambda)-2 \frac{Y}{X}-\delta_{X}\right) & \text { if } w_{i}=1 \\
\operatorname{Prob}_{w_{i}, X}= & G\left(2 \frac{Y}{X}-(1+\lambda)-\delta_{X}\right) & \text { if } w_{i}=-1 \\
\operatorname{Prob}_{w_{i}, X}=1-G\left((1+\lambda)-2 \frac{Y}{X}-\delta_{X}\right)-G\left(2 \frac{Y}{X}-(1+\lambda)-\delta_{X}\right) & \text { if } w_{i}=0,
\end{array}
$$


and three for those endowed with $Y, \operatorname{Prob}_{w_{i}, Y}$,

$$
\begin{array}{lcl}
\operatorname{Prob}_{w_{i}, Y}= & G\left(2-(1+\lambda) \frac{Y}{X}-\delta_{X}\right) & \text { if } w_{i}=-1 \\
\operatorname{Prob}_{w_{i}, Y}= & G\left((1+\lambda) \frac{Y}{X}-2-\delta_{X}\right) & \text { if } w_{i}=1 \\
\operatorname{Prob}_{w_{i}, Y}= & 1-G\left(2-(1+\lambda) \frac{Y}{X}-\delta_{X}\right)-G\left((1+\lambda) \frac{Y}{X}-2-\delta_{X}\right) & \text { if } w_{i}=0 .
\end{array}
$$

Similarly, there are three potential probabilities associated with the three potential liking ratings for those endowed with $X, \operatorname{Prob}_{l_{i}, X}$,

$$
\begin{array}{lll}
\operatorname{Prob}_{l_{i}, X}= & G\left((1+\lambda)-2 \frac{Y}{X}-\delta_{X}\right) & \text { if } l_{i}=1 \\
\operatorname{Prob}_{l_{i}, X}= & G\left(2 \frac{Y}{X}-(1+\lambda)-\delta_{X}\right) & \text { if } l_{i}=-1 \\
\operatorname{Prob}_{l_{i}, X}=1-G\left((1+\lambda)-2 \frac{Y}{X}-\delta_{X}\right)-G\left(2 \frac{Y}{X}-(1+\lambda)-\delta_{X}\right) & \text { if } l_{i}=0,
\end{array}
$$

and three for those endowed with $Y, \operatorname{Prob}_{l_{i}, Y}$,

$$
\begin{array}{lcl}
\operatorname{Prob}_{l_{i}, Y}= & G\left(2-(1+\lambda) \frac{Y}{X}-\delta_{X}\right) & \text { if } l_{i}=-1 \\
\operatorname{Prob}_{l_{i}, Y}= & G\left((1+\lambda) \frac{Y}{X}-2-\delta_{X}\right) & \text { if } l_{i}=1 \\
\operatorname{Prob}_{l_{i}, Y}=1-G\left(2-(1+\lambda) \frac{Y}{X}-\delta_{X}\right)-G\left((1+\lambda) \frac{Y}{X}-2-\delta_{X}\right) & \text { if } l_{i}=0 .
\end{array}
$$

Lastly, there are two potential probabilities associated with the two hypothetical choice statements for those endowed with $X \operatorname{Prob}_{h_{i}, X}$,

$$
\begin{array}{ll}
\operatorname{Prob}_{h_{i}, X}=G\left((1+\lambda)-2 \frac{Y}{X}\right) & \text { if } w_{i}=1 \\
\operatorname{Prob}_{h_{i}, X}=G\left(2 \frac{Y}{X}-(1+\lambda)\right) & \text { if } w_{i}=-1,
\end{array}
$$

and two for those endowed with $Y, \operatorname{Prob}_{h_{i}, Y}$,

$$
\begin{array}{ll}
\operatorname{Prob}_{h_{i}, Y}=G\left(2-(1+\lambda) \frac{Y}{X}\right) & \text { if } w_{i}=-1 \\
\operatorname{Prob}_{h_{i}, Y}=G\left((1+\lambda) \frac{Y}{X}-2\right) & \text { if } w_{i}=1 .
\end{array}
$$


Let $\mathbf{1}_{X}$ indicate an individual endowed with object $X$. A single individual's choice probability would thus be

$$
L_{i}=\left(\operatorname{Prob}_{w_{i}, X} \cdot \operatorname{Prob}_{l_{i}, X} \cdot \operatorname{Prob}_{h_{i}, X}\right)^{\mathbf{1}_{X}} \cdot\left(\operatorname{Prob}_{w_{i}, Y} \cdot \operatorname{Prob}_{l_{i}, Y} \cdot \operatorname{Prob}_{h_{i}, Y}\right)^{\left(1-\mathbf{1}_{X}\right)}
$$

and the grand log likelihood would be

$$
\mathcal{L}=\sum_{i=1}^{N} \log \left(L_{i}\right)
$$

Moving from this logit formulation to our mixed logit formulation is straightforward and follows Train (2009). For estimating the heterogeneity of gain-loss attitudes, we assume that the value $\lambda$ is drawn from a log-normal distribution with $\log (\lambda) \sim N\left(\mu_{\lambda}, \sigma_{\lambda}^{2}\right)$. Let $\theta \equiv\left(\mu_{\lambda}, \sigma_{\lambda}^{2}\right)$, represent the parameters of this distribution, and let $f(\lambda \mid \theta)$ be the distribution of $\lambda$ given these parameters. A single individual's choice probabilities are thus

$$
L_{i}=\int L_{i}(\lambda) f(\lambda \mid \theta) d \lambda
$$

where $L_{i}(\lambda)$ is the individual choice probability evaluated at a given draw of $f(\lambda \mid \theta)$. We construct these choice probabilities through simulation. Let $r=1, \ldots, R$ represent simulations of $\lambda$ from $f(\lambda \mid \theta)$ at a given set of parameters, $\theta$. Let $\lambda^{r}$ be the $r^{\text {th }}$ simulant. We simulate $L_{i}$ as

$$
\check{L}_{i}=\frac{1}{R} \sum_{r=1}^{R} L_{i}\left(\lambda^{r}\right),
$$

And these simulated probabilities replace the standard choice probabilities in the grand log likelihood to create a simulated log likelihood,

$$
\mathcal{S} \mathcal{L}=\sum_{i=1}^{N} \log \left(\check{L}_{i}\right)
$$


This simulated $\log$ likelihood is maximized to deliver estimates of $\mu_{\lambda}$ and $\sigma_{\lambda}^{2}$ alongside the homogeneous utility ratio $\frac{X}{Y}$.

When considering heterogeneous utility, the exercise is analogous. We assume that the value $\frac{X}{Y}$ is drawn from a $\log$-normal distribution with $\log \left(\frac{X}{Y}\right) \sim N\left(\frac{X}{Y}, \sigma_{\frac{X}{Y}}^{2}\right)$. Let $\theta^{\prime} \equiv$ $\left(\mu_{\frac{X}{Y}}, \sigma_{\frac{X}{Y}}^{2}\right)$, represent the parameters of this distribution, and let $f\left(\frac{X}{Y} \mid \theta^{\prime}\right)$ be the distribution of $\frac{X}{Y}$ given these parameters. A single individual's choice probabilities are thus

$$
L_{i}=\int L_{i}\left(\frac{X}{Y}\right) f\left(\frac{X}{Y} \mid \theta^{\prime}\right) d \frac{X}{Y}
$$

where $L_{i}\left(\frac{X}{Y}\right)$ is the individual choice probability evaluated at a given draw of $f\left(\frac{X}{Y} \mid \theta^{\prime}\right)$. We construct these choice probabilities through simulation. Let $r=1, \ldots, R$ represent simulations of $\frac{X}{Y}$ from $f\left(\frac{X}{Y} \mid \theta^{\prime}\right)$ at a given set of parameters, $\theta^{\prime}$. Let $\frac{X^{r}}{Y}$ be the $r^{\text {th }}$ simulant. We simulate $L_{i}$ as

$$
\check{L}_{i}=\frac{1}{R} \sum_{r=1}^{R} L_{i}\left(\frac{X^{r}}{Y}\right)
$$

And these simulated probabilities replace the standard choice probabilities in the grand log likelihood to create a simulated log likelihood,

$$
\mathcal{S} \mathcal{L}=\sum_{i=1}^{N} \log \left(\check{L}_{i}\right)
$$

This simulated $\log$ likelihood is maximized to deliver estimates of $\mu_{\frac{X}{Y}}$ and $\sigma_{\frac{X}{Y}}^{2}$ alongside the homogeneous gain-loss parameter, $\lambda$.

Operationally for implementing both of our simulated likelihood techniques we use 1000 Halton draws for each heterogeneous parameter and implement the code in Stata. The code for our procedure estimating the distribution of gain-loss attitudes is presented below. 


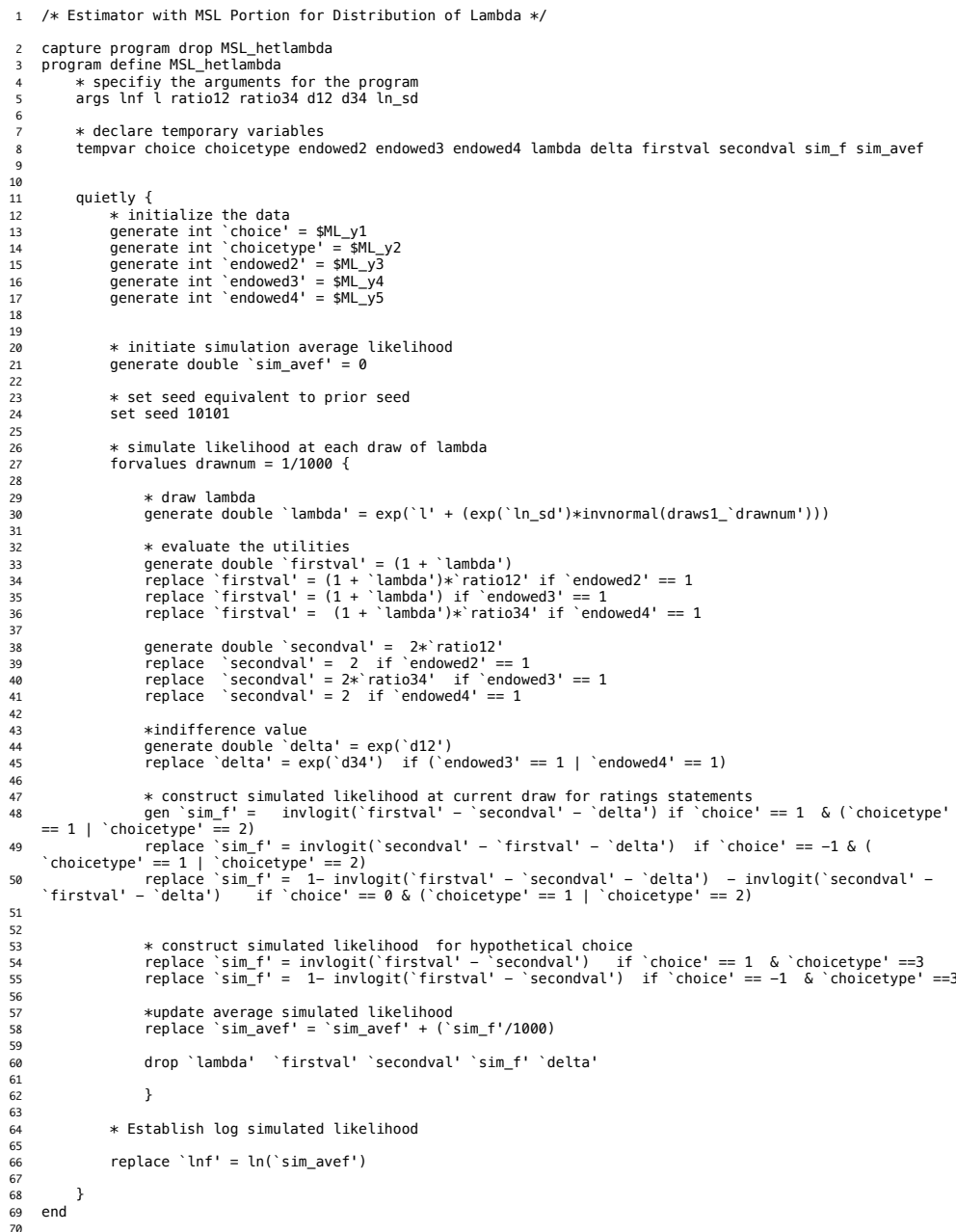

Page 1 of 1 


\section{Additional Tables}

Table A3: Method of Simulated Likelihood Estimates: Sensitivity Analysis

\begin{tabular}{|c|c|c|c|c|c|c|}
\hline & (1) & $(2)$ & $(3)$ & $(4)$ & $(5)$ & (6) \\
\hline & Estimate & (Std. Error) & Estimate & (Std. Error) & Estimate & (Std. Error) \\
\hline & \multicolumn{2}{|c|}{ Heterogeneous $\lambda$} & \multicolumn{2}{|c|}{ Heterogeneous $\lambda$} & \multicolumn{2}{|c|}{ Heterogeneous $\lambda$} \\
\hline \multicolumn{7}{|l|}{ Gain-Loss Attitudes: } \\
\hline$\hat{\lambda}$ & 1.29 & $(0.04)$ & 1.37 & $(0.08)$ & 1.64 & $(0.21)$ \\
\hline$\hat{\mu_{\lambda}}$ & 0.26 & $(0.03)$ & 0.17 & $(0.07)$ & 0.04 & $(0.08)$ \\
\hline$\hat{\sigma_{\lambda}^{2}}$ & 0.00 & $(0.00)$ & 0.29 & $(0.21)$ & 0.91 & $(0.39)$ \\
\hline \multicolumn{7}{|c|}{ Pair 1 Utilities (USB Stick (X) - Pen Set (Y)) } \\
\hline$\frac{\hat{Y}}{X}($ Initial $)$ & 0.64 & $(0.03)$ & 0.62 & $(0.04)$ & 0.57 & $(0.04)$ \\
\hline$\frac{\hat{Y}}{X}$ (Replication) & 0.64 & $(0.04)$ & 0.61 & $(0.04)$ & 0.57 & $(0.05)$ \\
\hline \multicolumn{7}{|c|}{ Pair 2 Utilities (Picnic Mat (X) - Thermos (Y)): } \\
\hline$\frac{\hat{Y}}{X}($ Initial $)$ & 1.10 & $(0.03)$ & 1.11 & $(0.03)$ & 1.13 & $(0.04)$ \\
\hline$\frac{\hat{Y}}{X}($ Replication $)$ & 0.90 & $(0.04)$ & 0.88 & $(0.04)$ & 0.87 & $(0.05)$ \\
\hline \multicolumn{7}{|l|}{ Discernibility: } \\
\hline$\delta_{X}$ & 0.50 & - & 0.55 & - & 0.60 & - \\
\hline \# Observations & \multicolumn{2}{|c|}{3,072} & \multicolumn{2}{|c|}{3,072} & \multicolumn{2}{|c|}{3,072} \\
\hline
\end{tabular}


Table A4: Exchange Behavior and Probabilistic Forced Exchange, Clustered SE

\begin{tabular}{|c|c|c|c|}
\hline & \multicolumn{3}{|c|}{$\begin{array}{l}\text { Dependent Variable: Exchange }(=1) \\
(1)\end{array}$} \\
\hline Condition F & $\begin{array}{l}-0.004 \\
(0.027)\end{array}$ & $\begin{array}{l}-0.340 \\
(0.076)\end{array}$ & $\begin{array}{l}-0.004 \\
(0.026)\end{array}$ \\
\hline$E[\lambda]$ & & $\begin{array}{l}-0.136 \\
(0.036)\end{array}$ & \\
\hline Condition $\mathrm{F}^{*} E[\lambda]$ & & $\begin{array}{c}0.225 \\
(0.046)\end{array}$ & \\
\hline Reduced Form Measure & & & $\begin{array}{l}-0.050 \\
(0.014)\end{array}$ \\
\hline Condition $\mathrm{F} *$ Reduced Form & & & $\begin{array}{c}0.077 \\
(0.018)\end{array}$ \\
\hline Constant (Condition B) & $\begin{array}{c}0.380 \\
(0.020)\end{array}$ & $\begin{array}{c}0.584 \\
(0.061)\end{array}$ & $\begin{array}{c}0.380 \\
(0.019)\end{array}$ \\
\hline R-Squared & 0.000 & 0.017 & 0.014 \\
\hline \# Observations & 1024 & 1024 & 1024 \\
\hline \# Clusters & 53 & 53 & 53 \\
\hline$H_{0}:$ Zero Endowment Effect in B & $\begin{array}{l}F_{1,52}=34.96 \\
\quad(p<0.01)\end{array}$ & $\begin{array}{c}F_{1,52}=1.87 \\
(p=0.18)\end{array}$ & $\begin{array}{l}F_{1,52}=38.26 \\
\quad(p<0.01)\end{array}$ \\
\hline$H_{0}:$ Zero Treatment Effect $(\mathrm{F}-\mathrm{B})$ & $\begin{array}{l}F_{1,52}=.02 \\
(p=0.89)\end{array}$ & $\begin{array}{l}F_{1,52}=20.07 \\
\quad(p<0.01)\end{array}$ & $\begin{array}{l}F_{1,52}=0.02 \\
(p=0.89)\end{array}$ \\
\hline$H_{0}$ : Gain-Loss Attitudes $\perp$ Exchange in B & & $\begin{array}{l}F_{1,52}=13.98 \\
\quad(p<0.01)\end{array}$ & $\begin{array}{l}F_{1,52}=13.19 \\
\quad(p<0.01)\end{array}$ \\
\hline$H_{0}:$ Gain-Loss Attitudes $\perp$ Treatment Effect & & $\begin{array}{l}F_{1,52}=24.03 \\
\quad(p<0.01)\end{array}$ & $\begin{array}{l}F_{1,52}=19.48 \\
\quad(p<0.01)\end{array}$ \\
\hline
\end{tabular}

Notes: Ordinary least square regression. Standard errors clustered at session level in parentheses. Null hypotheses tested for 1) zero baseline endowment effect regression (Constant coefficient $=0.5$ ); 2 ) zero treatment effect (Condition $\mathrm{F}$ coefficient= 0); 3) no relationship between gain-loss attitudes and behavior in Condition $\mathrm{B}$ behavior $(E[\lambda]$ or Reduced Form Measure coefficient $=0)$; 4$)$ constant treatment effect over gain-loss attitudes (Condition $\mathrm{F}^{*} E[\lambda]$ or Condition $\mathrm{F} *$ Reduced Form coefficient $=0$ ). $F$-statistics and two-sided $p$-values reported. 
Table A5: Stage 2 Behavior and Stage 1 Experience, Clustered SE

\begin{tabular}{|c|c|c|c|c|}
\hline & $\begin{array}{l}D \\
\text { Stage } 1 \text { Objec } \\
(1)\end{array}$ & $\begin{array}{l}\text { Dendent Variabl } \\
\text { Not Replaced } \\
(2)\end{array}$ & $\begin{array}{l}\text { e: Exchange }(= \\
\text { Stage } 1 \mathrm{Obj} \\
(3)\end{array}$ & $\begin{array}{l}\text { 1) } \\
\text { ect Replaced } \\
\qquad(4)\end{array}$ \\
\hline Condition F & $\begin{array}{c}0.013 \\
(0.035)\end{array}$ & $\begin{array}{c}-0.255 \\
(0.120)\end{array}$ & $\begin{array}{c}-0.019 \\
(0.044)\end{array}$ & $\begin{array}{l}-0.418 \\
(0.124)\end{array}$ \\
\hline$E[\lambda]$ & & $\begin{array}{l}-0.121 \\
(0.053)\end{array}$ & & $\begin{array}{l}-0.153 \\
(0.064)\end{array}$ \\
\hline Condition $\mathrm{F} * E[\lambda]$ & & $\begin{array}{l}0.176 \\
(0.071)\end{array}$ & & $\begin{array}{c}0.272 \\
(0.077)\end{array}$ \\
\hline Constant (Condition B) & $\begin{array}{l}0.386 \\
(0.027)\end{array}$ & $\begin{array}{l}0.569 \\
(0.092)\end{array}$ & $\begin{array}{c}0.374 \\
(0.032)\end{array}$ & $\begin{array}{l}0.600 \\
(0.104)\end{array}$ \\
\hline R-Squared & 0.000 & 0.011 & 0.000 & 0.024 \\
\hline \# Observations & 511 & 511 & 513 & 513 \\
\hline \# Clusters & 53 & 53 & 53 & 53 \\
\hline$H_{0}:$ Zero Endowment Effect in B & $\begin{array}{c}F_{1,52}=17.82 \\
(p<0.01)\end{array}$ & $\begin{array}{c}F_{1,52}=0.57 \\
(p=0.45)\end{array}$ & $\begin{array}{c}F_{1,52}=15.78 \\
(p<0.01)\end{array}$ & $\begin{array}{c}F_{1,52}=0.92 \\
(p=0.34)\end{array}$ \\
\hline$H_{0}:$ Zero Treatment Effect (F-B) & $\begin{array}{c}F_{1,52}=0.13 \\
(p=0.72)\end{array}$ & $\begin{array}{c}F_{1,52}=4.51 \\
(p=0.04)\end{array}$ & $\begin{array}{c}F_{1,52}=0.18 \\
(p=0.67)\end{array}$ & $\begin{array}{l}F_{1,52}=11.31 \\
\quad(p<0.01)\end{array}$ \\
\hline$H_{0}$ : Gain-Loss Attitudes $\perp$ Exchange in B & & $\begin{array}{c}F_{1,52}=5.25 \\
(p=0.03)\end{array}$ & & $\begin{array}{c}F_{1,52}=5.81 \\
(p=0.02)\end{array}$ \\
\hline$H_{0}$ : Gain-Loss Attitudes $\perp$ Treatment Effect & & $\begin{array}{c}F_{1,52}=6.19 \\
(p=0.02)\end{array}$ & & $\begin{array}{c}F_{1,52}=12.62 \\
(p<0.01)\end{array}$ \\
\hline
\end{tabular}


Table A6: Replication Consistency and Additional Controls, Clustered SE

\begin{tabular}{|c|c|c|c|c|c|}
\hline & \multicolumn{5}{|c|}{ Dependent Variable: Exchange $(=1)$} \\
\hline & \multicolumn{2}{|c|}{ Initial Study } & \multicolumn{3}{|c|}{ Replication Study } \\
\hline & (1) & $(2)$ & $(3)$ & $(4)$ & (5) \\
\hline Condition F & 0.004 & -0.409 & -0.010 & -0.239 & -0.805 \\
\hline & $(0.034)$ & $(0.111)$ & $(0.044)$ & $(0.102)$ & $(0.411)$ \\
\hline$E[\lambda]$ & & -0.159 & & -0.103 & -0.116 \\
\hline & & $(0.053)$ & & $(0.053)$ & $(0.053)$ \\
\hline Condition $\mathrm{F}^{*} E[\lambda]$ & & 0.266 & & 0.161 & 0.174 \\
\hline & & $(0.065)$ & & $(0.064)$ & $(0.064)$ \\
\hline Constant (Condition B) & 0.365 & 0.616 & 0.399 & 0.542 & 0.917 \\
\hline & $(0.028)$ & $(0.093)$ & $(0.030)$ & $(0.081)$ & $(0.343)$ \\
\hline Additional Controls & No & No & No & No & Yes \\
\hline Additional Interactions & No & No & No & No & Yes \\
\hline R-Squared & 0.000 & 0.023 & 0.000 & 0.008 & 0.060 \\
\hline \# Observations & 607 & 607 & 417 & 417 & 417 \\
\hline \# Clusters & 31 & 31 & 22 & 22 & 22 \\
\hline$H_{0}:$ Zero Endowment Effect in B & $\begin{array}{c}F_{1,30}=23.85 \\
(p<0.01)\end{array}$ & $\begin{array}{c}F_{1,30}=1.53 \\
(p=0.23)\end{array}$ & $\begin{array}{c}F_{1,21}=11.73 \\
(p<0.01)\end{array}$ & $\begin{array}{c}F_{1,21}=0.26 \\
(p=0.61)\end{array}$ & $\begin{array}{c}F_{1,21}=1.48 \\
(p=0.24)\end{array}$ \\
\hline$H_{0}:$ Zero Treatment Effect (F-B) & $\begin{array}{c}F_{1,30}=0.01 \\
(p=0.90)\end{array}$ & $\begin{array}{c}F_{1,30}=13.44 \\
(p<0.01)\end{array}$ & $\begin{array}{c}F_{1,21}=0.05 \\
(p=0.82)\end{array}$ & $\begin{array}{c}F_{1,21}=5.51 \\
(p=0.03)\end{array}$ & $\begin{array}{c}F_{1,21}=3.84 \\
(p=0.06)\end{array}$ \\
\hline$H_{0}:$ Gain-Loss Attitudes $\perp$ Exchange in B & & $\begin{array}{c}F_{1,30}=9.09 \\
(p<0.01)\end{array}$ & & $\begin{array}{c}F_{1,21}=3.79 \\
(p=0.07)\end{array}$ & $\begin{array}{c}F_{1,21}=4.78 \\
(p=0.04)\end{array}$ \\
\hline$H_{0}$ : Gain-Loss Attitudes $\perp$ Treatment Effect & & $\begin{array}{c}F_{1,30}=16.61 \\
(p<0.01)\end{array}$ & & $\begin{array}{c}F_{1,21}=6.32 \\
(p<0.01)\end{array}$ & $\begin{array}{c}F_{1,21}=7.47 \\
(p=0.01)\end{array}$ \\
\hline
\end{tabular}

Notes: Ordinary least square regression. Standard errors clustered at session level in parentheses. Null hypotheses tested for 1) zero baseline endowment effect regression (Constant coefficient $=0.5) ; 2$ ) zero treatment effect (Condition $\mathrm{F}$ coefficient $=0$ ); 3 ) no relationship between gain-loss attitudes and behavior in Condition $\mathrm{B}$ behavior $(E[\lambda]=0) ; 4)$ constant treatment effect over gain-loss attitudes $(\mathrm{Condition} \mathrm{F} * E[\lambda]$ $=0)$. The number of clusters in replication data does not permit test for effect of additional controls or interactions (all coefficients $=0$ ), which would require. Additional controls include: gender, age, educational status, monthly income bracket, knowledge of economics, composite Raven matrices score, composite CRT score, and fixed effects for experimental assistant. Interactions include all controls interacted with Condition F. $F$-statistics and two-sided $p$-values reported. 


\section{E Instructions and Material Presented to Participants}

\section{E.1 Images of Objects Presented to Participants}

The following images were projected to the wall of the lecture room at the beginning of the respective stage. For the displayed example, the Stage 1 pair consisted of the USB stick and erasable pens, but this was counter-balanced at the session level.

\section{Part 1}

\section{USB stick}

- 8GB, USB 2.0, from brand Kingston

- Slim metallic case, eye for key ring

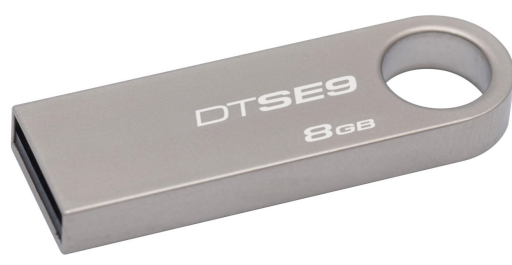

\section{Erasable pens}

- Erasable rollerball, from brand Pilot

- 3 pieces: black, blue, red

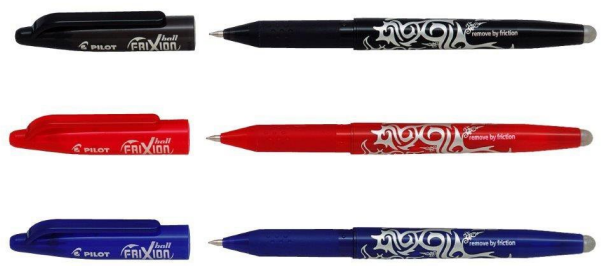

Figure A4: Image 1 Projected on the Wall to Present Objects. For Stage 1 with objects pair consisting of USB stick and erasable pens.

\section{E.2 Original instructions in German (computer-based)}

Willkommen in Teil 1 von 2 in diesem Experiment! 


\section{Part 2}

Thermos bottle

- Stainless steel, $500 \mathrm{ml}$, double-wall insulated

- For warm and and cold drinks

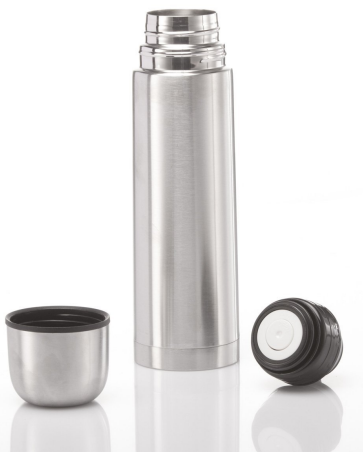

\section{Picnic mat}

- Foldable, water-resistant PVC bottom side

- Ca. 120x140cm, with Velcro fastener

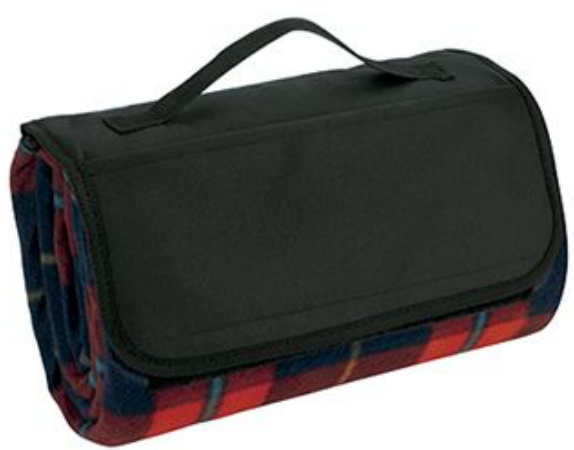

Figure A5: Image 2 Projected on the Wall to Present Objects. For Stage 2 with objects pair consisting of thermos and picnic mat.

Bitte schließen Sie den Vorhang Ihrer Kabine und lesen die folgenden Informationen. Alle Eingaben, die Sie in diesem Experiment am Computer machen, sind völlig anonym und können nicht mit Ihrer Person in Verbindung gebracht werden. Es geht an keiner Stelle in diesem Experiment um Schnelligkeit. Bitte nehmen Sie sich stets ausreichend Zeit, um die Anweisungen zu lesen und zu verstehen.

Sie besitzen nun das Produkt vor Ihnen. Sie können es jederzeit anfassen und inspizieren. Bitte öffnen Sie jedoch noch nicht die Verpackung und benutzen das Produkt nicht.

Die beiden Ihnen vorgestellten Produkte wurden zufällig und in gleichen Mengen auf die Kabinen verteilt. Ihre Kabinennummer hat sich ebenfalls rein zufällig aus der Wahl Ihres Sitzplatzes im Präsentationsraum ergeben. 
Klicken Sie OK, wenn Sie diese Informationen gelesen haben. Falls Sie Fragen haben, rufen Sie bitte den Leiter des Experiments.

\section{Bitte beantworten Sie die Fragen.}

[ USB stick / Thermoskanne ]

Wie gut gefällt Ihnen das Produkt?

Wie gern würden Sie dieses Produkt mitnehmen?

[ Radierbare Kugelschreiber / Picknick-Matte ]

Wie gut gefällt Ihnen das Produkt?

Wie gern würden Sie dieses Produkt mitnehmen?

Wenn Sie sich für ein Produkt entscheiden müssten, welches würden Sie lieber behalten? [ USB stick / Thermoskanne ] [ Radierbare Kugelschreiber / Picknick-Matte

\section{Bitte lesen Sie die folgenden Informationen aufmerksam.}

Der Leiter des Experiments wird gleich mit einer Bingo-Trommel eine Zufallszahl zwischen 1 und 20 ziehen.Die gezogene Zahl wird danach laut durchgesagt. Wenn die gezogene Zahl eine Zahl [ von 11 bis 20 / von 1 bis 10 ] ist, werden/wird [ Ihr USB-Stick / Ihre radierbaren Kugelschreiber / Ihre Picknick-Matte / Ihre Thermoskanne ] weggenommen und Sie erhalten stattdessen eine/einen [ USB-Stick / radierbare Kugelschreiber / eine Picknick-Matte / eine Thermoskanne ]. Wenn die gezogene Zahl eine Zahl [ von 1 bis 10 / von 11 bis 20 ] ist, behalten Sie [ Ihr USB-Stick / Ihre radierbaren Kugelschreiber / Ihre Picknick-Matte / Ihre Thermoskanne ] und es passiert nichts. Nachdem die Zahl gezogen wurde und gegebenenfalls ein Austausch der Produkte vollzogen wurde, passiert nichts mehr in diesem Teil des Experiments. Sie können das Produkt dann endgültig behalten.

Bitte bestätigen Sie erst, wenn Sie alles verstanden haben. Falls Sie Fragen haben, rufen 
Sie bitte den Leiter des Experiments und warten, bis er zu Ihnen kommt.

\section{[ Mood elicitation 1]}

Bitte beantworten Sie die folgenden Fragen dazu, wie Sie sich gerade fülen. Welche Ausdrücke treffen auf Sie jetzt im Moment eher zu? Positionieren Sie den Schieberegler entsprechend. "Unglücklich, Wütend, Unzufrieden, Traurig, Verzweifelt" - "Glücklich, Begeistert, Zufrieden, Frühlich"

\section{Es ist soweit! Bitte warten Sie, bis die Zahl gezogen wurde.}

Zur Erinnerung: Wenn die gezogene Zahl [ von 11 bis 20 / von 1 bis 10 ] ist, verlieren Sie [ Ihr USB-Stick / Ihre radierbaren Kugelschreiber / Ihre Picknick-Matte / Ihre Thermoskanne ] und erhalten stattdessen eine/einen [ USB-Stick / radierbare Kugelschreiber / eine Picknick-Matte / eine Thermoskanne ]. Wenn die gezogene Zahl [ von 1 bis 10 / von 11 bis 20 ] ist, behalten Sie [ Ihr USB-Stick / Ihre radierbaren Kugelschreiber / Ihre Picknick-Matte / Ihre Thermoskanne ].

Die gezogene Zahl ist $[1 / 2 / \ldots / 20]$.

Dies ist eine Zahl [ von 1 bis 10 / von 11 bis 20 ]. Daher [ verlieren Sie [ Ihren USB-Stick / Ihre radierbaren Kugelschreiber / Ihre Picknick-Matte / Ihre Thermoskanne ] und erhalten stattdessen eine/einen [ USB-Stick / radierbare Kugelschreiber / eine Picknick-Matte / eine Thermoskanne ] / können Sie [ Ihren USB-Stick"/ Ihre radierbaren Kugelschreiber

/ Ihre Picknick-Matte / Ihre Thermoskanne ] behalten ]. Bitte warten Sie, während der Leiter des Experiments den Austausch in den Kabinen durchführt.

\section{[ Mood elicitation 2 and control question. ]}

Bitte beantworten Sie die folgenden Fragen dazu, wie Sie sich gerade fülen. Welche 
Ausdrücke treffen auf Sie jetzt im Moment eher zu? Positionieren Sie den Schieberegler entsprechend. "Unglücklich, Wütend, Unzufrieden, Traurig, Verzweifelt" - "Glücklich, Begeistert, Zufrieden, Frühlich"

In der Lottoziehung die eben stattgefunden hat: Wie hoch war die Wahrscheinlichkeit (in Prozent), dass Sie Ihr ursprüngliches Produkt verlieren würden? Bitte geben Sie eine Zahl zwischen 0 und 100 ein. Please enter a number between 0 and 100.

\section{Teil 1 des Experiments ist vorbei!}

Bitte befolgen Sie die Anweisungen.

- Prägen Sie sich die Nummer Ihrer Kabine ein.

- Sie können jetzt zurück in den Präsentationsraum gehen.

- Bitte lassen Sie [ Ihren USB-Stick/ Ihre radierbaren Kugelschreiber / Ihre PicknickMatte / Ihre Thermoskanne ] in der Kabine liegen. Sie werden in wenigen Minuten zurück in der gleichen Kabine sein.

- Zur Erinnerung: Das Produkt gehört nun endgültig Ihnen und Sie werden es mit aus dem Experiment nehmen.

\section{Willkommen in Teil 2 in diesem Experiment!}

Bitte schließen Sie den Vorhang Ihrer Kabine und lesen die folgenden Informationen.

Sie besitzen nun den/die [ USB-Stick / radierbare Kugelschreiber / eine Picknick-Matte / eine Thermoskanne ] vor Ihnen. Sie können es jederzeit anfassen und inspizieren. Bitte öffnen Sie jedoch noch nicht die Verpackung und benutzen das Produkt nicht.

Die beiden für Teil 2 vorgestellten Produkte ( [ USB Stick und radierbare Kugelschreiber ] / [ Thermoskanne und Picknick-Matte ]) wurden erneut zufällig und in gleichen Mengen auf die Kabinen verteilt. 
Klicken Sie OK, wenn Sie diese Informationen gelesen haben. Falls Sie Fragen haben, rufen Sie bitte den Leiter des Experiments.

\section{[ Instructions Stage 2 - ONLY BASELINE $(\mathrm{p}=0.0)$ ]}

Bitte lesen Sie die folgenden Informationen aufmerksam. Der/Die [ USB-Stick / radierbare Kugelschreiber / eine Picknick-Matte / eine Thermoskanne ] aus Teil 2 des Experiments gehört nun Ihnen und Sie können es behalten. Wenn Sie möchten, können Sie [ Ihren USB-Stick/ Ihre radierbaren Kugelschreiber / Ihre Picknick-Matte / Ihre Thermoskanne ] freiwillig gegen ein/eine [ USB-Stick / radierbare Kugelschreiber / eine Picknick-Matte / eine Thermoskanne ] tauschen. Wie auch immer Sie sich entscheiden, Ihre Wahl ist endg, ltig und Sie werden Ihr gewähltes Produkt danach mit aus dem Experiment nehmen. Bitte bestätigen Sie erst, wenn Sie alles verstanden haben. Falls Sie Fragen haben, rufen Sie bitte den Leiter des Experiments und warten, bis er zu Ihnen kommt

\section{[ Instructions Stage 2 - ONLY FORCED EXCHANGE $(\mathrm{p}=0.5)$ ]}

Bitte lesen Sie die folgenden Informationen aufmerksam. Sie haben ein neues Produkt in Teil 2 des Experiments erhalten ( [ einen USB-Stick / radierbare Kugelschreiber / eine Picknick-Matte / eine Thermoskanne ] ).

Sie erhalten gleich die Gelegenheit, [ Ihren USB-Stick/ Ihre radierbaren Kugelschreiber / Ihre Picknick-Matte / Ihre Thermoskanne ] freiwillig gegen [ einen USB-Stick / radierbare Kugelschreiber / eine Picknick-Matte / eine Thermoskanne ] zu tauschen. Wenn Sie sich für einen Tausch entscheiden, erhalten Sie wie gewüscht [ einen USB-Stick / radierbare Kugelschreiber / eine Picknick-Matte / eine Thermoskanne] für [ Ihren USB-Stick/ Ihre radierbaren Kugelschreiber / Ihre Picknick-Matte / Ihre Thermoskanne ] und können [ Ihren USB-Stick/ Ihre radierbaren Kugelschreiber / Ihre Picknick-Matte / Ihre Thermoskanne ] endgültig behalten. Das Experiment ist damit abgeschlossen. 
Wenn Sie sich gegen einen Tausch entscheiden, besteht danach eine Wahrscheinlichkeit von $50 \%$, dass der Austausch dennoch erzwungen wird und sie trotzdem tauschen müssen.

Folgendes passiert konkret im Fall, dass Sie sich gegen einen freiwilligen Tausch entscheiden: Der Leiter des Experiments wird (wie in Teil 1 des Experiments) mit einer Bingo-Trommel eine Zufallszahl zwischen 1 und 20 ziehen. Die gezogene Zahl wird danach laut durchgesagt. Wenn die gezogene Zahl eine Zahl [ von 11 bis 20 / von 1 bis 10 ] ist, wird/werden Ihnen [ Ihr USB-Stick/ Ihre radierbaren Kugelschreiber / Ihre Picknick-Matte / Ihre Thermoskanne ] weggenommen und Sie erhalten stattdessen [ einen USB-Stick / radierbare Kugelschreiber / eine Picknick-Matte / eine Thermoskanne ]. Wenn die gezogene Zahl eine Zahl [ von 1 bis 10 / von 11 bis 20 ] ist, behalten Sie [ Ihren USB-Stick/ Ihre radierbaren Kugelschreiber

/ Ihre Picknick-Matte / Ihre Thermoskanne ] und es passiert nichts. Nachdem die Zahl gezogen wurde und gegebenenfalls ein Austausch der Produkte vollzogen wurde, passiert nichts mehr in diesem Teil des Experiments. Sie können das Produkt dann endgültig behalten.

Bitte bestätigen Sie erst, wenn Sie alles verstanden haben. Falls Sie Fragen haben, rufen Sie bitte den Leiter des Experiments und warten, bis er zu Ihnen kommt

\section{[ Mood elicitation 3]}

Bevor Sie die Möglichkeit erhalten, Ihr Produkt zu tauschen, beantworten Sie bitte die folgenden Fragen dazu, wie Sie sich gerade fülen. Welche Ausdrücke treffen auf Sie jetzt im Moment eher zu? Positionieren Sie den Schieberegler entsprechend. "Unglücklich, Wütend, Unzufrieden, Traurig, Verzweifelt" - "Glücklich, Begeistert, Zufrieden, Frühlich"

Möchten Sie [ Ihren USB-Stick / Ihre radierbaren Kugelschreiber / Ihre PicknickMatte / Ihre Thermoskanne ] gegen [ einen USB-Stick / radierbare Kugelschreiber / eine Picknick-Matte / eine Thermoskanne ] tauschen? 
Ja, ich möchte tauschen.

Nein, ich möchte nicht tauschen.

\section{[ ONLY BASELINE $(p=0.0)]$}

Sie haben sich [ für / gegen ] einen freiwilligen Tausch enschieden. Bitte warten Sie, während der Leiter des Experiments den Austausch in den Kabinen durchführt.

\section{[ ONLY FORCED EXCHANGE $(p=0.5)$ ]}

Sie haben sich [ für / gegen ] einen freiwilligen Tausch enschieden. Bitte warten Sie, während der Leiter des Experiments den Austausch in den Kabinen durchführt.

[ ONLY NON-TRADERS ] Danach entscheidet sich, ob Sie trotzdem tauschen müssen. [ ONLY TRADERS ] Bitte warten Sie, bis das Experiment weitergeht. Es wird nun eine Zufallszahl für diejenigen gezogen, die sich gegen den freiwilligen Austausch entschieden haben. Danach geht das Experiment für Sie weiter.

[ ONLY NON-TRADERS ] Zur Erinnerung: Wenn die gezogene Zahl [ von 11 bis 20 / von 1 bis 10 ] ist, verlieren Sie [ Ihr USB-Stick" / Ihre radierbaren Kugelschreiber / Ihre Picknick-Matte / Ihre Thermoskanne ] und erhalten stattdessen eine/einen [ USB-Stick / radierbare Kugelschreiber / eine Picknick-Matte / eine Thermoskanne ]. Wenn die gezogene Zahl [ von 1 bis 10 / von 11 bis 20 ] ist, behalten Sie [ Ihr USB-Stick" / Ihre radierbaren Kugelschreiber / Ihre Picknick-Matte / Ihre Thermoskanne ].

\section{[ ONLY NON-TRADERS ]}

Die gezogene Zahl ist $[1 / 2 / \ldots / 20]$.

Dies ist eine Zahl [ von 1 bis 10 / von 11 bis 20 ]. Daher [ verlieren Sie [ Ihren USB-Stick / Ihre radierbaren Kugelschreiber / Ihre Picknick-Matte / Ihre Thermoskanne ] und erhalten stattdessen eine/einen [ USB-Stick / radierbare Kugelschreiber / eine Picknick-Matte / eine Thermoskanne ] / können Sie [ Ihren USB-Stick" / Ihre radierbaren Kugelschreiber / Ihre Picknick-Matte / Ihre Thermoskanne ] behalten ]. Bitte warten Sie, während der 
Leiter des Experiments den Austausch in den Kabinen durchführt.

\section{[ Mood elicitation 4]}

Bitte beantworten Sie die folgenden Fragen dazu, wie Sie sich gerade fülen. Welche Ausdrücke treffen auf Sie jetzt im Moment eher zu? Positionieren Sie den Schieberegler entsprechend. "Unglücklich, Wütend, Unzufrieden, Traurig, Verzweifelt" - "Glücklich, Begeistert, Zufrieden, Frühlich"

\section{Das Experiment ist zu Ende!}

Sie können beide Produkte behalten. Zudem erhalten Sie gleich eine Teilnahmevergütung von 4 Euro. Bitte warten Sie noch kurz in Ihrer Kabine, bis Sie der Experimentator herausruft. Vielen Dank für Ihre Teilnahme!

\section{E.3 English translation of instructions}

\section{Welcome to part 1 of 2 in this experiment!}

Please close the curtain of you cabin and read the following information. All computer entries that you make in this experiment are fully anonymous and cannot be traced back to you. Speed is not important at any point in this experiment. Please always take sufficient time to read and understand the instructions.

You are currently in possession the product in front of you. You may touch it and inspect it anytime. However, please do not open the packaging and do not use the product The two objects presented to you ( [ USB stick and erasable pens / thermos and picnic mat ] ) have been randomly allocated to the cabins in equal quantities. Your cabin number was also randomly determined based on your choice of seat in the presentation room.

Please click on OK when you have read these information. If you have questions, please call an experimenter. 


\section{Please answer the questions.}

[ USB stick / thermos]

How much do you like this product?

How much would you want to have this product?

[ Erasable pens / picnic mat ]

How much do you like this product?

How much would you want to have this product?

If you had to choose one of the objects, which one would you prefer to keep?

[ Erasable pens / picnic mat ] [ USB stick / thermos ]

\section{Please read the following information carefully.}

The experimenter will soon draw a random number between 1 and 20 using a lotto drum. The drawn number will then be announced loudly. If the drawn number is a number [ from 11 to 20 / from 1 to 10 ], your [ USB stick / erasable pens / thermos / picnic mat ] will be taken away from you and you instead receive [ USB stick / erasable pens / thermos / picnic mat ]. If the drawn number is a number [ from 1 to $10 /$ from 11 to 20 ], you will keep your [ USB stick / erasable pens / thermos / picnic mat ] and nothing happens. After the number has been drawn and the exchange of objects has taken place (if applicable), nothing else happens in this part of the experiment. You can then keep your object for good.

Please only confirm below once you have understood everything. If you have questions, please call the experimenter and wait until he comes to your cabin.

\section{[ Mood elicitation 1 ]}

Please answer the following questions about how you currently feel. Which expressions 
better apply to you at the moment?

"Unhappy, Angry, Unsatisfied, Sad, Desperate" - "Happy, Thrilled, Satisfied, Content, Hopeful"

The time has come. Please wait until the number has been drawn.

Remember: If the drawn number is a number [ from 11 to $20 /$ from 1 to 10 ], your [ USB stick / erasable pens / thermos / picnic mat ] will be taken away from you and you instead receive [ USB stick / erasable pens / thermos / picnic mat ]. If the drawn number is a number [ from 1 to 10 / from 11 to 20 ], you will keep your [ USB stick / erasable pens / thermos / picnic mat ].

The drawn number is $[1 / 2 / \ldots / 20]$.

This number is a number [ from 1 to $10 /$ from 11 to 20 ]. Therefore [ you can keep your [ USB stick / erasable pens / thermos / picnic mat ] / your [USB stick / erasable pens / thermos / picnic mat ] will be taken away from you and you instead receive [ USB stick / erasable pens / thermos / picnic mat ] ]. Please wait while the experimenter carries out the exchange in all cabins.

\section{[ Mood elicitation 2 and control question. ]}

Please answer the following questions about how you currently feel. Which expressions better apply to you at the moment?

"Unhappy, Angry, Unsatisfied, Sad, Desperate" - "Happy, Thrilled, Satisfied, Content, Hopeful"

Regarding the lottery draw, that has just taken place: What was the probability (in percent) that you would lose your initial object? Please enter a number between 0 and 100 . 


\section{Part 1 of the experiment is over!}

Please follow the instructions.

- Memorize your cabin number.

- You can no go back to the presentation room.

- Please leave your [ USB stick / erasable pens / thermos / picnic mat ] in the cabin. You will be back in the same cabin in a few minutes.

- Remember: The object now belongs to you for good and you will take it away from this experiment.

\section{Welcome to part 2 in this experiment!}

Please close the curtain of you cabin and read the following information. You are now also in possession of the [ USB stick / erasable pens / thermos / picnic mat ] in front of you. You can touch and inspect it at any time. However, please do not yet open the packaging and do not use the object yet. The two objects presented to you for part 2 ( [ USB stick and erasable pens / thermos and picnic mat ] ) have again been randomly allocated to the cabins in equal quantities.

Please click on OK when you have read these information. If you have questions, please call an experimenter.

\section{[ Instructions Stage 2 - ONLY BASELINE $(\mathrm{p}=0.0)$ ]}

Please read the following information carefully. The [ USB stick / erasable pens / thermos / picnic mat ] from part 2 of the experiment now belongs to you and you can keep it for good. If you like, you can exchange your [ USB stick / erasable pens / thermos / picnic

mat ] voluntarily for [ USB stick / erasable pens / thermos / picnic mat ]. Whichever way you decide, your choice is final and you will take your selected object with you from this 
experiment.

Please only confirm below once you have understood everything. If you have questions, please call the experimenter and wait until he comes to your cabin.

\section{[ Instructions Stage $2-$ ONLY FORCED EXCHANGE $(p=0.5)$ ]}

Please read the following information carefully. You have received a new object in part 2 of the experiment ( [ USB stick / erasable pens / thermos / picnic mat ] ). You will soon get the opportunity to exchange your [ USB stick / erasable pens / thermos / picnic mat ] voluntarily for [USB stick / erasable pens / thermos / picnic mat ].

If you decide to exchange, you will receive [ USB stick / erasable pens / thermos / picnic mat ] as requested for your [ USB stick / erasable pens / thermos / picnic mat ] and you can then keep your [ USB stick / erasable pens / thermos / picnic mat ] for good. The experiment is then finished.

If you decide against an exchange, there will be a probability of 50 percent that the exchange will be forced anyways and you have to exchange nevertheless.

Concretely, the following happens in the case that you decide against a voluntary exchange: The experimenter will draw a random number between 1 and 20 using a lotto drum (as in part 1 of the experiment). The drawn number will then be announced loudly. If the drawn number is a number [ from 11 to 20 / from 1 to 10 ], your [ USB stick / erasable pens / thermos / picnic mat ] will be taken away from you and you instead receive [ USB stick / erasable pens / thermos / picnic mat ]. If the drawn number is a number [ from 1 to 10 / from 11 to 20 ], you will keep your [ USB stick / erasable pens / thermos / picnic mat ] and nothing happens. After the number has been drawn and the exchange of objects has taken place (if applicable), nothing else happens in this part of the experiment. You can then keep your object for good.

Please only confirm below once you have understood everything. If you have questions, please call the experimenter and wait until he comes to your cabin. 


\section{[ Mood elicitation 3 ]}

Before you get the opportunity to exchange your object, please answer the following questions about how you currently feel. Which expressions better apply to you at the moment? "Unhappy, Angry, Unsatisfied, Sad, Desperate" - "Happy, Thrilled, Satisfied, Content, Hopeful"

Do you want to exchange your [ USB stick / erasable pens / thermos / picnic mat ] for a [ USB stick / erasable pens / thermos / picnic mat ]?

Yes, I want to exchange.

No, I do not want to exchange.

[ ONLY BASELINE $(p=0.0)$ ]

You have decided [ for / against ] a voluntary exchange. Please wait while the experimenter carries out the exchange in all cabins.

\section{[ ONLY FORCED EXCHANGE $(p=0.5)$ ]}

You have decided [ for / against ] a voluntary exchange. Please wait while the experimenter carries out the exchange in all cabins.

[ ONLY NON-TRADERS ] After this, it will be determined whether you have to exchange anyways.

[ ONLY TRADERS ] Please wait until the experiment continues. A random number will now be drawn for those who decided against a voluntary exchange. After that the experiment continues for you.

[ ONLY NON-TRADERS ] Remember: If the drawn number is a number [ from 11 to 20

/ from 1 to 10 ], your [ USB stick / erasable pens / thermos / picnic mat ] will be taken 
away from you and you instead receive [ USB stick / erasable pens / thermos / picnic mat ]. If the drawn number is a number [ from 1 to 10 / from 11 to 20 ], you will keep your [ USB stick / erasable pens / thermos / picnic mat ].

[ ONLY NON-TRADERS ]

The drawn number is $[1 / 2 / \ldots / 20]$

This number is a number [ from 1 to 10 / from 11 to 20]. Therefore [ you can keep you [ USB stick / erasable pens / thermos / picnic mat ] / your [ USB stick / erasable pens / thermos / picnic mat ] will be taken away from you and you instead receive [ USB stick / erasable pens / thermos / picnic mat ]. Please wait while the experimenter carries out the exchange in all cabins.

\section{[ Mood elicitation 4 ]}

Please answer the following questions about how you currently feel. Which expressions better apply to you at the moment?

"Unhappy, Angry, Unsatisfied, Sad, Desperate" - "Happy, Thrilled, Satisfied, Content, Hopeful"

\section{The experiment is over!}

You can keep both your objects. You will also receive a show-up fee of 4 euros. Please wait shortly in you cabin until the experimenter calls you out. Thank you for your participation! 